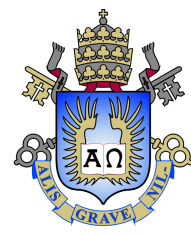

Daiane Marcolino de Mattos

\title{
Estimação do núcleo da inflação via score
} driven models

Dissertação apresentada como requisito parcial para obtenção do grau de Mestre pelo Programa de Pós-graduação em Engenharia Elétrica do Departamento de Engenharia Elétrica do Centro Técnico Científico da PUC-Rio.

Orientador: Prof. Cristiano Augusto Coelho Fernandes 


\title{
Estimação do núcleo da inflação via score driven models
}

Dissertação apresentada como requisito parcial para obtenção do grau de Mestre pelo Programa de Pós-graduação em Engenharia Elétrica do Departamento de Engenharia Elétrica do Centro Técnico Científico da PUC-Rio. Aprovada pela Comissão Examinadora abaixo assinada.

\author{
Prof. Cristiano Augusto Coelho Fernandes \\ Orientador \\ Departamento de Engenharia de Elétrica - PUC-Rio
}

\author{
Prof. Pedro Guilherme Costa Ferreira
}

FGV/RJ

Prof. Eduardo Fonseca Mendes

$\mathrm{FGV} / \mathrm{RJ}$

Prof. - Silvia Maria Matos

$\mathrm{FGV} / \mathrm{RJ}$

Prof. Márcio da Silveira Carvalho

Coordenador Setorial do Centro Técnico Científico - PUC-Rio 
Todos os direitos reservados. É proibida a reprodução total ou parcial do trabalho sem autorização da universidade, do autor e do orientador.

Daiane Marcolino de Mattos

Graduou-se em Estatística pela Escola Nacional de Ciências Estatísticas (ENCE/IBGE) em julho de 2015 e e atualmente é pesquisadora no Núcleo de Métodos Estatísticos e Computacionais do Instituto Brasileiro de Economia da Fundação Getulio Vargas (FGV IBRE).

Ficha Catalográfica

Mattos, Daiane Marcolino de

Estimação do núcleo da inflação via score driven models / Daiane Marcolino de Mattos; orientador: Cristiano Augusto Coelho Fernandes. - 2018.

v., 76 f: il. color. ; $30 \mathrm{~cm}$

Dissertação (mestrado) - Pontifícia Universidade Católica do Rio de Janeiro, Departamento de Engenharia de Elétrica , 2018.

Inclui bibliografia

1. Engenharia Elétrica - Teses. 2. Núcleo da inflação. 3. Tendência da inflação. 4. Previsão. 5. Dynamic Conditional Score models. 6. Generalized Autoregressive Score models. I. Fernandes, Cristiano Augusto Coelho. II. Pontifícia Universidade Católica do Rio de Janeiro. Departamento de Engenharia de Elétrica. III. Título. 


\section{Agradecimentos}

Meus agradecimentos principais vão para a CAPES e PUC-Rio, para os meus orientadores Cristiano e Pedro, para a família NMEC e para a minha mãe.

À CAPES e à PUC-Rio pelos auxílios concedidos, sem os quais este trabalho não poderia ter sido realizado.

Ao Cristiano porque soube executar de forma brilhante o seu papel de educador e orientador, me inspirando, me guiando e me mostrando os passos necessários para a criação e finalização dessa dissertação.

Ao Pedro por abrir meus olhos, me desafiar, me incentivar, acreditar em mim e por tornar simples a parte econômica que me assusta tanto na vida. Sem seu apoio e suporte, não sei o que seria de mim.

À família NMEC por entender meu mau humor durante a elaboração desse documento e tornar meus dias mais bonitos. Sou feliz por ter vocês em minha vida.

À minha mãe por se importar comigo e cuidar de mim. Eu dedico esse trabalho à você, mãe, que me ensinou que devemos sempre fazer as coisas da melhor forma possível.

Também sou grata àqueles que facilitam e contribuem para a vida de estudantes/pesquisadores compartilhando informações, dados e funções. Por fim, sou grata a todos os envolvidos que colaboraram para que eu terminasse esse trabalho com palavras de incentivo e alimentos gostosos que mantiveram minha sanidade e impediram que eu surtasse. Escrever o nome aqui é mera formalidade. Quem é sabe. 


\section{Resumo}

Marcolino de Mattos, Daiane; Augusto Coelho Fernandes, Cristiano. Estimação do núcleo da inflação via score driven models. Rio de Janeiro, 2018. 76p. Dissertação de Mestrado - Departamento de Engenharia de Elétrica , Pontifícia Universidade Católica do Rio de Janeiro.

O objetivo da dissertação é apresentar uma nova medida de núcleo de inflação para o Brasil com o intuito de verificar a tendência atual dos preços. Inicialmente são propostos dois núcleos. O primeiro é calculado a partir de métodos tradicionais encontrados na literatura, porém visando a alcançar algumas características desejáveis que um núcleo tenha, algumas alterações são propostas. O segundo método é via Dynamic Conditional Score Models (DCS). Nesse, a inflação é decomposta em componentes não observáveis e o núcleo é definido como a componente de tendência. Fazse uma comparação entre os núcleos propostos e os núcleos divulgados atualmente no Brasil e conclui-se que os núcleos divulgados hoje não contribuem para o entendimento da tendência da inflação e que para isso os dois núcleos propostos são mais indicados. O núcleo via modelo DCS é mais indicado ainda por sua estimação não ser afetada por muita informação defasada como ocorre para o primeiro núcleo. Além disso, algumas análises econômicas sugerem que a utilização do núcleo via modelo DCS pode auxiliar o Banco Central na condução da política monetária, uma vez que este mostra indicativos do desenvolvimento futuro da inflação acumulada no ano (medida alvo para a verificação do controle da meta). As duas metodologias propostas podem ser facilmente recalculadas, uma vez que os códigos de implementação estão disponíveis gratuitamente para qualquer usuário interessado, e também podem ser replicadas para outros índices de inflação.

\section{Palavras-chave}

Núcleo da inflação; Tendência da inflação; Previsão; Dynamic Conditional Score models; Generalized Autoregressive Score models. 


\section{Abstract}

Marcolino de Mattos, Daiane; Augusto Coelho Fernandes, Cristiano (Advisor). Core inflation estimation via score driven models. Rio de Janeiro, 2018. 76p. Dissertação de mestrado Departamento de Engenharia de Elétrica , Pontifícia Universidade Católica do Rio de Janeiro.

The objective of this dissertation is to present a new measure of core inflation to brazilian inflation in order to verify the current trend of prices. Initially two core inflation are proposed. The first one is calculated from traditional methods found in the literature with some changes proposed in order to achieve some desirable core inflation characteristics. The second method of estimation is Dynamic Conditional Score Models (DCS), where inflation is decomposed into unobservables components and the core is defined as the trend component. A comparison is made between the proposed cores measures and that ones currently available in Brazil. The conclusion is that the core inflation disclosed today do not contribute to the understanding of the inflation trend. The two proposed core inflation measures are better suited for this purpose. The core by DCS model is further indicated because its estimation is not affected by lagged information as it happens for the first core measure. In addition, some economic analyzes suggest that the use of the core by DCS model can help the Central Bank in the conduct of monetary policy, since this shows indicative of the future development of the accumulated inflation in the year (measure used to verify the inflation target in Brazil). The two proposed methodologies can easily be recalculated, since implementation codes are freely available to any interested user, and it can also be replicated to other inflation indicators.

\section{Keywords}

Core inflation; Trend inflation; Forecast; Dynamic Conditional Score models; Generalized Autoregressive Score models. 


\section{Sumário}

$\begin{array}{lll}1 & \text { Introdução } & 10\end{array}$

2 Revisão bibliográfica $\quad 12$

2.1 Inflação e núcleo da inflação 12

2.2 O desenvolvimento dos núcleos ao longo do tempo 12

2.3 Núcleos utilizados no mundo 16

$\begin{array}{ll}2.4 \text { Núcleos no Brasil } & 16\end{array}$

2.5 Implementação dos núcleos mais utilizados no mundo 18

2.6 Como avaliar a utilidade de um núcleo? 23

3 Uma análise sobre as medidas de núcleo divulgadas no Brasil $\quad 26$

3.1 Que medidas de núcleo são divulgadas hoje no Brasil? 26

3.2 Avaliação segundo as propriedades desejáveis de um núcleo 27

3.2.1 Conclusão 32

4 Propostas metodológicas $\quad 33$

4.1 Suavização dos núcleos tradicionais 34

4.2 Núcleo via Dynamic Conditional Score Models 35

4.2.1 O arcabouço DCS para modelos de séries temporais 36

$\begin{array}{lll}\text { 4.2.1.1 } & \text { GAS }(p, q) & 37\end{array}$

4.2.1.2 Componentes não observáveis 39

4.2.2 Modelo DCS para estimação do núcleo da inflação no Brasil 43

4.2.3 Estimação e inicialização 44

4.2.4 Parametrização 45

4.2.5 Diagnósticos 46

$\begin{array}{lll}4.2 .6 & \text { Previsão } & 47\end{array}$

5 Resultados $\quad 49$

5.1 Estimação 49

5.1.1 Núcleo-S: via suavização 49

5.1.2 Núcleo-DCS: via Dynamic Conditional Score Models 51

5.2 Comparação e avaliação segundo às características esperadas de um núcleo 60

5.3 Qual é a "melhor" medida de núcleo? 66

5.4 Análise Econômica e Previsão 66

5.4.1 Comparação entre a inflação acumulada em 12 meses e o Núcleo-DCS 66

5.4.2 Inflação no Brasil em $2018 \quad 70$

$\begin{array}{lll}6 & \text { Conclusão e trabalhos futuros } & 71\end{array}$

$\begin{array}{ll}\text { Referências bibliográficas } & 73\end{array}$ 


\section{Lista de figuras}

$\begin{array}{lll}\text { Figura 3.1 Núcleos da inflação disponíveis no Brasil. } & 27\end{array}$

Figura 5.1 Núcleo-S (Núcleo via suavização) no período de jan/2001 a dez/2017.

Figura 5.2 As três etapas de estimação do Núcleo-S. 50

Figura 5.3 Núcleo via modelo DCS (Núcleo-DCS). 51

Figura 5.4 Núcleos via modelos DCS. $\quad 52$

Figura 5.5 Análise residual modelo DCS-N 1. 53

Figura 5.6 Análise residual modelo DCS-N 1 com dummy. 53

Figura 5.7 Análise residual modelo DCS-N 2 com dummy. 55

Figura 5.8 Análise residual modelo DCS-N 3 com dummy. 56

Figura 5.9 Tendências $\left(\mu_{t \mid t-1}\right)$ dos modelos DCS-Normal e DCS-t. $\quad 58$

Figura 5.10 Tendências via DCS-N e DCS-t para o IPC-Br a partir de jul/2003.

Figura 5.11 IPC-Br, Núcleo-S e Núcleo-DCS. 60

Figura 5.12 Núcleo-S vs. Núcleo-DCS. 61

Figura 5.13 Previsão do IPC-Br via modelo DCS. 64

Figura 5.14 Estabilidade histórica dos núcleos. 65

Figura 5.15 IPCA acumulado em 12 meses, Núcleo-DCS e Selic. $\quad 67$

Figura 5.16 IPCA acumulado em 12 meses, Núcleo-DCS e expectativa da inflação do consumidor. 


\section{Lista de tabelas}

Tabela 2.1 Tipos de núcleo da inflação utilizados por diversos países. 17

Tabela 3.1 Núcleos da inflação divulgados no Brasil. 26

Tabela 3.2 Teste de Sazonalidade QS. 28

Tabela 3.3 Estatísticas descritivas para as medidas de núcleo existentes no Brasil. 28

Tabela 3.4 Teste de raiz unitária (ADF) no IPC-Br, IPCA e seus núcleos.

Tabela 3.5 Teste de cointegração de Johansen entre o IPC-Br, IPCA e seus núcleos.

Tabela 3.6 Dinâmica entre IPC-Br, IPCA e seus núcleos. 30

Tabela 3.7 Análise da previsão da inflação utilizando núcleos. 31

Tabela 3.8 Erro de previsão (RMSE) 1 passo à frente para os últimos 12 meses.

Tabela 5.1 Estatísticas e testes nos resíduos do modelo DCS-N 1. 53

Tabela 5.2 Estatísticas e testes nos resíduos do modelo DCS-N 1 com dummy.

Tabela 5.3 Parâmetros estimados via máxima verossimilhança $(\theta)$ para os modelos DCS-N 1, DCS-N 2 e DCS-N 3.

Tabela 5.4 Estatísticas e testes nos resíduos do modelo DCS-N 2 com dummy.

Tabela 5.5 Estatísticas e testes nos resíduos do modelo DCS-N 3 com dummy.

Tabela 5.6 Parâmetros estimados via máxima verossimilhança $(\theta)$ para os modelos DCS-t.

Tabela 5.7 Estatísticas e testes nos resíduos do modelo DCS-t 3 com dummy.

Tabela 5.8 Comparação DCS-N e DCS-t para o IPC-Br a partir de $\mathrm{jul} / 2003$.

Tabela 5.9 Teste de Sazonalidade QS.

Tabela 5.10 Estatísticas descritivas dos núcleos propostos e do IPC-Br. 62

Tabela 5.11 Teste de raiz unitária (ADF) nos núcleos propostos e no IPC-Br.

Tabela 5.12 Teste de cointegração de Johansen entre o IPC-Br e os núcleos propostos.

Tabela 5.13 Dinâmica entre IPC-Br e os núcleos propostos. 63

Tabela 5.14 Análise da previsão da inflação utilizando núcleos.

Tabela 5.15 Erro de previsão (RMSE) 1 passo à frente para os últimos 12 meses.

Tabela 5.16 Teste de causalidade de Granger entre IPCA e o NúcleoDCS.

Tabela 5.17 Previsão do IPC-Br, do IPCA e do Núcleo-DCS para 2018. 70 


\section{Introdução}

Núcleo da inflação, apesar de não possuir uma definição muito precisa, pode ser entendido atualmente como uma medida de tendência da inflação. Um tipo de medida livre de movimentos de curto prazo que acrescentam volatilidade ao indicador. Não há uma única forma definida para o cálculo de núcleos. Alguns métodos são puramente estatísticos, outros fundamentados em conceitos econômicos. Para avaliar qual método tende a ser superior aos demais, os estudiosos costumam comparar as medidas segundo a capacidade de informação que cada uma traz. No entanto, a forma de avaliar não é algo bem estruturado. O que se percebe é que há um consenso sobre as características que uma medida de núcleo deveria usufruir.

Núcleo da inflação é mais uma ferramenta que os bancos centrais utilizam para a tomada de decisão na condução da política monetária, que tem como objetivo principal controlar o nível geral dos preços em uma economia fazendoo convergir para a meta previamente estabelecida. No Brasil, seis medidas de núcleos são divulgadas mensalmente em conjunto pelo Banco Central do Brasil (BCB) e pela Fundação Getulio Vargas (FGV). Como será visto a seguir, as medidas não parecem captar a tendência da inflação adequadamente. Por isso esse trabalho propõe uma medida de núcleo que reflita de forma mais clara a tendência dos preços, contribuindo com mais uma ferramenta que pode auxiliar os agentes econômicos na tomada de decisão. É válido destacar que embora os resultados encontrados critiquem a capacidade dos núcleos do Brasil em trazer informação sobre a tendência da inflação, tais medidas ainda podem ser úteis para outro propósito. Por exemplo, a previsão da inflação no curto-prazo. Assim, como a literatura sobre núcleo da inflação sugere, enfatiza-se que cada medida de núcleo deve ser usada de acordo com a finalidade que foi criada.

Para cumprir tal objetivo, a dissertação foi dividida em mais 5 capítulos. O Capítulo 2 apresenta uma revisão da literatura sobre o núcleo, mostrando sua relação com a inflação, seu desenvolvimento ao longo dos anos no âmbito nacional e internacional, quais são os métodos mais populares utilizados internacionalmente e como avaliá-los. Em seguida, no Capítulo 3, faz-se uma análise sobre os núcleos presentes atualmente no Brasil buscando qualificá-los segundo os métodos de avaliação visto no Capítulo 2. Após isso, no Capítulo 4, duas 
metodologias são propostas para o cálculo de um novo núcleo para a inflação do Brasil. Um dos métodos sugere o aprimoramento da metodologia popularmente utilizada e nomeada como núcleo por médias aparadas. Em resumo, o aprimoramento é uma suavização do núcleo resultante dessa metodologia, visto que a medida ainda apresenta sazonalidade, mascarando a tendência da inflação, que é a componente de interesse nesse estudo. O outro método proposto utiliza um modelo estatístico denominado classificado como score driven models e também conhecido por Dynamic Conditional Score Model. Nesse modelo, o núcleo da inflação é estimado após a decomposição do índice de inflação em algumas componentes não observáveis. A literatura sobre este modelo é relativamente recente (formalmente definida em 2013) e tem trazido resultados satisfatórios na extração de sinal de variáveis voláteis. No Capítulo 5, os núcleos novos são apresentados e avaliados. Como exercício, algumas análises econômicas são feitas e mostra-se a previsão para inflação para o ano de 2018. As conclusões e os trabalhos futuros são ditos no Capítulo 6, finalizando o trabalho.

Os métodos que são propostos aqui podem ser replicados facilmente para qualquer outro índice de inflação de qualquer economia. A implementação foi totalmente desenvolvida no software $\mathrm{R}$ e está disponível gratuitamente em https://github.com/daianemarcolino/gascoreinflation e no pacote Inflation do R para replicação e utilização livre. O pacote, até a elaboração desse trabalho, ainda se encontrava em fase de desenvolvimento. 


\section{2}

\section{Revisão bibliográfica}

Este capítulo destina-se a apresentar a relação entre inflação e núcleo, bem como o desenvolvimento da definição, identificação, avaliação e utilização das medidas de núcleo ao longo do tempo no Brasil e no mundo. Apresentase, além disso, quais as medidas de núcleo utilizadas atualmente nos bancos centrais no âmbito internacional.

\section{1}

\section{Inflação e núcleo da inflação}

A inflação pode ser entendida como um aumento generalizado no nível dos preços em uma economia. Com o objetivo de manter estável esse nível geral dos preços, as autoridades monetárias de qualquer país buscam ferramentas que auxiliem na tomada de decisão. No Brasil, o Copom (Comitê de Política Monetária), órgão do BCB, é o responsável por essa tarefa.

Apesar de ser caracterizado como um fenômeno monetário, o aumento no nível dos preços também pode ser afetado por eventos não monetários como, por exemplo, péssimas condições climáticas que tornam os preços dos alimentos mais caros em razão da diminuição da oferta desses produtos para a população. Esse tipo de evento é passageiro e, com a melhoria do clima e das condições de produção, os preços dos alimentos podem retornar ao nível anterior. Tal comportamento transitório, por conseguinte, adiciona ruído ao índice da inflação e não reflete o aumento persistente no nível dos preços.

Em razão disso, as autoridades monetárias deveriam ser capazes de distinguir entre um efeito transitório e um efeito persistente no nível dos preços para o exercício de suas decisões. Uma medida que fornecesse essa informação, isto é, uma medida livre de interferências transitórias que reflete adequadamente a tendência do nível dos preços, pode ser útil na execução dessa atividade. Tal medida é o que se entende hoje como núcleo da inflação.

\section{2}

\section{O desenvolvimento dos núcleos ao longo do tempo}

O termo "núcleo da inflação" foi primeiramente formalizado por Otto Eckstein (1) em 1981 em seu livro intitulado Core Inflation. O autor definiu 
núcleo de inflação como a tendência da taxa de crescimento no custo dos fatores de produção. No entanto, tal definição parece ter sido abandonada uma vez que nos trabalhos subsequentes o núcleo é definido como a inflação livre de movimentos transitórios. Apesar do termo ser formalmente definido apenas em 1981, a ideia de núcleo da inflação começou a surgir, academicamente, por volta de 1952, como reportado por Wynne em 2008 (2). Em janeiro de 1978, o Bureau of Labor Statistics (BLS) começou a divulgar o CPI (Consumer Price Index) All Items less food and energy, mas somente em 2001 essa medida e algumas outras passaram a ser classificadas como núcleo do CPI. Percebe-se então a dificuldade de definir algo como um núcleo da inflação. O CPI All Items less food and energy é a medida de núcleo mais conhecida e sua popularidade influenciou no entendimento de núcleo como a inflação após a remoção dos itens de alimentação e energia, justamente os itens mais voláteis que poderiam causar ruído a inflação agregada nos Estados Unidos.

Com o passar do tempo, no entanto, diversos autores sugeriram outras maneiras de remover o ruído do índice da inflação, destacando que as fontes de perturbação não provinham apenas das componentes de alimentação e energia. Em 1991, Bryan \& Pike (3) sugeriram calcular a inflação por mediana no lugar de uma média ponderada. Essa medida poderia ser entendida como o CPI menos tudo, a não ser a variação central dos itens da cesta. Em 1994, Bryan \& Cecchetti (4) sugeriram estimadores de influência limitada (mediana ponderada e médias aparadas) para o cálculo da inflação. Tais estimadores desconsideram as variações extremas no cálculo da inflação, fornecendo intuitivamente uma medida menos volátil do que a inflação original e uma medida mais satisfatória para a componente persistente da inflação em comparação ao núcleo que exclui os itens de alimentação e de energia. Nesses tipos de estimadores sugeridos, elimina-se do cálculo da inflação, a cada mês, os itens com as variações extremas (caudas inferior e superior) e recalcula-se a inflação com os itens restantes. Dessa forma, um item específico pode ser excluído do cálculo num determinado mês e em outro, não. Sua exclusão depende apenas de sua variação em comparação com a variação dos outros itens da cesta. Outra forma de calcular um núcleo, proposta na mesma época, é o que se chama de dupla ponderação. Esse método surgiu após os estudos de Dow (1994) (5) e de Diewert (1995) (6). As metodologias buscavam reponderar a cesta de produtos dos índices de preço de acordo com a variabilidade de cada item. Dessa forma, os itens mais voláteis perderiam peso enquanto os menos voláteis ganhariam peso no cálculo do índice da inflação. Assim, nenhum item da cesta é removido do cálculo como acontece nos outros métodos apresentados anteriormente.

Em 1995, Quah \& Vahey (7) criticaram os métodos usados até aquele 
momento para a definição e estimação de um núcleo da inflação. A crítica era imposta devido aos métodos mais utilizados para estimar uma tendência para inflação não terem fundamentos econômicos. Por exemplo, usar média móvel e em seguida dessazonalizar a série temporal não era justificável pois não há na literatura algo sugerindo a dimensão apropriada para a média móvel. Outra técnica criticada é utilizar o Filtro de Kalman para estimar a tendência, uma vez que é necessário supor uma forma funcional para essa tendência e também não há na literatura esse resultado. Por isso, os autores sugeriram utilizar um modelo VAR bivarido entre uma medida de produto (produção industrial ou PIB) e a medida de inflação desejada. Partindo do pressuposto que a inflação não tem efeito de médio a longo-prazo no produto (curva de Phillips de longo prazo vertical), o sistema VAR poderia ser identificado e a componente de tendência associada ao choque desse pressuposto econômico seria uma estimativa de núcleo da inflação.

Em 1997, Freeman (8) buscou comparar o desempenho da medida de núcleo tradicional (CPI less food and energy) com o median CPI, sugerido por Bryan \& Cechetti (4). Utilizando testes num contexto onde a inflação e os núcleos são considerados não-estacionários e cointegrados, os autores concluíram que são boas medidas para refletir a tendência da inflação, no entanto, têm potencial praticamente nulo em ajudar a prevê-la.

Em 1999, Wynne (9) revisou o que havia de núcleo na literatura daquela época buscando encontrar alguma medida útil para entender o desenvolvimento da inflação na área do euro. Mostra-se que há confusão sobre o conceito de núcleo, uma vez que os estudiosos da época não chegam a um consenso de como deve ser estimada a parte monetária da inflação: se deve-se levar em conta definições teóricas da economia no cálculo (modelos econométricos) ou se os métodos puramente estatísticos já são suficientes para captar essa componente. Assim, há diversas maneiras de se calcular um núcleo da inflação, no entanto, não há critério para definir qual é a melhor ou mais adequada. Dessa forma, o autor sugere alguns critérios para avaliar se uma medida deve ser escolhida como um núcleo da inflação. Os critérios são apresentados e discutidos com mais detalhes na seção 2.6, mas podem ser resumidos em: capturar tendência da inflação, ajudar a prever a inflação, ser fácil de entender pelo público e ter fundamento teórico. Em 2008, Wynne refez a revisão de literatura sobre núcleo, acrescentando as metodologias novas que surgiram. No entanto, não há conclusão a respeito da medida de núcleo perfeita.

Em 2001, Clark (10) estudou as medidas de núcleos divulgadas para o CPI e estimou outras sugeridas por outros autores. Concluiu que os núcleos por médias aparadas e exclusão da componente de energia, seriam os núcleos 
mais informativos de acordo com alguns critérios sugeridos por Wynne (9). No entanto, tais medidas ainda preservavam alguma componente de alta frequência, apesar de serem menos voláteis do que CPI, como observou Cogley em 2002 (11).

Cogley apontou que esse ruído remanescente poderia ser a causa do pouco poder de predição da inflação. Dessa forma, sugeriu uma nova medida que poderia ser interpretada como uma atualização constante da média da inflação. Tal medida era estimada a partir de um modelo de alisamento exponencial, simples de replicar e de ser entendido pelo público, segundo o autor, além de não ser necessária a revisão histórica. A medida, menos volátil do que os outros núcleos, aumentava o poder de predição da inflação em um modelo macroeconômico de cerca de $20 \%$ para algo em torno de $50 \%$ a $65 \%$.

Ainda em 2002, Cristadoro et al. (12) propõem um núcleo da inflação estimado por um modelo de fator dinâmico generalizado, após definir núcleo como a componente de longo prazo comum aos produtos da cesta de inflação e a outras variáveis macroeconômicas. Os autores discutem que na zona do euro a política monetária é definida sobre o índice de inflação com variação anual devido ao índice com variação mensal ser muito irregular. Criticam essa utilização pois a variação anual é uma medida muito defasada apesar de ser suave. A medida sugerida é mais suave que a inflação com variação mensal e antecipa o comportamento da variação anual em cerca de 6 meses, além de ser um excelente preditor da variável em horizontes de 6 meses ou mais. Seguindo a mesma linha de raciocínio, Stock \& Watson (2015) (13) propõem um modelo de fator dinâmico com volatilidade estocástica para a estimativa da tendência da inflação. O uso da volatilidade estocástica os fez concluir que a categoria de alimentação, que possuía alta volatilidade antes da década de 1980, teve a volatilidade reduzida após esse tempo, o que levou a uma contribuição maior da categoria na estimativa da tendência. Os autores sugerem então, que o núcleo da inflação dos Estados Unidos excluindo apenas a categoria de energia deveria receber mais atenção do que o núcleo que exclui a alimentação também. Além disso, os autores mostram que a medida proposta fornece previsões da inflação mais precisas num horizonte de 1 a 3 anos do que as medidas tradicionais.

Em 2005, Rich \& Steindel (14) revisam empírica e conceitualmente os núcleos da inflação nos Estados Unidos. Os autores afirmam que um núcleo deve ser visto como uma meta intermediária e não o alvo final da política monetária, isto é, a estabilização do núcleo como meta contribuirá para a estabilização dos preços agregados. Dessa forma, o Banco Central não ignora o movimento de certos preços na condução da política monetária, não indicando a falta de preocupação com o impacto de alguns preços no custo de vida 
do público em geral. A trajetória do núcleo serviria como uma maneira de monitorar o progresso em direção à estabilização do nível geral dos preços. Ainda nesse estudo, os autores contribuem com critérios de avaliação do desempenho de núcleos, similar aqueles propostos por Wynne em 1999. Em seguida os autores analisam o desempenho de núcleos de exclusão, médias aparadas, mediana e alisamento exponencial de Cogley. Concluem que não há sequer um núcleo que supere o desempenho de todos considerando os critérios de avaliação e, por isso, recomendam a utilização dos indicadores com cautela, sabendo extrair a capacidade informativa que cada um pode fornecer.

\section{3}

\section{Núcleos utilizados no mundo}

A Tabela 2.1 apresenta os tipos de núcleos da inflação divulgados pelos bancos centrais em alguns países do mundo. Nota-se que a maioria estima mais de uma medida de núcleo, confirmando que não há um consenso sobre qual é a melhor ou a mais indicada. Além disso, das 21 instituições, apenas quatro apresentam núcleos estimados via modelagem estatística/econométrica (componentes principais, modelos de fatores dinâmicos ou VAR), corroborando a ideia de que os métodos de estimação de núcleo por exclusão e médias aparadas, que são mais intuitivos para o público em geral, são os mais divulgados.

\section{4}

\section{Núcleos no Brasil}

O regime de metas, no qual o banco central se compromete a atuar de forma a garantir que a inflação esteja controlada, foi implantado no Brasil em 1999, época de incerteza em que o cenário econômico brasileiro enfrentava a desvalorização do real. O índice escolhido para ser controlado foi o IPCA (Índice de Preços ao Consumidor Amplo), calculado pelo IBGE (Instituto Brasileiro de Geografia e Estatística) (15), justificado por ser o índice de preços de maior abrangência existente no país, que mede a inflação para domicílios com renda entre 1 a 40 salários-mínimos em 13 cidades ou regiões metropolitanas. Existia a possibilidade de escolher-se um núcleo como índice a ser controlado. No entanto, o receio de que as dúvidas geradas quanto a mais um conceito, além do sistema de metas, de uma medida de inflação que não reflete efetivamente a inflação do consumidor poderiam contestar a transparência e credibilidade da atuação do BCB. Assim, preferiu-se o índice cheio. Os núcleos, todavia, ainda seriam utilizados no conjunto de informações para auxiliar o processo decisório de política monetária. 


\begin{tabular}{cccccc}
\hline Países & EX & DP & MA & ME & Modelo \\
\hline Austrália & $\times$ & & $\times$ & $\times$ & \\
África do Sul & $\times$ & & $\times$ & & \\
Argentina & $\times$ & & $\times$ & & $\times$ \\
Brasil & $\times$ & $\times$ & $\times$ & & \\
Bolívia & $\times$ & & $\times$ & & \\
Canadá & $\times$ & $\times$ & $\times$ & $\times$ & $\times$ \\
Chile & $\times$ & & & & \\
Colômbia & $\times$ & & $\times$ & & \\
Equador & $\times$ & & & & \\
Estados Unidos & $\times$ & & $\times$ & $\times$ & \\
Japão & & & $\times$ & $\times$ & \\
México & $\times$ & & $\times$ & & \\
Noruega & $\times$ & & $\times$ & $\times$ & \\
Nova Zelândia & $\times$ & & $\times$ & $\times$ & $\times$ \\
Paraguai & $\times$ & $\times$ & $\times$ & & \\
Peru & $\times$ & & & & $\times$ \\
Suécia & & $\times$ & $\times$ & & \\
Suíça & $\times$ & & $\times$ & & \\
Uruguai & $\times$ & & & & \\
Venezuela & $\times$ & & & & \\
Zona do Euro & $\times$ & & & & \\
\hline
\end{tabular}

EX: exclusão; DP: dupla ponderação; MA: médias aparadas; ME: mediana; Modelo: fatores dinâmicos, componentes principais ou VAR.

Fonte: informações coletadas dos bancos centrais dos países.

Tabela 2.1: Tipos de núcleo da inflação utilizados por diversos países.

Com a implantação do sistema de metas, o BCB iniciou também o cálculo dos núcleos no Brasil. Segundo as Notas do Copom, a Fundação Getulio Vargas (FGV) foi a pioneira na divulgação desse tipo de medida ${ }^{1}$. O Instituto Brasileiro de Economia (FGV IBRE) (16) calculou o núcleo por médias aparadas com suavização de alguns produtos para o IPC-Br (Índice de Preços ao Consumidor - Brasil), também calculado pela mesma instituição. O trabalho desenvolvido por Rebecca Barros \& Jack Schechtman (17) apresenta uma discussão sobre a relevância de núcleo da inflação e justifica a escolha desse núcleo pioneiro no Brasil.

Em agosto de 2000, o BCB fez referência ao núcleo por médias aparadas calculado por eles próprios ${ }^{2}$. Um ano depois citou o núcleo por exclusão ${ }^{3}$ e, após 2 anos, o núcleo por médias aparadas sem suavização ${ }^{4}$. Todos referentes ao IPCA. Em 2009, o BCB alterou o conjunto de núcleos periodicamente

\footnotetext{
${ }^{1}$ Notas do Copom - Março/2000 - 45 $5^{\text {a }}$ Reunião: http://www.bcb.gov.br/?copom45.

${ }^{2}$ Notas do Copom - Agosto/2000 - 50 Reunião: http://www.bcb.gov.br/?copom50.

${ }^{3}$ Notas do Copom - Setembro/2001 - $63^{\text {a }}$ Reunião: http://www.bcb.gov.br/?copom63.

${ }^{4}$ Notas do Copom - Junho/2003 - 85 $5^{\text {a }}$ Reunião: http://www.bcb.gov.br/?copom85.
} 
divulgados, acrescentando um novo núcleo por exclusão e outro por dupla ponderação.

Estudos feitos em 2011 e 2014 por Silva Filho \& Figueiredo (18, 19) avaliam se tais núcleos para o IPCA tem sido úteis no Brasil. Os autores concluem que algumas qualidades (ver seção 2.6), como ausência de viés e capacidade de prever a inflação não são encontradas nas medidas e, portanto, sugerem ao mercado usar tais medidas com cautela.

Para complementar a literatura de núcleo desenvolvida no Brasil, sugerese a leitura de tais outros estudos sobre o tema:

- Picchetti \& Kanczuk (2001) (20): os autores aplicam a metodologia proposta por Quah \& Vahey (1995), que considera teoria econômica na estimação do núcleo, em dados brasileiros (IPCA).

- Figueiredo (2001) (21): o autor avalia cinco núcleos para a inflação brasileira e afirma que os núcleos por dupla ponderação e médias aparadas com suavização possuem melhor performance.

- Fiorencio \& Moreira (2002) (22): os autores estimam um núcleo usando um modelo dinâmico multivariado que extrai o fator comum nas variações dos preços.

\section{5 \\ Implementação dos núcleos mais utilizados no mundo}

Como visto ao longo deste capítulo, há diversas maneiras de estimar uma medida de núcleo da inflação. Dentre as observadas, algumas se destacam (Tabela 2.1). Serão apresentadas os passos de construção dos núcleos por exclusão, por dupla ponderação, por médias aparadas e por mediana ponderada. Tais metodologias podem ser aplicadas a qualquer índice de inflação no mundo, desde que se tenha disponível a variação dos preços e o peso dos produtos que compõem a cesta do índice. Os procedimentos apresentados são baseados na metodologia dos núcleos do índice de inflação do Brasil fornecida pelo $\mathrm{BCB}^{5} \mathrm{e}$ nos documentos citados nas seções 2.2 e 2.4.

Todas as metodologias apresentadas a seguir estão implementadas no software R no pacote Inflation (23).

\section{- Exclusão}

${ }^{5} \mathrm{~A}$ metodologia pode ser acessada em https://www.bcb.gov.br/htms/relinf/port/ 2009/12/ri200912b7p.pdf. Data de acesso: 18-05-2017. 
O núcleo por exclusão é um dos tipos de núcleo mais populares e seu fácil entendimento pelo público o torna uma grande vantagem em utilizálo. Este núcleo é criado ao se excluir alguns itens do cálculo do índice da inflação. Geralmente, exclui-se aqueles que são mais voláteis historicamente ou administrados pelo governo. Considere, por exemplo, o núcleo all items less food and energy do índice de preços ao consumidor dos Estados Unidos (CPI), que não contabiliza alimentos e energia em sua formulação. A justificativa para tal exclusão é fundamentada na ideia de que esses itens têm alterações rápidas nas taxas de variações e esse comportamento pode não estar relacionado a tendência do nível dos preços na economia, pois os preços de tais itens estão mais relacionados a fatores temporários (por exemplo, fatores ambientais) que podem se reverter mais tarde, e assim não necessitar de intervenção econômica. Dessa forma, o curso da inflação pode ser analisado sem influência desses produtos.

Uma crítica na utilização deste tipo de núcleo é que excluir determinados itens implica dizer que eles não carregam informações relevantes sobre o curso da inflação e que os itens não excluídos são sempre informativos, o que às vezes pode não ser necessariamente verdade. Um estudo do Federal Reserve Bank of St. Louis em 2002 (24) questiona se os itens alimentícios não deveriam retornar a cesta de produtos do núcleo da inflação dos Estados Unidos, pois esses já não são tão voláteis como eram na criação do núcleo (década de 70). Os autores compararam a previsão da inflação quando se utiliza um núcleo que exclui energia e alimentação e outro que exclui somente energia e mostraram que o último apresenta menor erro de previsão. A mesma recomendação de adicionar a alimentação de volta à cesta do núcleo também é documentada por Stock \& Watson (2015) utilizando um modelo de volatilidade estocástica (seção 2.2). Dessa forma, é válido investigar de tempos em tempos a necessidade de eliminar determinados itens no cálculo de um núcleo por exclusão.

Uma maneira de escolher quais itens devem ser excluídos tomando como base o cálculo da volatilidade é dada nos passos a seguir:

i. Calcular o desvio-padrão de cada item $i$ considerando toda a série histórica:

$$
x_{i}=s d\left(\pi_{i}\right)=\sqrt{\frac{\sum_{t=1}^{T}\left(\pi_{i, t}-\bar{\pi}_{i}\right)^{2}}{T-1}}
$$

em que:

$\pi_{i, t}$ é a variação do preço do item $i$ no tempo $t$; 


$$
\bar{\pi}_{i}=\frac{\sum_{t=1}^{T} \pi_{i, t}}{T}
$$

ii. Padronizar os devios-padrão obtidos em (i.);

$$
x p_{i}=\frac{x_{i}-\frac{\sum_{i=1}^{n} x_{i}}{n}}{\sqrt{\frac{\sum_{i=1}^{n}\left(x_{i}-\frac{\sum_{i=1}^{n} x_{i}}{n}\right)^{2}}{n-1}}}
$$

em que: $n$ é o número de itens na cesta.

iii. Recalcular o índice considerando apenas os itens cujo desvio-padrão padronizado $\left(x p_{i}\right)$ não ultrapasse, em valor absoluto, o valor 2 :

$$
\pi_{t}^{E X}=\sum_{i=1}^{m} w_{i, t} \pi_{i, t}
$$

em que:

$\sum_{i=1}^{m} w_{i, t}=1$;

$i=1, \ldots, m$, tal que $m<n$ é número de itens que obedecem a condição $\left|x p_{i}\right|<2$.

\section{- Dupla Ponderação}

Em vez de definir antecipadamente quais itens devem ser descartados do cálculo da inflação para eliminar ruídos irrelevantes, como é feito no núcleo por exclusão, o núcleo por dupla ponderação repondera os pesos dos itens pelo inverso da volatilidade. Dessa forma, nenhum item é excluído, mas perde sua importância no cálculo quanto maior for a sua volatilidade. Para calcular um núcleo por dupla ponderação, deve-se proceder como a seguir:

i. Calcular a variação relativa $\pi_{i, t}^{r e l}$ de cada item:

$$
\pi_{i, t}^{r e l}=\pi_{i, t}-\pi_{t}
$$

em que:

$\pi_{i, t}$ é a variação do preço do item $i$ no tempo $t$;

$\pi_{t}$ é a variação da inflação agregada.

ii. Calcular o desvio-padrão da variação relativa de cada item considerando uma janela móvel $j$ de 48 meses: 


$$
\sigma_{i, t}=\sqrt{\frac{\sum_{k=0}^{j-1}\left(\pi_{i, t-k}^{r e l}-\overline{\pi_{i, t}^{r e l}}\right)^{2}}{j-1}}
$$

em que:

$j=48$;

$\overline{\pi_{i, t}^{r e l}}=\frac{\sum_{k=0}^{j-1} \pi_{i, t-k}^{r e l}}{j}$.

iii. Calcular os novos pesos $\left(z_{i, t}\right)$ a partir de $\sigma_{i, t}$ e dos pesos originais $\left(w_{i, t}\right)$ :

$$
z_{i, t}=\frac{\frac{1}{\sigma_{i, t}}}{\sum_{i=1}^{n} \frac{1}{\sigma_{i, t}}} w_{i, t}
$$

em que:

$n$ é o número de itens na cesta;

$\sum_{i=1}^{n} z_{i, t}=1$.

iv. Recalcular o índice considerando os novos pesos:

$$
\pi_{t}^{D P}=\sum_{i=1}^{n} z_{i, t} \pi_{i, t}
$$

A definição de $j=48$ é relativa, o usuário pode escolher o tamanho da janela de cálculo da forma que desejar. Por exemplo, pode ser escolhido de acordo com erro de previsão do índice de referência.

\section{- Médias Aparadas}

O núcleo por médias aparadas exclui do cálculo do índice de preços os itens que apresentam variações extremas, isto é, as maiores e menores variações em um dado período. De forma diferente do núcleo por exclusão, que exclui itens em toda a série histórica, no núcleo por médias aparadas, é decidido a cada mês se um item permanece ou é excluído do cálculo do índice ao comparar a sua variação com a variação dos demais itens.

Há duas versões para esse tipo de núcleo: sem e com suavização. A versão sem suavização exclui os itens que apresentam variações extremas sem examinar se este é um comportamento regular. Considere, por exemplo, itens que apresentam variações infrequentes no ano, como cursos formais de educação (ensino fundamental, médio, superior, etc). Embora tais itens apresentem alta variação quando são reajustados, geralmente em janeiro, ao calcular o núcleo sem suavização, esses itens provavelmente seriam excluídos e o nível da inflação seria subestimado. Para minimizar a probabilidade desses 
tipos de itens serem excluídos e, consequentemente, a perda de informação, fazse uso da versão com suavização. A versão com suavização reparte, a cada mês, a variação desses itens, previamente definidos, em 12 parcelas iguais. Assim, a variação de um item no mês corrente é definida como a soma composta de $1 / 12$ da variação corrente e $1 / 12$ das variações nos 11 meses anteriores. Para calcular um núcleo por médias aparadas com suavização, siga os passos:

i. Suavizar os itens previamente definidos:

$$
\pi_{i, t}^{*}= \begin{cases}{\left[\prod_{k=0}^{11}\left(\frac{\pi_{i, t-k}}{100}+1\right)^{\frac{1}{12}}-1\right] \times 100} & \text { se } i \text { deve ser suavizado } \\ \pi_{i, t} & \text { c.c. }\end{cases}
$$

ii. Considerando $t$, ordenar de forma crescente os pesos dos itens segundo a variação;

iii. Calcular a soma dos pesos acumulados;

iv. Desconsiderar os itens cujo peso acumulado é inferior a $20 \%$ e superior a 80\%. Assim, a soma dos pesos dos itens que ficaram no cálculo deve ser exatamente $60 \%$.

v. Reponderar os pesos dos itens restantes para que somem 1 e recalcular o índice:

$$
\pi_{t}^{M A}=\sum_{i=1}^{m} w_{i, t} \pi_{i, t}^{*}
$$

em que:

$\sum_{i=1}^{m} w_{i, t}=1$;

$i=1, \ldots, m$, tal que $m<n$ é número de itens não excluídos do cálculo;

$n$ é o número de itens na cesta.

O corte de $20 \%$ das caudas inferior e superior é relativo, o usuário pode escolhê-lo da forma que julgar. Por exemplo, pode ser escolhido de acordo com erro de previsão do índice de referência ou aquele que mantém a média das duas medidas estatisticamente iguais.

\section{- Mediana Ponderada}

O cálculo do núcleo por mediana ponderada é similar ao por médias aparadas. Nesse caso, em vez de ignorar os extremos das distribuições dos pesos, considera-se apenas o peso central ou o imediatamente superior.

i. Considerando o período $t$, ordenar de forma crescente os pesos dos itens segundo a variação; 
ii. Calcular a soma dos pesos acumulados;

iii. A variação do item que corresponde ao peso acumulado de $50 \%$ ou ao imediatamente superior é o núcleo por mediana ponderada naquele tempo $t$.

Essa metodologia não deve ser confundida com o núcleo por mediana. Neste desconsidera-se o peso de cada item da cesta. O núcleo por mediana é a mediana das variações de preço dos itens da cesta no tempo $t$.

\section{6}

\section{Como avaliar a utilidade de um núcleo?}

A confiabilidade de uma medida de núcleo da inflação deve ser avaliada, isto é, faz-se necessário verificar se a medida exerce a função que foi destinada a exercer teoricamente. Após surgirem diversos métodos de estimação de núcleos da inflação, percebeu-se a necessidade de avaliar sua utilidade. Além disso, alguma técnica de avaliação é necessária quando se pretende comparar diversas medidas.

Em 1999, Wynne listou algumas características que devem ser consideradas ao estimar e escolher uma medida de núcleo da inflação. Tais características são similares às sugeridas por Rich \& Steindel em 2005 (14).

1. Estimação em tempo real: um núcleo deve ser computado em tempo real, isto é, após a divulgação das variações de preços de cada item da cesta em tempo $t$, tem-se a estimativa do núcleo em tempo $t$.

2. Entendimento pelo público: um núcleo construído de forma simples e objetiva pode facilitar a comunicação com o público em análises políticas, bem como a replicação de resultados e análises empíricas por estudiosos, contribuindo para a transparência do banco central na condução da política monetária;

3. Base teórica: é desejável que a medida de núcleo seja estimada segundo a teoria econômica pois isso torna mais fácil a justificação de sua criação;

4. Similaridade de médias: a média de um núcleo deve ser comparável à média da série de inflação durante um longo período de tempo;

5. Acompanhar a tendência da inflação: a medida de núcleo deve ser um bom indicador da tendência da inflação, sendo esta menos volátil do que a inflação agregada;

6. Trajetória explicativa: a medida de núcleo deve explicar movimentos passados da inflação, bem como fornecer informações sobre potenciais desenvolvimentos futuros. 
Praticamente todas as medidas de núcleos podem ser estimadas em tempo real, exceto aquelas via filtros de médias móveis que não são calculadas para as pontas da série, uma vez que utilizam observações futuras e passadas para um ponto central. O entendimento pelo público é algo válido. Os bancos centrais já têm essa preocupação. É benéfico buscar uma medida que, em sua construção, facilite a iteração entre a política e o público e ainda permita que os interessados no assunto consigam replicar e analisar os resultados, contribuindo para a credibilidade do órgão e para a transparência na condução da política monetária. Com respeito a base teórica, por se tratar de um tema econômico, estimar um núcleo fundamentado em justificativas econômicas fornece mais confiança, porém, tal critério não é bem respeitado quando se examina os núcleos mais difundidos no mundo (Tabela 2.1). É esperado que a média do núcleo e da inflação agregada sejam similares, justamente porque esperase que a inflação flutue em torno da medida de tendência após a remoção dos ruídos. Assim, se o núcleo está acima da inflação, há indicativos que a inflação vá aumentar num tempo futuro para que as médias se mantenham similares estatisticamente, fornecendo então informações sobre os potenciais desenvolvimentos futuros da inflação. Apesar de tudo, o que se percebe é que os estudos que propõem núcleos da inflação focam mais na capacidade da medida em trazer informações sobre os movimentos futuros da inflação, o que é intuitivo. Para que serve um núcleo que não produza informações úteis na estabilização geral dos preços?

Os critérios 4 a 6 podem ser avaliados segundo testes estatísticos apresentados a seguir. Os critérios 4 e 5 buscam medir a capacidade do núcleo em capturar a tendência da inflação. Segundo Clark (2001), um núcleo captura a tendência da inflação se as médias das duas medidas são similares (ausência de viés).

Se as medidas forem estacionárias, ainda é possível testar a significância desse viés. Sejam as séries da inflação $\left(\pi_{t}\right)$ e do núcleo $\left(\pi_{t}^{\text {núcleo }}\right)$. A ausência de viés pode ser verificada pelo teste $F$, sob hipótese nula $\alpha=0$ e $\beta=1$, na equação (2-1):

$$
\pi_{t}=\alpha+\beta \pi_{t}^{\text {núcleo }}+\varepsilon_{t}
$$

A rejeição da hipótese nula revela evidências de viés da medida de núcleo. A ideia por trás desse teste é simples. Tomando o operador de esperança nos dois lados da equação e assumindo que $\alpha=0, \beta=1$ e que a inflação é decomposta por um núcleo e uma parte transitória estacionária com média zero, tem-se que o valor esperado da inflação e do núcleo são estatisticamente 
similares.

$$
\mathrm{E}\left[\pi_{t}\right]=\mathrm{E}\left[\alpha^{\star}+\not \beta^{1} \pi_{t}^{\text {núcleo }}\right]+\mathrm{E}\left[\varepsilon_{t}\right]^{0}=\mathrm{E}\left[\pi_{t}^{\text {núcleo }}\right]
$$

No entanto, a inflação pode ser uma medida não-estacionária, como acontece para as medidas de núcleo do Brasil (seção 3.2) e em outros estudos vistos na revisão de literatura (seção 2.2). Nesse caso, esse teste se torna inapropriado.

Confirma-se também o núcleo como um indicador de longo-prazo da inflação aplicando testes de cointegração. Além das medidas serem cointegradas, é válido verificar como se dá a dinâmica de ajustamento entre elas, isto é, o movimento comum entre as medidas se dá em razão da inflação se mover em direção ao núcleo ou do núcleo em direção à inflação? Essa avaliação fornece indicativos dos movimentos futuros da inflação e pode ser feita na análise dos coeficientes $\lambda$ e $\lambda_{\text {núcleo }}$ das equações (2-2) e (2-3) sugeridas em Mehra \& Reilly (2009) (25), que indicam como a inflação e o núcleo se ajustam quando há alguma diferença entre eles, considerando que ambos são não-estacionários e cointegrados. Se $\lambda$ for negativo e $\lambda_{\text {núcleo }}$ nulo, estatisticamente, pode-se concluir que a inflação se move em direção ao núcleo e o núcleo não se move em direção à inflação. Se $\lambda$ for negativo e $\lambda_{\text {núcleo }}$ for positivo, conclui-se que as medidas se atraem simultaneamente.

$$
\begin{gathered}
\Delta \pi_{t}=\alpha+\lambda \mu_{t-1}+\sum_{k=1}^{p} \alpha_{k} \Delta \pi_{t-k}+\varepsilon_{t} \\
\Delta \pi_{t}^{\text {núcleo }}=\alpha+\lambda_{\text {núcleo }} \mu_{t-1}+\sum_{k=1}^{p} \alpha_{k} \Delta \pi_{t-k}^{\text {núcleo }}+\varepsilon_{t}
\end{gathered}
$$

em que:

$\mu_{t-1}$ é o vetor de cointegração, que se resume a $\pi_{t}-\pi_{t}^{\text {núcleo }}$ se o núcleo não é viesado;

$\Delta=1-L$ em que $L$ é o operador de defasagem tal que $L^{n} y_{t}=y_{t-n}$.

Para avaliar a trajetória explicativa de um núcleo, um sugestão é estimar modelos de previsão para a inflação utilizando o núcleo como variável explicativa e mensurar o quanto poder de explicação do modelo com e sem o núcleo. 


\section{Uma análise sobre as medidas de núcleo divulgadas no Brasil}

Neste capítulo encontra-se uma análise estatística, segundo os métodos de avaliação propostos na seção 2.6, sobre os núcleos disponíveis atualmente no Brasil. Tal análise já foi executada por Ferreira et al. (27) em 2016 e está sendo refeita a seguir para o mesmo conjunto de dados porém com mais observações disponíveis.

\section{1}

\section{Que medidas de núcleo são divulgadas hoje no Brasil?}

Atualmente, seis medidas de núcleo da inflação são divulgadas oficialmente no Brasil (Tabela 3.1). Cinco delas são estimadas pelo BCB e têm referência ao IPCA (Índice de Preços ao Consumidor Amplo), este o índice oficial da inflação no país divulgado pelo Instituto Brasileiro de Geografia e Estatística (IBGE) (15). A sexta medida refere-se ao IPC-Br (Índice de Preços ao Consumidor - Brasil), ambas estimadas pelo Instituto Brasileiro de Economia da Fundação Getúlio Vargas (FGV IBRE) (16). Nesse estudo a janela temporal vai de jan/2001 a dez/2017, totalizando 204 observações, e são exibidas na Figura 3.1. As análises a seguir serão feitas tanto para a série completa como para o histórico dividido pela metade (primeira parte terminando em jun/2009 e segunda parte iniciando em jul/2009).

\begin{tabular}{l|lc}
\hline Sigla & Nome completo & Fonte \\
\hline IPC-Br-MAS & Núcleo por médias aparadas com suavização para o IPC-Br & FGV \\
IPCA-MA & Núcleo por médias aparadas sem suavização para o IPCA & BCB \\
IPCA-MAS & Núcleo por médias aparadas com suavização para o IPCA & BCB \\
IPCA-EX1 & Núcleo por exclusão (monitorados e alimentação no domicílio) para o IPCA & BCB \\
IPCA-EX2 & Núcleo por exclusão (10 itens mais voláteis) para o IPCA & BCB \\
IPCA-DP & Núcleo por dupla ponderação para o IPCA & BCB \\
\hline
\end{tabular}

Tabela 3.1: Núcleos da inflação divulgados no Brasil.

É visível que todas preservam bastante ruído em seu histórico e também sugerem indícios de sazonalidade. Os três núcleos por médias aparadas com suavização são os que aparentam ser mais suaves dentre o conjunto. Para entender e analisar a trajetória da inflação no Brasil, no entanto, é desejável 

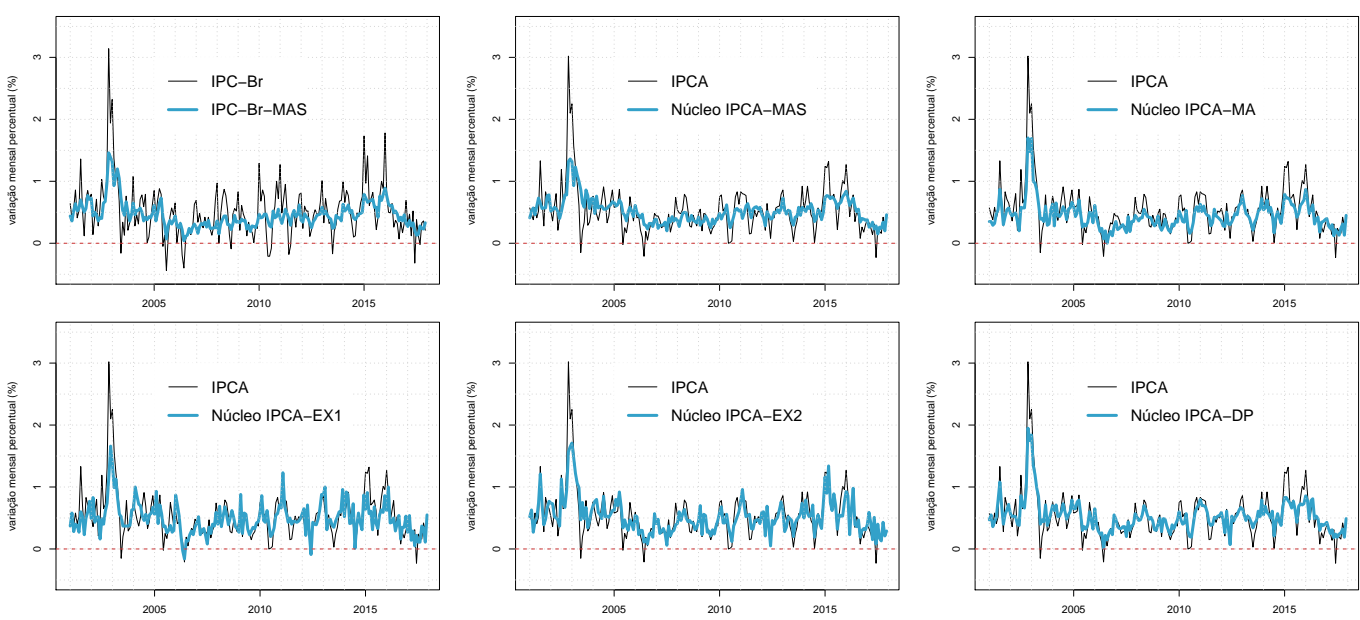

Figura 3.1: Núcleos da inflação disponíveis no Brasil.

uma medida menos ruidosa e sem sazonalidade, pois tais componentes podem mascarar a real trajetória de uma série temporal.

Para verificar a sazonalidade nas séries temporais, aplicou-se o teste QS fornecido pelo programa de ajuste sazonal X-13ARIMA-SEATS mantido pelo U.S. Census Bureau (26). O X-13ARIMA-SEATS (e versões anteriores) é um programa bem reconhecido no contexto econômico para verificar e remover sazonalidade em séries temporais. Para calcular a estatística de teste, a autocorrelação amostral é calculada para a série estacionária após tomarse diferenças necessárias. O teste verifica se há autocorrelação positiva e significativa no lag $s(12)$. Assume-se que a estatística segue distribuição $\chi_{(2)}^{2}$ (Qui-quadrado com 2 graus de liberdade). O leitor mais interessado pode obter mais informações sobre o teste consultando o manual do programa em (26), cap. 7.17, páginas 202-203.

O teste de sazonalidade (Tabela 3.2) sugere, considerando $5 \%$ de significância, que apenas os núcleos IPCA-MA e IPCA-DP não apresentam a componente sazonal em todo o seu histórico. Para o período mais antigo, o núcleo IPCA-MAS entra no grupo dos núcleos sem sazonalidade. Para o período mais recente, no entanto, apenas o IPC-Br-MAS e o IPCA-EX1 apontam evidências de sazonalidade.

\section{2}

\section{Avaliação segundo as propriedades desejáveis de um núcleo}

A avaliação segundo as características desejáveis vistas na seção 2.6 é feita a seguir. A Tabela 3.3 exibe estatísticas descritivas para as seis medidas de núcleo. Todas apresentam variabilidade (desvio-padrão) inferior ao índice de inflação de referência, destacando-se os núcleos por médias aparadas com suavização. Vale ressaltar que grande parte dos núcleos possuem médias 


\begin{tabular}{l|cc|cc|cc}
\hline & \multicolumn{2}{|c|}{ Total } & \multicolumn{2}{c}{ Parte inicial } & \multicolumn{2}{c}{ Parte final } \\
& qs-stat & p-valor & qs-stat & p-valor & qs-stat & p-valor \\
\hline IPC-Br-MAS & 21,04 & 0,0000 & 17,79 & 0,0001 & 17,73 & 0,0001 \\
IPCA-MA & 2,50 & 0,2869 & 2,69 & 0,2609 & 0,53 & 0,7684 \\
IPCA-MAS & 12,74 & 0,0017 & 4,82 & 0,0896 & 5,66 & 0,0590 \\
IPCA-EX1 & 33,25 & 0,0000 & 6,17 & 0,0000 & 21,87 & 0,0456 \\
IPCA-EX2 & 8,65 & 0,0132 & 23,78 & 0,0000 & 0,00 & 1,0000 \\
IPCA-DP & 3,33 & 0,1888 & 0,76 & 0,6843 & 3,59 & 0,1661 \\
\hline
\end{tabular}

$H_{0}$ : Não há sazonalidade na série temporal.

Tabela 3.2: Teste de Sazonalidade QS.

menores do que a do índice de inflação para o período completo, indicando que subestimam a tendência de longo prazo da variação dos preços, e essa diferença de médias (viés) é mais acentuada para o núcleo IPCA-MA e para o único núcleo divulgado pela FGV, IPC-Br-MAS. Tal diferença não é amenizada quando se considera o período mais recente. O IPCA-DP e o IPCA-EX2 são os únicos núcleos não viesados para o comprimento completo da série, no entanto, apresentam uma das variabilidades mais altas em relação ao IPCA.

\begin{tabular}{l|cccc}
\hline & Média & Mediana & Desvio-padrão & Viés \\
\hline IPC-Br & $0,51(0,49)$ & $0,47(0,49)$ & $0,43(0,37)$ & - \\
IPC-Br-MAS & $0,45(0,43)$ & $0,42(0,43)$ & $0,21(0,15)$ & $-0,06(-0,06)$ \\
\hline IPCA & $0,53(0,49)$ & $0,47(0,46)$ & $0,38(0,29)$ & - \\
IPCA-MA & $0,44(0,42)$ & $0,42(0,42)$ & $0,23(0,17)$ & $-0,09(-0,07)$ \\
IPCA-MAS & $0,52(0,50)$ & $0,51(0,50)$ & $0,20(0,15)$ & $-0,01(0,01)$ \\
IPCA-EX1 & $0,49(0,44)$ & $0,45(0,44)$ & $0,25(0,23)$ & $-0,04(-0,05)$ \\
IPCA-EX2 & $0,53(0,47)$ & $0,49(0,47)$ & $0,27(0,23)$ & $0,00(-0,02)$ \\
IPCA-DP & $0,53(0,50)$ & $0,50(0,50)$ & $0,25(0,18)$ & $0,00(0,01)$ \\
\hline
\end{tabular}

Nota: os valores entre parenteses são calculados considerando o histórico de jul/2009 a dez/2017 (segunda metade da amostra), enquanto os outros consideram a série histórica com início em jan/2001.

Tabela 3.3: Estatísticas descritivas para as medidas de núcleo existentes no Brasil.

A Tabela 3.4 apresenta o teste de raiz unitária Augmented Dickey Fuller (ADF) nos índices de inflação e seus respectivos núcleos. Considerou-se 5\% de significância. Para o período mais recente, todas as medidas são não estacionárias. O teste foi reaplicado para as medidas em primeira diferença e para todas não há evidências contra a afimarção de estacionariedade.

Após o teste de raiz unitária, fez-se o teste de cointegração de Johansen para avaliar se a inflação e o núcleo possuem relação de longo-prazo. A conclusão foi favorável para todas as medidas, como se observa na Tabela 3.5 . 


\begin{tabular}{|c|c|c|c|c|c|}
\hline & lag & equação & $\begin{array}{l}\text { Estatística } \\
\text { de teste }\end{array}$ & Valor Crítico & Conclusão \\
\hline IPC-Br & $\begin{array}{c}12 \\
(12)\end{array}$ & $\begin{array}{l}\text { s/ tend. c/ const. } \\
\text { (s/ tend. c/ const.) }\end{array}$ & $\begin{array}{c}-2,89 \\
(-1,34)\end{array}$ & $\begin{array}{l}-2,88 \\
(-2,88)\end{array}$ & $\begin{array}{c}\text { estacionário } \\
\text { (não estacionário) }\end{array}$ \\
\hline IPC-Br-MAS & $\begin{array}{c}12 \\
(12) \\
\end{array}$ & $\begin{array}{l}\text { s/ tend. c/ const. } \\
\text { (s/ tend. c/ const.) }\end{array}$ & $\begin{array}{l}-2,55 \\
(-1,77) \\
\end{array}$ & $\begin{array}{l}-2,88 \\
(-2,88) \\
\end{array}$ & $\begin{array}{c}\text { não estacionário } \\
\text { (não estacionário) }\end{array}$ \\
\hline IPCA & $\begin{array}{c}07 \\
(12)\end{array}$ & $\begin{array}{l}\text { s/ tend. c/ const. } \\
\text { (s/ tend. c/ const.) }\end{array}$ & $\begin{array}{c}-3,68 \\
(-1,62)\end{array}$ & $\begin{array}{l}-2,88 \\
(-2,88)\end{array}$ & $\begin{array}{c}\text { estacionário } \\
\text { (não estacionário) }\end{array}$ \\
\hline IPCA-MA & $\begin{array}{c}07 \\
(07) \\
\end{array}$ & $\begin{array}{l}\text { s/ tend. c/ const. } \\
\text { (s/ tend. c/ const.) }\end{array}$ & $\begin{array}{l}-3,08 \\
(-1,78) \\
\end{array}$ & $\begin{array}{l}-2,88 \\
(-2,88) \\
\end{array}$ & $\begin{array}{c}\text { estacionário } \\
\text { (não estacionário) }\end{array}$ \\
\hline IPCA-MAS & $\begin{array}{c}12 \\
(12) \\
\end{array}$ & $\begin{array}{l}\text { s/ tend. c/ const. } \\
\text { (s/ tend. c/ const.) }\end{array}$ & $\begin{array}{l}-2,00 \\
(-1,59) \\
\end{array}$ & $\begin{array}{l}-2,88 \\
(-2,88) \\
\end{array}$ & $\begin{array}{c}\text { não estacionário } \\
\text { (não estacionário) }\end{array}$ \\
\hline IPC-EX1 & $\begin{array}{c}11 \\
(11) \\
\end{array}$ & $\begin{array}{l}\text { s/ tend. c/ const. } \\
\text { (s/ tend. c/ const.) }\end{array}$ & $\begin{array}{c}-1,73 \\
(-1,34) \\
\end{array}$ & $\begin{array}{l}-2,88 \\
(-2,88) \\
\end{array}$ & $\begin{array}{c}\text { não estacionário } \\
\text { (não estacionário) }\end{array}$ \\
\hline IPCA-EX2 & $\begin{array}{c}11 \\
(08)\end{array}$ & $\begin{array}{l}\text { s/ tend. c/ const. } \\
\text { (s/ tend. c/ const.) }\end{array}$ & $\begin{array}{l}-1,82 \\
(-1,78)\end{array}$ & $\begin{array}{l}-2,88 \\
(-2,88)\end{array}$ & $\begin{array}{l}\text { não estacionário } \\
\text { (não estacionário) }\end{array}$ \\
\hline IPCA-DP & $\begin{array}{c}07 \\
(07)\end{array}$ & $\begin{array}{l}\text { s/ tend. c/ const. } \\
\text { (s/ tend. c/ const.) }\end{array}$ & $\begin{array}{l}-3,10 \\
(-1,53)\end{array}$ & $\begin{array}{l}-2,88 \\
(-2,88)\end{array}$ & $\begin{array}{l}\text { não estacionário } \\
\text { (não estacionário) }\end{array}$ \\
\hline
\end{tabular}

Os valores entre parenteses são obtidos sobre a série a partir de jul/2009.

O nível de significância considerado é de $5 \%$.

Tabela 3.4: Teste de raiz unitária (ADF) no IPC-Br, IPCA e seus núcleos.

\begin{tabular}{l|ccc}
\hline & $\begin{array}{c}\text { Estatística } \\
\text { de teste }\end{array}$ & Valor Crítico & Conclusão \\
\hline IPC-Br \& IPC-Br-MAS & 59,01 & 14,90 & séries cointegradas \\
IPCA \& IPCA-MA & 75,72 & 14,90 & séries cointegradas \\
IPCA \& IPCA-MAS & 58,33 & 14,90 & séries cointegradas \\
IPCA \& IPCA-EX1 & 60,59 & 14,90 & séries cointegradas \\
IPCA \& IPCA-EX2 & 74,33 & 14,90 & séries cointegradas \\
IPCA \& IPCA-DP & 68,75 & 14,90 & séries cointegradas \\
\hline
\end{tabular}

O nível de significância considerado é de $5 \%$.

Tabela 3.5: Teste de cointegração de Johansen entre o IPC-Br, IPCA e seus núcleos.

Uma vez que há evidências que as medidas possuem relação de longoprazo, como que se dá essa relação? Os próximos resultados disponíveis na Tabela 3.6 têm a intenção de avaliar isso. A tabela mostra que para todas as medidas, o gap entre a inflação e o núcleo diminue em razão de a inflação ir ao encontro do núcleo ( $\lambda<0$ e significativo) e, simultaneamente, o núcleo ir em direção à inflação ( $\lambda_{\text {núcleo }}>0$ e significativo), tanto para o período completo quanto para o período mais recente. Tal conclusão só não é a mesma para o 
núcleo IPCA-EX2, em que conclui-se que a inflação não é atraída pelo núcleo $(\lambda=0)$.

\begin{tabular}{l|cc}
\hline & $\lambda$ & $\lambda_{\text {núcleo }}$ \\
\hline IPC-Br \& IPC-Br-MAS & $\begin{array}{c}-0,5285^{* * *} \\
\left(-0,4927^{* * *}\right)\end{array}$ & $\begin{array}{c}0,00847^{* *} \\
\left(0,0966^{*}\right)\end{array}$ \\
\hline IPCA \& IPCA-MA & $\begin{array}{c}-0,4041^{* *} \\
\left(-0,5468^{* * *}\right)\end{array}$ & $\begin{array}{c}0,2897^{* * *} \\
\left(0,2337^{* *}\right)\end{array}$ \\
\hline IPCA \& IPCA-MAS & $\begin{array}{c}-0,3179^{* * *} \\
\left(-0,3482^{* *}\right)\end{array}$ & $\begin{array}{c}0,2023^{* * *} \\
\left(0,1727^{* *}\right)\end{array}$ \\
\hline IPCA \& IPCA-EX1 & $-0,3020^{* * *}$ & $0,2747^{* * *}$ \\
\hline IPCA \& IPCA-EX2 & $\left(-0,3889^{* * *}\right)$ & $\left(0,2255^{*}\right)$ \\
\hline IPCA \& IPCA-DP & $\begin{array}{c}0,1669 \\
(-0,0472)\end{array}$ & $\begin{array}{c}0,4301^{* * *} \\
\left(0,4649^{* * *}\right)\end{array}$ \\
\hline
\end{tabular}

Nota: níveis de significância: $5 \%(*), 1 \%(* *)$ e $0.1 \%\left(^{(* *}\right)$.

Os resultados entre parenteses são obtidos considerando o histórico de jul/2009 a dez/2017.

Tabela 3.6: Dinâmica entre IPC-Br, IPCA e seus núcleos.

Para finalizar os diagnósticos, tem-se a Tabela 3.7 que tem o objetivo de avaliar se a diferença entre a inflação e o núcleo hoje ajudam a prever o quanto a inflação mudará de hoje para daqui a $h=1,3,6$ e 12 meses. Nota-se que para todos os núcleos essa relação é válida ( $\beta$ significativo em todas as equações), porém, utilizar o histórico mais recente traz resultados melhores. Por exemplo, o núcleo do IPC-Br aparenta trazer mais informações sobre a variação da inflação para o período mais recente $\left(R^{2}\right.$ varia de $45 \%$ para $\left.63 \%\right)$ para um horizonte de 6 meses. Em geral, os núcleos apresentam maior poder de predição para o horizonte de médio prazo (3 e 6 meses). Os indicadores via médias aparadas com suavização são os que mais se destacam, em seguida vem o médias aparadas sem suavização, dupla ponderação e, por último, os núcleos por exclusão.

Tal análise foi feita para fora da amostra para os últimos 12 meses com o intuito de verificar se o padrão de dentro da amostra se repetia. A Tabela 3.8 mostra que não. A medida que o horizonte aumenta, o erro aumenta. 


\begin{tabular}{|c|c|c|c|c|c|c|c|}
\hline & & \multicolumn{3}{|c|}{ jan/2001 a dez/2017 } & \multicolumn{3}{|c|}{ jul/2009 a dez/2017 } \\
\hline & & $R^{2}$ & $\beta$ & t-stat & $R^{2}$ & $\beta$ & t-stat \\
\hline \multirow{6}{*}{$h=1$} & IPC-Br \& IPC-Br-MAS & 0,26 & $0,69(0,08)$ & $8,3^{* * *}$ & 0,28 & $0,69(0,11)$ & $6,2^{* * *}$ \\
\hline & IPCA \& IPCA-MA & 0,15 & $0,57(0,09)$ & $5,8^{* * *}$ & 0,17 & $0,57(0,13)$ & $4,4^{* * *}$ \\
\hline & IPCA \& IPCA-MAS & 0,14 & $0,41(0,07)$ & $5,7^{* * *}$ & 0,12 & $0,40(0,11)$ & $3,7^{* * *}$ \\
\hline & IPCA \& IPCA-EX1 & 0,09 & $0,33(0,07)$ & $4,4^{* * *}$ & 0,08 & $0,32(0,10)$ & $2,9^{* *}$ \\
\hline & IPCA \& IPCA-EX2 & 0,04 & $0,28(0,09)$ & $2,9^{* *}$ & 0,00 & $0,08(0,14)$ & 0,5 \\
\hline & IPCA \& IPCA-DP & 0,13 & $0,61(0,11)$ & $5,5^{* * *}$ & 0,14 & $0,54(0,13)$ & $4,0^{* * *}$ \\
\hline \multirow{6}{*}{$h=3$} & IPC-Br \& IPC-Br-MAS & 0,37 & $1,08(0,10)$ & $10,8^{* * *}$ & 0,44 & $1,14(0,13)$ & $8,7^{* * *}$ \\
\hline & IPCA \& IPCA-MA & 0,26 & $1,13(0,13)$ & $8,5^{* * *}$ & 0,32 & $1,20(0,18)$ & $6,8^{* * *}$ \\
\hline & IPCA \& IPCA-MAS & 0,25 & $0,81(0,10)$ & $8,2^{* * *}$ & 0,30 & $0,94(0,15)$ & $6,4^{* * *}$ \\
\hline & IPCA \& IPCA-EX1 & 0,15 & $0,65(0,11)$ & $6,1^{* * *}$ & 0,19 & $0,73(0,16)$ & $4,7^{* * *}$ \\
\hline & IPCA \& IPCA-EX2 & 0,15 & $0,84(0,14)$ & $6,1^{* * *}$ & 0,14 & $0,82(0,21)$ & $3,9 * * *$ \\
\hline & IPCA \& IPCA-DP & 0,25 & $1,14(0,15)$ & $7,7^{* * *}$ & 0,32 & $1,23(0,18)$ & $6,8^{* * *}$ \\
\hline \multirow{6}{*}{$h=6$} & IPC-Br \& IPC-Br-MAS & 0,45 & $1,40(0,11)$ & $12,8^{* * *}$ & 0,63 & $1,64(0,13)$ & $12,6^{* * *}$ \\
\hline & IPCA \& IPCA-MA & 0,37 & $1,70(0,16)$ & $10,7^{* * *}$ & 0,47 & $1,87(0,20)$ & $9,1^{* * *}$ \\
\hline & IPCA \& IPCA-MAS & 0,40 & $1,29(0,11)$ & $11,5^{* * *}$ & 0,53 & $1,60(0,16)$ & $10,2^{* * *}$ \\
\hline & IPCA \& IPCA-EX1 & 0,20 & $0,94(0,13)$ & $7,1^{* * *}$ & 0,14 & $0,80(0,21)$ & $3,9 * * *$ \\
\hline & IPCA \& IPCA-EX2 & 0,30 & $1,47(0,16)$ & $9,2^{* * *}$ & 0,27 & $1,44(0,24)$ & $5,9 * * *$ \\
\hline & IPCA \& IPCA-DP & 0,35 & $1,88(0,18)$ & $10,2^{* * *}$ & 0,43 & $1,83(0,22)$ & $8,3^{* * *}$ \\
\hline \multirow{6}{*}{$h=12$} & IPC-Br \& IPC-Br-MAS & 0,28 & $0,87(0,10)$ & $8,6^{* * *}$ & 0,16 & $0,46(0,11)$ & $4,1^{* * *}$ \\
\hline & IPCA \& IPCA-MA & 0,33 & $1,44(0,15)$ & $9,7^{* * *}$ & 0,22 & $0,94(0,19)$ & $5,0^{* * *}$ \\
\hline & IPCA \& IPCA-MAS & 0,34 & $1,05(0,11)$ & $9,9^{* * *}$ & 0,16 & $0,63(0,16)$ & $4,0 * * *$ \\
\hline & IPCA \& IPCA-EX1 & 0,32 & $1,05(0,11)$ & $9,5^{* * *}$ & 0,17 & $0,67(0,15)$ & $4,4^{* * *}$ \\
\hline & IPCA \& IPCA-EX2 & 0,28 & $1,26(0,15)$ & $8,5^{* * *}$ & 0,09 & $0,60(0,21)$ & $2,9 * * *$ \\
\hline & IPCA \& IPCA-DP & 0,27 & $1,47(0,18)$ & $8,3^{* * *}$ & 0,14 & $0,75(0,20)$ & $3,7^{* * *}$ \\
\hline
\end{tabular}

Nota: desvio-padrão do coeficiente $\beta$ entre parênteses; t-stat é a estatística de teste para o parâmetro $\beta$.

Tabela 3.7: Análise da previsão da inflação utilizando núcleos.

\begin{tabular}{l|cccc|cccc}
\hline & \multicolumn{3}{|c|}{$\mathrm{jan} / 2001 \mathrm{a} \mathrm{dez} / 2017$} & \multicolumn{4}{c}{$\mathrm{jul} / 2009 \mathrm{a} \mathrm{dez} / 2017$} \\
\hline & $\mathbf{1}$ & $\mathbf{3}$ & $\mathbf{6}$ & $\mathbf{1 2}$ & $\mathbf{1}$ & $\mathbf{3}$ & $\mathbf{6}$ & $\mathbf{1 2}$ \\
\hline IPC-Br-MAS & 0,29 & 0,28 & 0,35 & 0,38 & 0,29 & 0,29 & 0,40 & 0,38 \\
IPCA-MA & 0,18 & 0,24 & 0,33 & 0,35 & 0,18 & 0,24 & 0,34 & 0,36 \\
IPCA-MAS & 0,20 & 0,19 & 0,24 & 0,40 & 0,20 & 0,20 & 0,28 & 0,41 \\
IPCA-EX1 & 0,19 & 0,18 & 0,29 & 0,32 & 0,20 & 0,18 & 0,28 & 0,35 \\
IPCA-EX2 & 0,25 & 0,25 & 0,29 & 0,39 & 0,24 & 0,25 & 0,31 & 0,41 \\
IPCA-DP & 0,18 & 0,20 & 0,29 & 0,40 & 0,19 & 0,21 & 0,30 & 0,40 \\
\hline
\end{tabular}

Tabela 3.8: Erro de previsão (RMSE) 1 passo à frente para os últimos 12 meses. 


\subsection{1}

\section{Conclusão}

Pode-se concluir a partir das análises elaboradas anteriormente que as medidas de núcleo disponíveis no Brasil não aderem por completo aos critérios sugeridos na seção 2.6. As medidas, em grande parte, apresentam alta volatilidade e sazonalidade ocultando a tendência da inflação.

É importante destacar que apesar disso, as medidas ainda podem trazer outra informação de interesse do Banco Central e de outros agentes econômicos. Por exemplo, os núcleos por dupla ponderação e por médias aparadas trazem alguma informação a respeito do desenvolvimento da inflação no curto prazo (Tabela 3.8). 


\section{4 \\ Propostas metodológicas}

A análise realizada no Capítulo 3 permite concluir que os núcleos disponíveis no Brasil hoje não aderem perfeitamente aos critérios desejáveis a esse tipo de medida (seção 2.6). Apesar de serem cointegrados, ainda apresentam considerável volatilidade e sazonalidade, mascarando o valor corrente da tendência. Percebe-se portanto que para esse tipo de interesse (análise da tendência) o conjunto de núcleos atual precisa ser aprimorado. Com esse intuito, essa dissertação propõe duas metodologias para estimação do núcleo da inflação, a saber: I) suavização dos núcleos tradicionais para a remoção da sazonalidade e de ruídos restantes e II) a estimação de um núcleo via Dynamic Conditional Score Models, em que a série temporal da inflação é decomposta em suas componentes não observáveis, sendo estas funções do escore da distribuição condicional das observações.

Para a estimação da primeira proposta, é necessária informações desagregadas do indicador da inflação. A FGV IBRE forneceu uma série longa dos subitens (menor desagregação da cesta) do IPC-Br e, por isso, os resultados desse estudo são aplicados somente ao IPC-Br. Ao longo da série histórica do IPC-Br existem 517 subitens, dos quais 338 compõem a cesta atual. O IPC-Br não é o indicador oficial de inflação do Brasil, mas é considerado uma proxy dele (IPCA), o que ainda torna relevante a aplicação do estudo. O IBGE também compartilha os dados do IPCA de forma desagregada, porém, essa informação foi conseguida de forma mais rápida e simples para o IPC-Br devido a minha relação com a instituição. É importante agradecer ao André Braz (coordenador dos índices de preços da FGV IBRE) por auxílio na montagem da base de dados.

$\mathrm{Na}$ segunda proposta, o núcleo da inflação é estimado sobre o índice cheio da inflação, não necessitando de seus componentes. Para que seja viável comparar o núcleo vindo desta metodologia com o núcleo vindo da outra metodologia proposta, estimou-se também tal núcleo sobre o IPC-Br. 


\section{1 \\ Suavização dos núcleos tradicionais}

Os núcleos por médias aparadas com suavização são os que mais se destacam dentre o conjunto analisado no Capítulo 3. Conclusões similares podem ser encontradas em outros estudos feitos sobre as medidas de núcleo no Brasil (da Silva Filho \& Figueiredo (2011 e 2014) (18, 19), Santos \& Castelar (2016) (28)). Com o intuito de aprimorar o seu desempenho, são sugeridos três procedimentos em seu cálculo:

1. Recalcular o núcleo de médias aparadas com suavização, alterando a proporção de subitens que serão removidos nos extremos inferior e superior;

2. Remover a sazonalidade identificada;

3. Aplicar um filtro curto de médias móveis para remover a componente de alta frequência restante após o ajuste sazonal.

A alteração da proporção de subitens que serão removidos do cálculo do núcleo tem o intuito de aproximar a média do núcleo à média da inflação, eliminando o viés de média. A remoção da componente sazonal é importante para evitar interpretações inadequadas a respeito da tendência da série temporal. Para dessazonalizar a série, fez-se uso do programa de ajuste sazonal X-13ARIMA-SEATS (26). Todavia, mesmo com ajuste sazonal, uma série temporal ainda pode ser considerada volátil, justamente porque o objetivo do ajuste sazonal é apenas remover a componente sazonal e não a componente de alta frequência (irregular/ruído). Analistas econômicos geralmente utilizam técnicas de suavização para tentar captar a suposta tendência de uma série temporal volátil como, por exemplo, médias móveis. Caso haja sazonalidade na série temporal, geralmente utiliza-se a ordem 12 (variação acumulada em 12 meses) ou superior para analisar a trajetória da inflação (como é feito no Brasil). O ponto negativo nesse caso é que a inflação corrente é muito afetada por valores passados.

No entanto, após a remoção da sazonalidade, pode-se empregar uma média móvel de ordem mais curta (três meses) com a finalidade de remover apenas as variações de alta frequência. Assim, a inflação no tempo atual é pouco influenciada por variações em meses distantes (equação 4-1). Após esses três filtros (variações extremas, sazonalidade, alta frequência), tem-se o núcleo suavizado. 
em que:

$$
\pi_{i, t}^{S}=\left[\left(\prod_{i=0}^{2} \frac{\pi_{i, t-i}^{A J}}{100}+1\right)^{\frac{12}{3}}-1\right] \times 100
$$

$\pi_{i, t}^{S}$ é o núcleo suavizado;

$\pi_{i, t}^{A J}$ é o núcleo com ajuste sazonal (\% a.m.);

$i$ é o subitem da cesta de produtos do IPC-Br.

Há alguns pontos que devem ser considerados na análise dessa medida de tendência. Uma vez que a metodologia é a de médias aparadas com suavização, o valor do núcleo atual é afetado pela informação de 12 meses atrás, embora em um valor reduzido. O uso de informações passadas é ainda mais intensificado ao utilizar o filtro curto de médias móveis de três meses. Dessa forma, essa medida de tendência pode não revelar de fato o valor corrente da variação dos preços. Sua utilidade em relação a inflação acumulada em 12 meses deve ser mensurada.

Os subsubitens que são suavizados correspondem a aproximadamente $37 \%$ da cesta atual: Aluguel Residencial, Condomínio Residencial, Tarifa De Eletricidade Residencial, Gás De Bujão, Tarifa De Gás Encanado, Taxa De Água E Esgoto Residencial, Dentista, Médico, Psicólogo, Plano E Seguro De Saúde, Outros Profissionais De Saúde, Gastroprotetor, Psicotrópico E Anorexígeno, Analgésico E Antitérmico, Antiinflamatório E Antibiótico, Antigripal E Antitussígeno, Antialérgico E Broncodilatador, Vasodilatador Para Pressão Arterial, Calmante E Antidepressivo, Anticoncepcional, Dermatológico, Vitamina E Fortificante, Antimicótico E Parasiticida, Remédio Para Diabete, Remédio Para Osteoporose, Remédios Oftamológicos, Curso De Ensino Fundamental, Curso De Ensino Médio, Curso De Educação Infantil (Pré-Escolar), Curso De Ensino Superior, Curso De Educação Infantil (Creche), Curso De Pós-Graduação, Tarifa De Barco E Aerobarco, Tarifa De Metrô, Tarifa De Ônibus Urbano, Tarifa De Táxi, Transporte Escolar, Tarifa De Trem Urbano, Tarifa De Transporte De Van E Similares, Tarifa De Ônibus Interurbano, Etanol, Gasolina, Óleo Lubrificante, Óleo Diesel, Gás Natural Veicular, Licenciamento - Ipva, Pedágio, Seguro Obrigatório Para Veículo, Cartão De Telefone, Tarifa Postal, Acesso À Internet Em Loja, Bilhete Lotérico, Jogo Lotérico, Tarifa De Telefone Residencial, Tarifa De Telefone Móvel.

\section{2}

\section{Núcleo via Dynamic Conditional Score Models}

Dynamic Conditional Score models (modelos DCS) também é conhecido como Generalized Autoregressive Score models (modelos GAS). Atualmente 
as duas nomenclaturas também são referenciadas como Score Driven models. Os modelos DCS pertencem à classe de modelos guiados por observações, isto é, modelos em que os parâmetros variam no tempo de acordo com um mecanimo que envolve os valores passados do parâmetro e o passado das observações via função escore. Tais modelos foram inicialmente propostos por Crea et al. (2013) (29) e por Harvey (2013) (30) e têm sido aplicados com sucesso, por exemplo, em modelagem de risco de crédito, volatilidade de ações, estruturas de dependência variando no tempo, dados de alta frequência, entre outras, devido a sua fácil implementação, estimação e interpretação. A página www.gasmodel.com/index.htm contém outros exemplos de aplicações e todas as ferramentas desenvolvidas ao usuário que deseja utilizar esse modelo.

Como será visto nas seções a seguir, é possível especificar modelos DCS em formas de componentes, decompondo a média condicional da série em componentes não observáveis, tais como tendência, sazonalidade, ciclo e erro. Utilizando essa metodologia é possível considerar que a fonte de erro da variável de interesse siga outra distribuição além da normal (distribuição comumente utilizada em modelos de componentes não observáveis (Unobserved Components Models - UC models)). Isso é interessante para a série temporal utilizada nesse estudo, uma vez que algumas observações podem ser consideradas outliers se tratadas nesse contexto quando na verdade podem ser provenientes de uma distribuição de cauda mais pesada, como a t-Student. A metodologia fornece resultados relativos à distribuição assintótica dos estimadores e outras propriedades estatísticas de uma maneira compreensiva e direta, mesmo ao aumentar a complexidade do modelo ao acrescentar restrições aos parâmetros e às variáveis de interesse.

Nas subseções a seguir apresenta-se de forma geral o arcabouço DCS para modelos de séries temporais. Em seguida, mostram-se as formas de atualização dos parâmetros que variam no tempo, a estimação dos parâmetros estáticos, como adicionar parametrizações (imposição de restrições), diagnosticar o modelo e obter previsões.

\subsection{1}

\section{0 arcabouço DCS para modelos de séries temporais}

Considere $y_{t}$ o vetor que representa a variável dependente, $f_{t}$ o vetor de parâmetros que variam no tempo, $x_{t}$ o vetor de covariáveis e $\theta$ o vetor de parâmetros estáticos. Ao definir $Y^{t}=\left\{y_{1}, \ldots, y_{t}\right\}, F^{t}=\left\{f_{0}, f_{1}, \ldots, f_{t}\right\}$ e $X^{t}=\left\{x_{1}, \ldots, x_{t}\right\}$, tem-se que o conjunto de informações disponíveis até o 
tempo $t$ consiste em $\left\{f_{t}, \mathcal{F}_{t}\right\}$, em que:

$$
\mathcal{F}_{t}=\left\{Y^{t-1}, F^{t-1}, X^{t}\right\}, \text { para } t=1, \ldots, T
$$

Assume-se que $y_{t}$ é gerada pela densidade condicional

$$
y_{t} \sim p\left(y_{t} \mid f_{t}, \mathcal{F}_{t} ; \theta\right)
$$

Com esse arcabouço em mente, é necessário, em seguida, definir a forma de atualização dos parâmetros que variam no tempo $f_{t}$. Existem duas abordagens para a atualização:

- GAS(p,q): $f_{t}$ é atualizado segundo uma equação similar a dos modelos $\operatorname{ARMA}(\mathrm{p}, \mathrm{q})$, mais precisamente $f_{t}$ é função de suas defasagens e de defasagens do vetor escore;

- Componentes não observáveis: $y_{t}$ é decomposto em componentes não observáveis que possuem interpretação direta, tais como tendência, sazonalidade, ciclo e irregular.

Aprensenta-se a seguir os detalhes de cada uma dessas abordagens.

\subsubsection{1}

\section{$\operatorname{GAS}(\mathbf{p}, \mathbf{q})$}

Nessa abordagen, o mecanismo de atualização dos parâmetros que variam no tempo $f_{t}$ é dado pela seguinte equação

$$
f_{t+1}=\omega+\sum_{i=1}^{p} A_{i} s_{t-i+1}+\sum_{i=1}^{q} B_{j} f_{t-j+1}
$$

em que $\omega$ é um vetor de constantes; $A_{i}$ e $B_{j}$ são matrizes cujas dimensões dependem da dimensão de $s_{t}$ e $f_{t}$; e $s_{t}$ é uma função de valores passados, isto é, $s_{t}=s_{t}\left(y_{t}, f_{t}, F_{t} ; \theta\right)$. Os coeficientes desconhecidos em (4-3) são aglutinados no vetor $\theta$. Por fim, é necessário definir $s_{t}$, que será dado pelo vetor escore ponderado:

$$
s_{t}=S_{t} \cdot \nabla_{t}, \quad \nabla_{t}=\frac{\partial \ln p\left(y_{t} \mid f_{t}, \mathcal{F}_{t} ; \theta\right)}{\partial f_{t}}, \quad S_{t}=S\left(t, f_{t}, \mathcal{F}_{t} ; \theta\right)
$$

em que $\nabla_{t}$ é o vetor escore e $S_{t}$ é uma matrix de ponderação, definida como uma função da informação de Fisher $\left(\mathcal{I}_{t \mid t-1}\right)$ : 


$$
S_{t}=\mathcal{I}_{t \mid t-1}^{-d}, \quad \mathcal{I}_{t \mid t-1}=E_{t-1}\left[\nabla_{t} \nabla_{t}^{\prime}\right]
$$

em que $d=0, \frac{1}{2}$ ou 2 e $E_{t-1}=E\left[. \mid f_{t}, \mathcal{F}_{t}\right]$.

Assim, as equações (4-2) - (4-4) definem o modelo $\operatorname{GAS}(p, q)$. O leitor deve estar atento que escolhas diferentes de $S_{t}$ resultarão em modelos DCS completamente diferentes. Veja os seguintes exemplos.

Exemplo 1: Seja $y_{t}=\mu_{t}+\varepsilon_{t}, \quad \varepsilon_{t} \sim N\left(0, \sigma^{2}\right)$. Encontre a equação de atualização para o parâmetro $\mu_{t}$.

Considerando $\mu_{t}=f_{t}$, segue que $\left(y_{t} \mid f_{t}, \mathcal{F}_{t}\right) \sim N\left(f_{t}, \sigma^{2}\right)$, ou seja,

$$
p\left(y_{t} \mid f_{t}, \mathcal{F}_{t}\right)=\frac{1}{\sqrt{2 \pi \sigma^{2}}} \exp \left\{-\frac{\left(y_{t}-f_{t}\right)^{2}}{2 \sigma^{2}}\right\}
$$

Assim, $\nabla_{t}$ é obtido por

$$
\nabla_{t}=\frac{\partial \ln p\left(y_{t} \mid f_{t}, \mathcal{F}_{t}\right)}{\partial f_{t}}=\frac{y_{t}-f_{t}}{\sigma^{2}}
$$

e $\mathcal{I}_{t \mid t-1}$ por

$$
\begin{gathered}
\frac{\partial^{2} \ln p\left(y_{t} \mid f_{t}, \mathcal{F}_{t}\right)}{\partial^{2} f_{t}}=-\frac{1}{\sigma^{2}} \\
\mathcal{I}_{t \mid t-1}=-E_{t-1}[-1]=\frac{1}{\sigma^{2}}
\end{gathered}
$$

E assim, considerando $d=1$,

$$
s_{t}=\mathcal{I}_{t \mid t-1}^{-1} \cdot \nabla_{t}=\frac{y_{t}-f_{t}}{\sigma^{2}}
$$

a equação de atualização de $f_{t}$ para um $\operatorname{GAS}(1,1)$ é dada por

$$
f_{t+1}=\omega+A_{1}\left(y_{t}-f_{t}\right)+B_{1} f_{t}
$$

Exemplo 2: Seja $y_{t}=\sigma_{t} \varepsilon_{t}, \quad \varepsilon_{t} \sim N(0,1)$. Encontre a equação de atualização para o parâmetro $\sigma_{t}^{2}$.

Considerando $\sigma_{t}^{2}=f_{t}$, segue que $\left(y_{t} \mid f_{t}, \mathcal{F}_{t}\right) \sim N\left(0, f_{t}\right)$, ou seja,

$$
\begin{array}{r}
p\left(y_{t} \mid f_{t}, \mathcal{F}_{t}\right)=\frac{1}{\sqrt{2 \pi f_{t}}} \exp \left\{-\frac{y_{t}^{2}}{2 f_{t}}\right\} \\
\ln p\left(y_{t} \mid f_{t}, \mathcal{F}_{t}\right)=-\frac{1}{2} \ln \left(2 \pi f_{t}\right)-\frac{y_{t}^{2}}{2 f_{t}}
\end{array}
$$


Assim, $\nabla_{t}$ é dado por

$$
\nabla_{t}=\frac{\partial \ln p\left(y_{t} \mid f_{t}, \mathcal{F}_{t}\right)}{\partial f_{t}}=-\frac{1}{2} \frac{1}{2 \pi f_{t}} 2 \pi-\frac{y_{t}^{2}}{2 f_{t}^{2}}(-1)=-\frac{1}{2 f_{t}}+\frac{y_{t}^{2}}{2 f_{t}^{2}}
$$

e $\mathcal{I}_{t \mid t-1}$ por

$$
\begin{gathered}
\frac{\partial^{2} \ln p\left(y_{t} \mid f_{t}, \mathcal{F}_{t}\right)}{\partial^{2} f_{t}}=-\frac{1}{2 f_{t}^{2}}(-1)+\frac{y_{t}^{2}}{2 f_{t}^{3}}(-2)=\frac{1}{2 f_{t}^{2}}-\frac{y_{t}^{2}}{f_{t}^{3}} \\
\mathcal{I}_{t \mid t-1}=-E_{t-1}\left[\frac{1}{2 f_{t}^{2}}-\frac{y_{t}^{2}}{f_{t}^{3}}\right]=-\frac{1}{2 f_{t}^{2}}+\frac{E_{t-1}\left[y_{t}^{2}\right]}{f_{t}^{3}}=-\frac{1}{2 f_{t}^{2}}+\frac{f_{t}^{2}}{f_{t}^{3}}=\frac{1}{2 f_{t}^{2}}
\end{gathered}
$$

E assim, considerando $d=1$,

$$
s_{t}=\mathcal{I}_{t \mid t-1}^{-1} \cdot \nabla_{t}=2 f_{t}^{2} \cdot\left(-\frac{1}{2 f_{t}}+\frac{y_{t}^{2}}{2 f_{t}^{2}}\right)=y_{t}^{2}-f_{t}
$$

a equação de atualização de $f_{t}$ para um $\operatorname{DCS}(1,1)$ é dada por

$$
f_{t+1}=\omega+A_{1}\left(y_{t}^{2}-f_{t}\right)+B_{1} f_{t}
$$

que pode ser reescrita como

$$
\sigma_{t+1}^{2}=\omega+A_{1} y_{t}^{2}+\left(B_{1}-A_{1}\right) \sigma_{t}^{2}
$$

que equivale a um modelo $\operatorname{GARCH}(1,1)$.

A partir desses exemplos, é fácil ver que alterando a forma funcional de $S_{t}$, a equação de atualização será completamente diferente da encontrada anteriormente.

\subsubsection{2}

\section{Componentes não observáveis}

De acordo com a decomposição clássica, séries temporais podem ser decompostas em quatro componentes não observáveis: tendência, sazonalidade, ciclo e erro. Estimar a componente de tendência é o principal interesse desse estudo. Um modelo de componentes não observáveis muito popular é o modelo estrutural básico (Basic Structural Model - BSM) representado na equação (4-5). Esse modelo é apresentado no livro Forecasting, Structural Time Series Models and the Kalman Filter de Andrew C. Harvey (1989) (31). 


$$
\begin{aligned}
y_{t} & =\mu_{t}+\gamma_{t}+\varepsilon_{t}, \quad \varepsilon_{t} \sim N\left(0, \sigma_{\varepsilon}^{2}\right) \\
\mu_{t+1} & =\mu_{t}+\beta_{t}+\eta_{t}, \quad \eta_{t} \sim N\left(0, \sigma_{\eta}^{2}\right) \\
\beta_{t+1} & =\beta_{t}+\zeta_{t}, \quad \zeta_{t} \sim N\left(0, \sigma_{\zeta}^{2}\right) \\
\gamma_{t+1} & =-\sum_{j=1}^{s-1} \gamma_{t+1-j}+\xi_{t}, \quad \xi_{t} \sim N\left(0, \sigma_{\xi}^{2}\right)
\end{aligned}
$$

em que $\mu_{t}$ é a componente de tendência, $\gamma_{t}$ é a componente periódica que representa a sazonalidade e $\varepsilon_{t}$ é a componente irregular. Assume-se que os erros $\varepsilon_{t}, \eta_{t}, \zeta_{t}$ e $\xi_{t}$ são mutual e serialmente independentes.

Uma vez que o modelo BSM em (4-5) está na forma de espaço de estados, sua estimação é realizada pelo filtro de Kalman (Durbin \& Koopman (2012) (32)) e os parâmetros estáticos podem ser estimados via maximização da função de verossimilhança.

Visto que já existe uma literatura bem desenvolvida para a estimação de modelos estruturais (ou modelos de componentes não observáveis), por que esta não será utilizada e por que é proposto a utilização de modelos DCS em seu lugar?

Para responder estes questionamentos, suponha que o modelo (4-5) fosse adotado para uma série temporal mas que, após a análise dos resíduos, fosse verificado um número acentuado de outliers. Nesse caso seria mais apropriado considerar um BSM em que a distribuição de $\varepsilon_{t}$ apresentasse cauda pesada. Por exemplo, $\varepsilon_{t}$ com distribuição $t$-Student com $\nu$ graus de liberdade. Assim, a estimação do modelo BSM com $\varepsilon_{t} t_{\nu}$ não mais deveria ser efetuada via filtro de Kalman. Métodos de simulação como MCMC (Markov chain Monte Carlo) e filtro de partículas proveem maneiras para estimar modelos em espaço de estado em ambientes não gaussianos (32). Métodos de simulação, todavia, são computacionalmente intensivos e de difícil implementação.

O arcabouço fornecido por modelos DCS permite criar um modelo análogo ao BSM e permite alterar a função densidade de probabilidade dos erros sem muito custo e, ainda assim, os resultados relativos à distribuição assintótica dos estimadores e outras propriedades estatísticas são obtidos de uma maneira compreensiva e direta.

O modelo DCS seguindo o arcabouço BSM é apresentado a seguir, já considerando a distribuição $t$-Student com $\nu$ graus de liberdade (com média zero e parâmetro de escala 1) para $\varepsilon_{t}$, seguindo Harvey (2013) (30), Cap. 3, pg 75. 


$$
\begin{aligned}
y_{t} & =\mu_{t \mid t-1}+\gamma_{t \mid t-1}+e^{\lambda} \varepsilon_{t}, \quad \varepsilon_{t} \sim t_{\nu} \\
\mu_{t+1 \mid t} & =\mu_{t \mid t-1}+\beta_{t \mid t-1}+\kappa_{1} u_{t} \\
\beta_{t+1 \mid t} & =\beta_{t \mid t-1}+\kappa_{2} u_{t} \\
\alpha_{t+1 \mid t} & =\alpha_{t \mid t-1}+\kappa_{t} u_{t} \\
\gamma_{t+1 \mid t} & =z_{t+1}^{\prime} \alpha_{t+1 \mid t}
\end{aligned}
$$

em que:

$$
\alpha_{t+1 \mid t}=\left[\begin{array}{c}
\alpha_{1, t+1 \mid t} \\
\alpha_{2, t+1 \mid t} \\
\vdots \\
\alpha_{s, t+1 \mid t}
\end{array}\right]=\left[\begin{array}{c}
\alpha_{1, t \mid t-1} \\
\alpha_{2, t \mid t-1} \\
\vdots \\
\alpha_{s, t \mid t-1}
\end{array}\right]+\left[\begin{array}{c}
\kappa_{1, t} \\
\kappa_{2, t} \\
\vdots \\
\kappa_{s, t}
\end{array}\right] u_{t}
$$

$z_{t}$ é um vetor de dimensão $s \times 1$ que contém apenas um valor 1 e (s-1) zeros para cada tempo $t$, sendo $s$ a periodicidade da série temporal (4 para trimestral e 12 para mensal, por exemplo). Sua função na equação é criar a componente de sazonalidade $\gamma_{t \mid t-1}$ ao identificar que mês refere-se ao tempo corrente. Por exemplo, suponha que $s=12$ e o mês no tempo $t=1$ é março. Logo,

$$
\begin{aligned}
z_{1} & =\left[\begin{array}{llllll}
0 & 0 & 1 & 0 & \ldots & 0
\end{array}\right]^{\prime}, \\
z_{2} & =\left[\begin{array}{llllll}
0 & 0 & 0 & 1 & \ldots & 0
\end{array}\right]^{\prime}
\end{aligned}
$$

$\kappa_{t}$ também é um vetor de dimensão $s \times 1$ que recebe $k_{s}$ ou $-k_{s} /(s-1), k_{s}>0$, dependendo se $t$ refere-se ao mês corrente. Por exemplo, supondo ainda que $t=1$ é março:

$$
\begin{aligned}
& \kappa_{1}=\left[\begin{array}{llllll}
-k_{s} /(s-1) & -k_{s} /(s-1) & k_{s} & -k_{s} /(s-1) & \ldots & -k_{s} /(s-1)
\end{array}\right]^{\prime} \\
& \kappa_{2}=\left[\begin{array}{llllll}
-k_{s} /(s-1) & -k_{s} /(s-1) & -k_{s} /(s-1) & k_{s} & \ldots & -k_{s} /(s-1)
\end{array}\right]^{\prime}
\end{aligned}
$$

De (4-6) é possível mostrar que $p\left(y_{t} \mid f_{t}, \mathcal{F}_{t} ; \theta\right) \sim t\left(m_{t \mid t-1}, \sigma_{t \mid t-1}^{2}, \nu\right)$ :

$$
p\left(y_{t} \mid f_{t}, \mathcal{F}_{t} ; \theta\right)=\frac{\Gamma\left(\frac{\nu+1}{2}\right)}{\sqrt{\pi \nu e^{2 \lambda}} \Gamma\left(\frac{\nu}{2}\right)}\left(1+\frac{\left(y_{t}-m_{t \mid t-1}\right)^{2}}{\nu e^{2 \lambda}}\right)^{-\frac{\nu+1}{2}}
$$

em que: 


$$
\begin{aligned}
m_{t \mid t-1} & =E\left[y_{t} \mid f_{t}, \mathcal{F}_{t} ; \theta\right]=\mu_{t \mid t-1}+\gamma_{t \mid t-1} \\
\sigma_{t \mid t-1}^{2} & =\operatorname{Var}\left[y_{t} \mid f_{t}, \mathcal{F}_{t} ; \theta\right]=\frac{\nu}{\nu-2} e^{\lambda}, \quad \nu>2
\end{aligned}
$$

Nesse caso, o vetor de parâmetros que variam no tempo $f_{t}$ é dado por

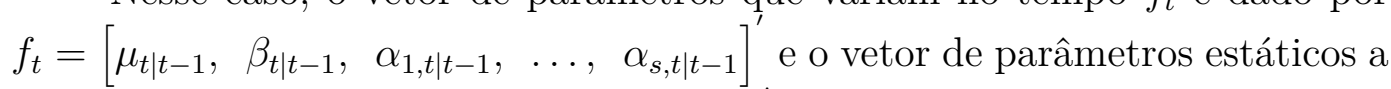
serem estimados $\theta$ por $\theta=\left[\begin{array}{lll}\kappa_{1}, & \kappa_{2}, & \kappa_{s}, \lambda\end{array}\right]^{\prime}$. Os valores iniciais de $f_{t}$ podem ser tratados como parâmetros estáticos (incluindo-os em $\theta$ ). Considerando $s=12$, 17 parâmetros deverão ser estimados (11 referente à sazonalidade ao restringir que a soma seja zero). Os parâmetros também podem ser inicializados como os coeficientes de uma regressão entre as primeiras $s+1$ observações de $y_{t} \mathrm{e}$ uma constante, tendência determinística e dummies sazonais. Neste estudo, os valores iniciais foram tratados como parâmetros fixos a serem estimados.

A variável $u_{t}$, representada na equação (4-6), é proporcional ao vetor escore condicional de $y_{t}$. A demonstração é feita a seguir.

$$
\begin{gathered}
\ln p\left(y_{t} \mid f_{t}, \mathcal{F}_{t} ; \theta\right)=\ln \frac{\Gamma\left(\frac{\nu+1}{2}\right)}{\sqrt{\pi \nu e^{2 \lambda}} \Gamma\left(\frac{\nu}{2}\right)}-\frac{\nu+1}{2} \ln \left(1+\frac{\left(y_{t}-m_{t \mid t-1}\right)^{2}}{\nu e^{2 \lambda}}\right) \\
\nabla_{t}=\frac{\partial \ln p\left(y_{t} \mid f_{t}, \mathcal{F}_{t} ; \theta\right)}{\partial m_{t \mid t-1}}=(\nu+1) \frac{1}{1+\frac{\left(y_{t}-m_{t \mid t-1}\right)^{2}}{\nu e^{2 \lambda}}} \frac{y_{t}-m_{t \mid t-1}}{\nu e^{2 \lambda}} \\
\nabla_{t}=\frac{(\nu+1)}{\nu e^{2 \lambda}} u_{t}
\end{gathered}
$$

Para graus de liberdade baixos, as observações que seriam vistas como outliers em uma distribuição Gaussiana pouco influenciam $u_{t}$. Quanto maior for $y_{t}$, mais próximo de zero será $u_{t}$. Todos os momentos de $u_{t}$ existem e este pode ser reescrito como $u_{t}=\left(1-b_{t}\right)\left(y_{t}-m_{t \mid t-1}\right)$, em que

$$
b_{t}=\frac{\left(y_{t}-\mu_{t \mid t-1}^{*}\right)^{2} / \nu e^{2 \lambda}}{1+\left(y_{t}-\mu_{t \mid t-1}^{*}\right)^{2} / \nu e^{2 \lambda}}, \quad 0 \leq b_{t} \leq 1
$$

segue distribuição beta $(1 / 2, \nu / 2)$. A demonstração desse resultado encontra-se em Harvey, 2013, Cap. 3, pg 61.

É possível incluir mais componentes no modelo, tais como ciclo, outra componente autorregressiva e/ou variáveis explicativas. Para isso, basta adicioná-la à média condicional $m_{t \mid t-1}$, a qual irá alterar, consequentemente, a função de verossimilhança e a expressão para $u_{t}$. 
É importante destacar que a inserção de variáveis exógenas é interessante para filtrar outros choques que afetam a inflação e não são capturados somente pelo próprio histórico da variável. Esse contexto não foi explorado durante a elaboração desse trabalho, mas é algo que pode influenciar as estimativas e, consequentemente, fornecer um núcleo mais informativo da tendência dos preços.

\subsection{2}

\section{Modelo DCS para estimação do núcleo da inflação no Brasil}

A forma do modelo DCS utilizada nesse estudo está estruturada a partir de componentes não observáveis vista na seção 4.2.1.2. Inicialmente utilizou-se a estrutura definida na equação (4-6) com os erros $\varepsilon_{t}$ seguindo distribuição normal com média zero e variância $\sigma^{2}=e^{2 \lambda}$, o qual nomeamos de DCS$\mathrm{N}$ mais adiante. No entanto, após a análise residual, notou-se a presença de outliers, que provocaram o diagnóstico inadequado do modelo (a maneira de diagnosticar modelos DCS é vista mais à frente na seção 4.2.5). Para corrigir tal complicação, uma alternativa foi a inclusão de variáveis dummies na equação de $y_{t}$. No entanto, não certo de que os erros deveriam ser modelados por uma distribuição normal, adotou-se outra alternativa: uma distribuição com cauda pesada para $\varepsilon_{t}$, a $t$-Student. Os modelos DCS com distribuição $t$-Student para os erros foram nomeados DCS-t. Todos esses resultados podem ser vistos no Capítulo 5.

Além da modificação da distribuição adotada em (4-6), outros ajustes também foram feitos. Ao analisar a componente da inclinação da tendência estocástica $\left(\beta_{t \mid t-1}\right)$ estimada para os modelos DCS-N e DCS-t, observou-se que sua variância era nula e, portanto, esta componente foi removida da equação de $\mu_{t \mid t-1}$ e o modelo foi reestimado, resultando em um modelo com tendência de passeio aleatório sem drift. A investigação dos resíduos desse modelo permitiu classificá-los como adequados. Porém, como será visto no Capítulo 5, a componente de tendência resultante carregava ainda muita variabilidade (em comparação com a inflação) em sua estrutura e também alguma estrutura autorregressiva. Por isso, adicionou-se outra componente à equação de $y_{t}, \psi_{t}$, a qual representa uma componente $\mathrm{AR}(1)$. Esta componente busca captar a parte autorregressiva estacionária de $y_{t}$, e ajudou a remover parte da variabilidade da tendência $\mu_{t}$.

Por fim, a estrutura final para os modelos DCS-N e DCS-t é apresentada a seguir, onde $\varepsilon_{t} \sim N(0,1)$ ou $\varepsilon_{t} \sim t(0,1, \nu)$, respectivamente. 


$$
\begin{aligned}
y_{t} & =\psi_{t \mid t-1}+\mu_{t \mid t-1}+\gamma_{t \mid t-1}+e^{\lambda} \varepsilon_{t} \\
\mu_{t+1 \mid t} & =\mu_{t \mid t-1}+\kappa_{1} u_{t} \\
\psi_{t+1 \mid t} & =\phi \psi_{t \mid t-1}+\kappa_{3} u_{t} \\
\alpha_{t+1 \mid t} & =\alpha_{t \mid t-1}+\kappa_{t} u_{t} \\
\gamma_{t+1 \mid t} & =z_{t+1}^{\prime} \alpha_{t+1 \mid t}
\end{aligned}
$$

em que $\kappa_{1}>0, \kappa_{3}>0$ e $\kappa_{t}=f\left(\kappa_{s}\right), \kappa_{s}>0$. O núcleo da inflação é definido como a componente $\mu_{t \mid t-1}$.

As dummies são inseridas diretamente na equação de $y_{t}$, conforme especificado a seguir.

$$
\begin{gathered}
D_{j, t}= \begin{cases}1, & \text { se }\left|\hat{\varepsilon}_{t}\right|=\left|y_{t}-\hat{y}_{t \mid t-1}\right|>3, \quad \hat{y}_{t \mid t-1}=E_{t-1}\left[y_{t}\right] \\
0, & c c\end{cases} \\
y_{t}=\psi_{t \mid t-1}+\mu_{t \mid t-1}+\gamma_{t \mid t-1}+\sum_{j=1}^{J} d_{j} D_{j, t}+e^{\lambda} \varepsilon_{t}
\end{gathered}
$$

em que $d_{j}$ é estimado por verossimilhança.

\subsection{3}

\section{Estimação e inicialização}

Um atrativo de modelos guiados por observações é facilidade de estimálos via maximização da função de verossimilhança. Essa propriedade se aplica aos modelos DCS. O problema de maximização pode ser representado da seguinte forma

$$
\hat{\theta}=\arg \max _{\theta} \sum_{t=1}^{T} \ell_{t}=\arg \max _{\theta} \ell(\theta)
$$

em que $\ell_{t}=\ln p\left(y_{t} \mid f_{t}, \mathcal{F}_{t} ; \theta\right)$.

Para o modelo visto na equação (4-9), a função log verossimilhança para $\varepsilon_{t} \sim N(0,1)$ é dada por

$$
\ell(\theta)=\sum_{t=1}^{T} \ln p\left(y_{t} \mid f_{t}, \mathcal{F}_{t} ; \theta\right)=-\frac{T}{2} \ln 2 \pi e^{2 \lambda}-\frac{1}{2} \sum_{t=1}^{T} \frac{\left(y_{t}-m_{t \mid t-1}\right)^{2}}{e^{2 \lambda}}
$$

e para $\varepsilon_{t} \sim t(0,1, \nu)$ por 


$$
\begin{aligned}
\ell(\theta)=\sum_{t=1}^{T} \ln p\left(y_{t} \mid f_{t}, \mathcal{F}_{t} ; \theta\right) & =T \ln \Gamma\left(\frac{\nu+1}{2}\right)-\frac{T}{2} \ln \pi-\frac{T}{2} \ln \Gamma \frac{\nu}{2}-\frac{T}{2} \ln \nu \\
& -\frac{\nu+1}{2} \sum_{t=1}^{T} \ln \left(1+\frac{\left(y_{t}-m_{t \mid t-1}\right)^{2}}{\nu e^{2 \lambda}}\right)
\end{aligned}
$$

Observe que para estimar $\theta$, é necessário a implementação da equação de atualização de $f_{t}$ para o cálculo de $m_{t \mid t-1}$. Uma vez que tal equação é recursiva, é necessário atribuir valores iniciais para o vetor $f_{t}$. Uma sugestão é considerar tais valores como parâmetros estáticos desconhecidos a serem estimados também via (4-10).

\subsection{4}

\section{Parametrização}

A especificação de modelos DCS se adapta naturalmente a diferentes parametrizações da densidade $p\left(y_{t} \mid f_{t}, \mathcal{F} ; \theta\right)$. As parametrizações são usadas para impor restrições aos parâmetros estáticos $(\theta)$ e aos parâmetros que variam no tempo $\left(f_{t+1}\right)$.

No Exemplo 2 visto na seção 4.2.1.1, o parâmetro $f_{t}=\sigma_{t}^{2}$, que representa uma quantidade ao quadrado, poderia ser forçado a apresentar apenas valores positivos se fosse definido como $f_{t}=\ln \sigma_{t}^{2}$, isto é, $\sigma_{t}^{2}=\exp f_{t}$, que é sempre maior do que zero. Com a nova parametrização, a densidade de $\left(y_{t} \mid f_{t}, \mathcal{F} ; \theta\right)$ pode ser reescrita como

$$
\begin{aligned}
& p\left(y_{t} \mid f_{t}, \mathcal{F}_{t}\right)=\frac{1}{\sqrt{2 \pi \exp \left(f_{t}\right)}} \exp \left\{-\frac{y_{t}^{2}}{2 \exp \left(f_{t}\right)}\right\} \\
& \ln p\left(y_{t} \mid f_{t}, \mathcal{F}_{t}\right)=-\frac{1}{2} \ln (2 \pi)-\frac{f_{t}}{2}-\frac{y_{t}^{2}}{2 \exp \left(f_{t}\right)}
\end{aligned}
$$

Assim, $\nabla_{t}$ é obtido por

$$
\nabla_{t}=\frac{\partial \ln p\left(y_{t} \mid f_{t}, \mathcal{F}_{t}\right)}{\partial f_{t}}=-\frac{1}{2}+\frac{y_{t}^{2}}{2 \exp f_{t}}
$$

e $\mathcal{I}_{t \mid t-1}$ por

$$
\begin{gathered}
\frac{\partial^{2} \ln p\left(y_{t} \mid f_{t}, \mathcal{F}_{t}\right)}{\partial^{2} f_{t}}=-\frac{y_{t}^{2}}{2 \exp f_{t}} \\
\mathcal{I}_{t \mid t-1}=-E_{t-1}\left[-\frac{y_{t}^{2}}{2 \exp f_{t}}\right]=\frac{1}{2}
\end{gathered}
$$

E assim, considerando $d=1$, 


$$
s_{t}=\mathcal{I}_{t \mid t-1}^{-1} \cdot \nabla_{t}=2 \cdot\left(-\frac{1}{2}+\frac{y_{t}^{2}}{2 \exp f_{t}}\right)=\frac{y_{t}^{2}}{\exp f_{t}}-1
$$

a equação de atualização de $f_{t}$ para um $\operatorname{DCS}(1,1)$ é dada por

$$
f_{t+1}=\omega+A_{1}\left(\frac{y_{t}^{2}}{\exp f_{t}}-1\right)+B_{1} f_{t}
$$

que pode ser reescrita como

$$
\ln \sigma_{t+1}^{2}=\omega+A_{1}\left(\frac{y_{t}^{2}}{\sigma_{t}^{2}}-1\right)+B_{1} \ln \sigma_{t}^{2}
$$

que equivale a um modelo $\operatorname{EGARCH}(1,1)$.

De forma geral, defina $\tilde{f}_{t}=h\left(f_{t}\right)$ como a nova parametrização para uma função $h($.$) contínua e invertível. Seja \dot{h}_{t}=\frac{\partial h\left(f_{t}\right)}{\partial f_{t}^{\prime}}$, que é determinística dada a informação contida em $\mathcal{F}_{t}$, é possível demonstrar que

$$
\begin{gathered}
\tilde{\nabla}_{t}=\left(\dot{h}_{t}^{\prime}\right)^{-1} \nabla_{t} \\
\tilde{\mathcal{I}}_{t \mid t-1}^{-1}=\left[E_{t-1}\left(\tilde{\nabla}_{t} \tilde{\nabla}_{t}^{\prime}\right)\right]^{-1}=\dot{h}_{t} \mathcal{I}_{t \mid t-1}^{-1} \dot{h}_{t}^{\prime}
\end{gathered}
$$

Utilizando tais definições, obtem-se os mesmos resultados anteriores. em que $\nabla_{t}$ é o vetor escore em relação a $f_{t}$.

\subsection{5}

\section{Diagnósticos}

O diagnóstico de modelos DCS será feito com base nos resíduos do modelo. Kalliovirta (2009) (33) propôs em sua tese de doutorado o uso dos resíduos quantílicos para avaliar a adequação de modelos de séries temporais lineares e não lineares. A autora mostra que a análise dos resíduos tradicionais, também chamado de resíduos de Pearson, pode levar a inferências erradas. Assim, criando uma generalização dos resíduos de Pearson (resíduos quantílicos), a classe de modelos que podem ser diagnosticados utilizando tal recurso é extensa, e os modelos DCS estão incluídos nessa lista.

Os resíduos quantílicos podem ser definidos para qualquer modelo baseado em uma distribuição contínua. Considerando o arcabouço de modelos DCS apresentado, os resíduos quantílicos são definidos por 


$$
r_{t, \hat{\theta}}=\Phi^{-1}\left(F\left(y_{t} \mid f_{t}, \mathcal{F}_{t} ; \hat{\theta}\right)\right)
$$

em que $\Phi^{-1}(\cdot)$ é a inversa da distribuição Normal e $F\left(y_{t} \mid f_{t}, \mathcal{F}_{t} ; \theta\right)$ é a função de distribuição acumulada condicional de $y_{t}$.

Com os resíduos quantílicos observados, faz-se o diagnóstico aplicando os testes de normalidade, autocorrelação e heterocedasticidade. O teste de Jarque-Bera (1987) (34) será utilizado para avaliar a normalidade e o teste de Ljung-Box (1978) (35) para autocorrelação e heterocedasticidade condicional (via quadrado dos resíduos).

\subsection{6}

\section{Previsão}

A previsão 1 passo à frente é dada diretamente pelo modelo. Isto é, uma vez que $y_{t}$ é função de $f_{t}$, obtendo-se $f_{t+1}$ e a componente aleatória de erro temse $y_{t+1 \mid t}$. No entanto, para mais passos à frente a forma analítica da expressão de $y_{t+k \mid t}$ para $k>1$ não é conhecida. Para facilitar o entendimento, considere a distribuição condicional para 2 passos à frente:

$$
p\left(y_{t+2} \mid f_{t}, \mathcal{F}_{t} ; \theta\right)=\int_{0}^{\infty} p\left(y_{t+2} \mid f_{t+1}, \mathcal{F}_{t+1} ; \theta\right) p\left(y_{t+1} \mid f_{t}, \mathcal{F}_{t} ; \theta\right) d y_{t+1}
$$

Embora as duas distribuições condicionais que aparecem no interior da integral em (4-14) sejam conhecidas, não há garantia que o produto entre elas seja. Logo, não se tem forma análitica para a solução de (4-14). Uma alternativa para se obter previsões para $k$ passos à frente para $k>1$ é utilizar o método de simulação de Monte Carlo descrito a seguir.

1. Considere o conjunto de informações disponíveis até o tempo $t: f_{t}, s_{t} \mathrm{e}$ as estimativas de máxima verossimilhança de $\theta$

2. Para cada $k=1, \ldots, K$ serão geradas $m$ trajetórias independentes segundo a rotina abaixo:

(a) simule um valor para $y_{t+k}$ considerando a distribuição preditiva do modelo dadas as estimativas de $\theta$ e os conjuntos de informação $f_{t+k-1}$ e $s_{t+k-1}$

(b) atualize $f_{t+k}$ e $s_{t+k}$

(c) retorne ao passo (a) até que $k=K$ 
3. A previsão final $\hat{y}_{t+k \mid t}$ será obtida via média das $m$ trajetórias simuladas para o passo $k$. O intervalo de confiança de $100(1-\alpha) \%$ pode ser definido pelos quantis de ordem $\frac{\alpha}{2}$ e $1-\frac{\alpha}{2}$ destas mesmas trajetórias. 


\section{Resultados}

Este capítulo apresenta os resultados de estimação dos núcleos obtidos via às metodologias propostas no Capítulo 4. Inicialmente os dois núcleos serão apresentados separadamente com o objetivo de mostrar as etapas da estimação de cada um. Em seguida, conjuntamente, as duas medidas serão avaliadas segundo os conceitos definidos na seção 2.6. Além disso, faz-se uma análise econômica com o intuito de verificar a informação que as medidas trazem a respeito do desenvolvimento futuro da inflação. Por fim, apresentamse previsões para a inflação em 2018.

\section{1}

\section{Estimação}

\subsection{1}

\section{Núcleo-S: via suavização}

O núcleo (Núcleo-S) apresentado na Figura 5.1, junto ao índice de inflação IPC-Br da Fundação Getulio Vargas, foi estimado considerando os procedimentos apresentados na seção 4.1.

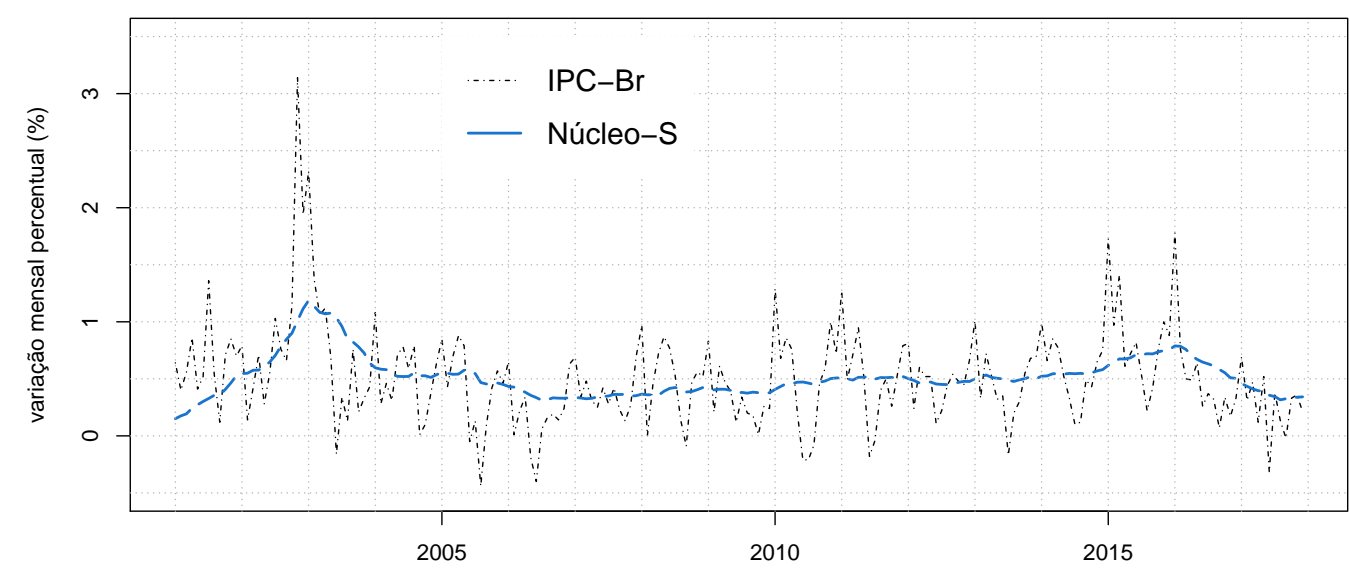

Figura 5.1: Núcleo-S (Núcleo via suavização) no período de jan/2001 a $\operatorname{dez} / 2017$.

Nota-se, claramente, que a partir de meados de 2006 a medida tem uma trajetória ascendente. Entre 2011 e o final de 2013, o núcleo flutua em torno 
de 0,5\%, mostrando alguma estabilidade da inflação. Em dois anos, a partir de 2014, observa-se um crescimento brusco e acelerado da inflação com o núcleo alcançando valores em torno de 0,75\%. De 2016 em diante, percebe-se uma queda rápida e acentuada na medida para níveis abaixo de $0,5 \%$.

Para avaliar a dimensão desses valores, uma vez que são livres de sazonalidade, pode-se anualizá-los e assim concluir se naquele mês específico o índice se mantém no intervalo da meta da inflação, por exemplo. Os $0,5 \%$ representam cerca de 6,17\% anualmente (bem próximo ao teto da meta da inflação de 6,5\%). Naquela época (2011-2013), portanto, o núcleo já poderia oferecer sinais de atenção em relação ao controle da inflação que iniciou sua ascenção acentuada a partir de 2014 e assim, talvez, pudesse ser evitado o que o que ocorreu em 2015, quando o IPC-Br atingiu 10,5\%.

\section{- Etapas da estimação}

A Figura 5.2 mostra o resultado final das três etapas de estimação do Núcleo-S.

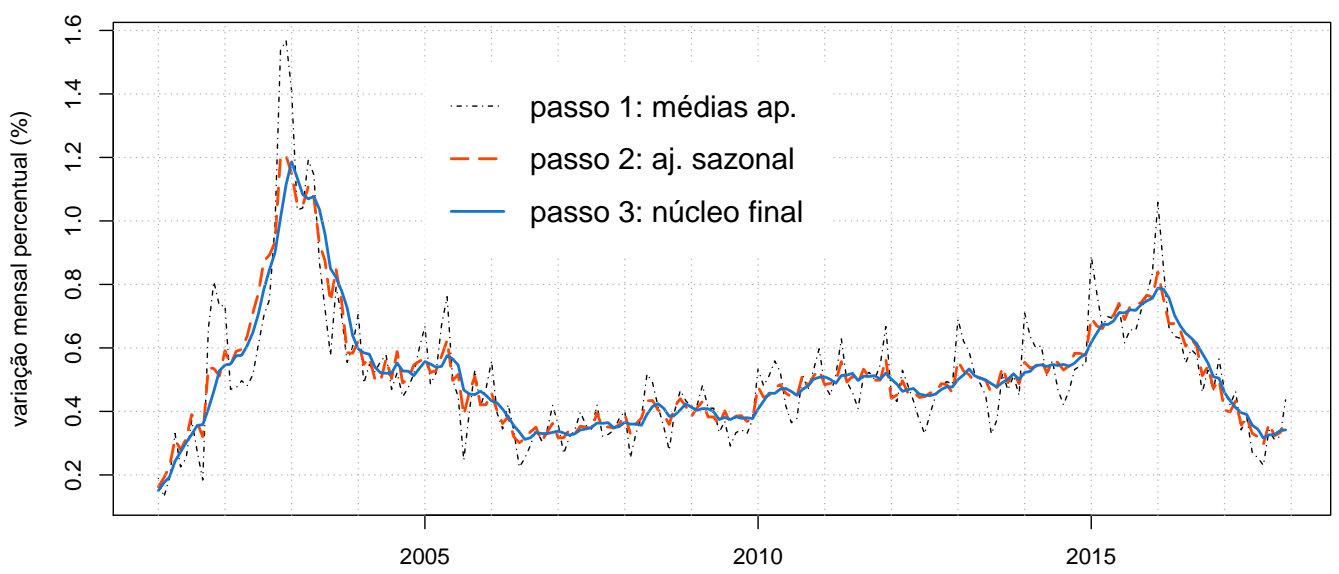

Figura 5.2: As três etapas de estimação do Núcleo-S.

A proporção de itens que foram removidos no cálculo do passo médias aparadas (linha pontilhada) foi de 35\% no total: $20 \%$ para a cauda inferior (itens com as menores variações de preço ou variações muito negativas) e 15\% para a cauda superior (itens com as maiores variações de preço positivas). Esses valores foram escolhidos de forma proposital a manter a média do núcleo similar a média do IPC-Br. O núcleo hoje divulgado pela FGV considera $20 \%$ para cada uma das duas caudas.

A sazonalidade do núcleo foi estimada utilizando o software X-13ARIMASEATS. O programa, apesar de estimar a sazonalidade para a série completa, considerou o histórico de jan/2009 a dez/2017 para definir as especificações do 
ajuste: nenhum outlier foi detectado; nenhuma transformação foi aplicada aos dados; e o modelo SARIMA escolhido foi $\left(\begin{array}{lll}1 & 1 & 0\end{array}\right)\left(\begin{array}{lll}1 & 0 & 0\end{array}\right)_{12}$.

O programa oferece o diagnóstico do ajuste sazonal (análise dos resíduos) e permite classificá-lo em adequado: resíduos estacionários, homocedásticos, sem autocorrelação e sem resquícios de sazonalidade.

Uma vez que a sazonalidade foi estimada, o novo núcleo (linha tracejada em tom laranja na Figura 5.2) passa a ser a diferença entre o IPC-Br com médias aparadas e a sazonalidade. Por fim, aplicou-se um fitro curto de médias móveis de ordem 3 à medida restante, resultando em uma série temporal mais suave (linha cheia na Figura 5.2).

\section{1 .2}

\section{Núcleo-DCS: via Dynamic Conditional Score Models}

O núcleo (Núcleo-DCS) apresentado na Figura 5.3, junto ao índice de inflação IPC-Br da Fundação Getulio Vargas, foi estimado considerando os procedimentos apresentados na seção 4.2 .

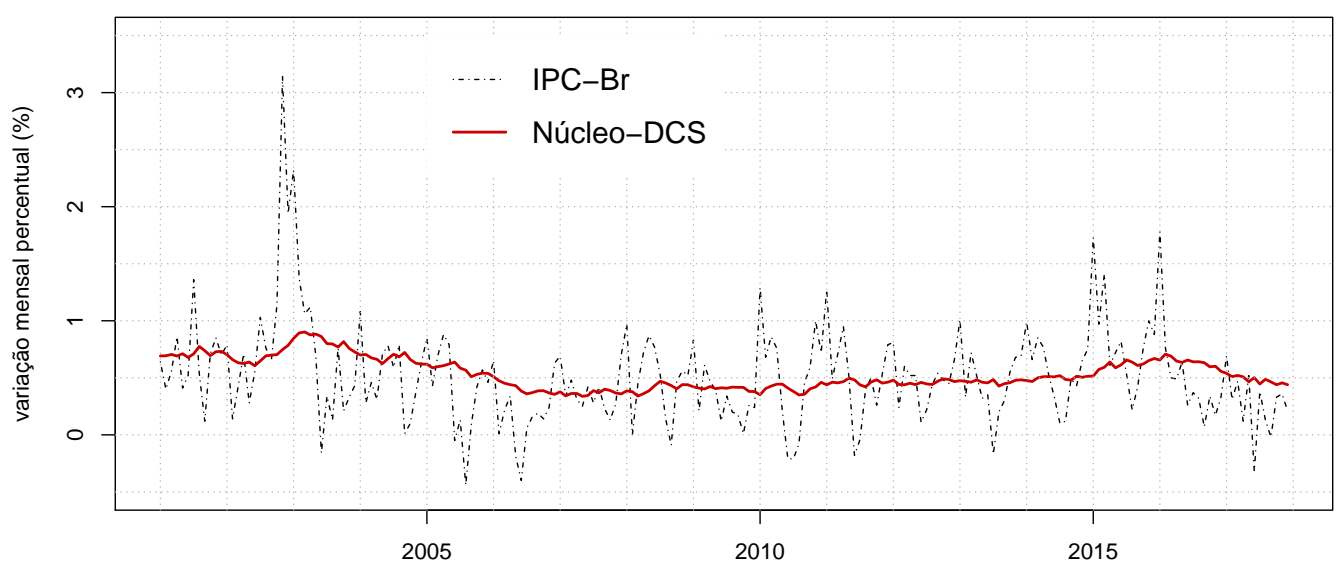

Figura 5.3: Núcleo via modelo DCS (Núcleo-DCS).

Tal como mostrou o Núcleo-S, o Núcleo DCS também mostra um trajetória ascendente sutil a partir de meados de 2006. De 2011 ao final de 2013 vê-se alguma estabilização e a partir de 2014 a ascenção é mais intensa.

\section{- Etapas da estimação}

As etapas de estimação do núcleo iniciaram-se ao considerar o erro $\varepsilon_{t}$ seguindo distribuição normal com média zero e variância 1 na equação (4-6). Alguns parâmetros foram excluídos e outros acrescentados e a distribuição do erro foi modificada até que o diagnóstico fosse válido e a medida de tendência 
não fosse tão volátil quanto o índice da inflação, resultando na equação 4-9. Em resumo estimaram-se os seguintes modelos, nessa ordem:

- DCS-N 1: modelo DCS da equação (4-6), em que $\varepsilon_{t} \sim N(0,1)$;

- DCS-N 2: DCS-N 1 sem a componente $\beta_{t}$;

- DCS-N 3: modelo DCS da equação (4-9), em que $\varepsilon_{t} \sim N(0,1)$;

- DCS-t 1: alteração da distribuição do erro do modelo DCS-N 1 para $t$-Student;

- DCS-t 2: alteração da distribuição do erro do modelo DCS-N 2 para $t$-Student;

- DCS-t 3: alteração da distribuição do erro do modelo DCS-N 3 para $t$-Student.

O modelo final utilizado e recomendado para estimar o núcleo da inflação é o DCS-t 3. Como será visto a seguir, considerar a distribuição normal para o erro não tornou o diagnóstico adequado. Para consertar isso, algumas dummies foram necessárias. No entanto, no contexto de distribuição normal, o modelo não se mostrou estável quando removeu-se o período inicial da série de inflação (período de alta inflação). Após essa remoção, o modelo não estimava uma tendência estocástica, afirmando que a tendência na verdade era apenas uma constante. Ao trocar a distribuição do erro para t-Student (distribuição com cauda mais pesada), a tendência permaneceu estocástica e as dummies já não foram mais necessárias para tornar o modelo adequado. Veja a seguir, todos os procedimentos adotados até a definição do modelo final.

Na Figura 5.4 é possível observar os três núcleos estimados via os seguintes modelos: DCS-N 1, DCS-N 2 e DCS-N 3.

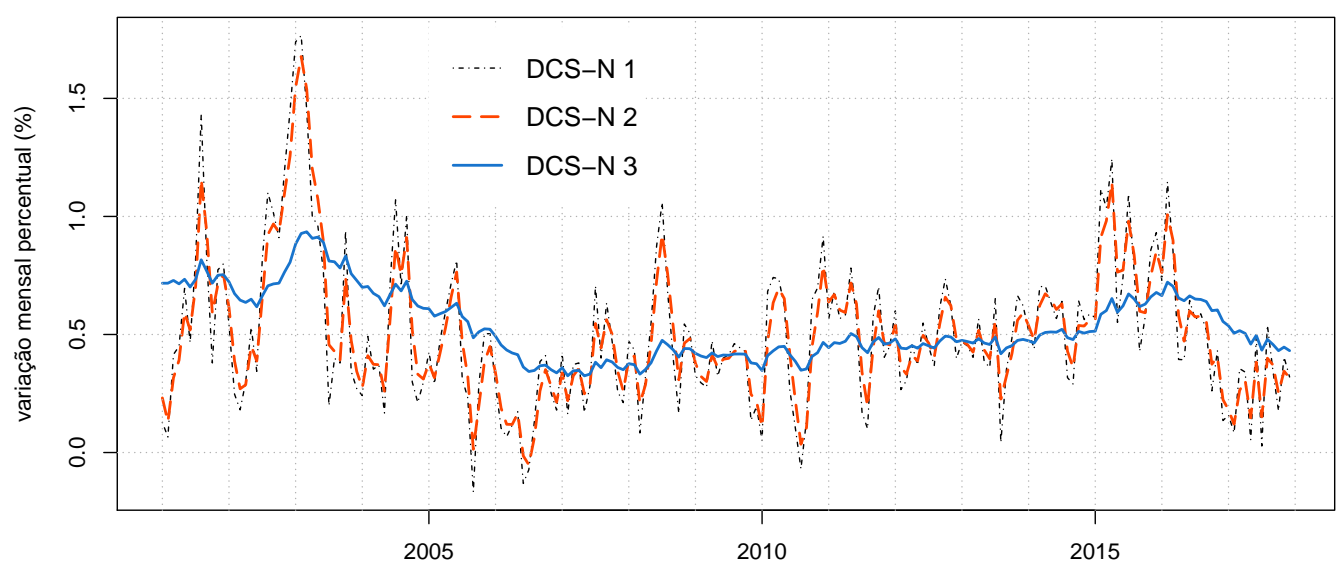

Figura 5.4: Núcleos via modelos DCS.

O primeiro procedimento foi estimar o modelo DCS-N 1. A análise residual desse modelo mostrou um resíduo padronizado com valor, em módulo, 
superior a 3 unidades $(5,31)$ no mês de novembro de 2002 (período de alta inflação no Brasil), que influenciou na conclusão de não normalidade residual no diagnóstico do modelo. A Figura 5.5 mostra tais resíduos, em que se destaca o resíduo não capturado adequadamente, e a Tabela 5.1 apresenta estatísticas e testes sobre esses resíduos.

Para solucionar o diagnóstico, adicionou-se uma dummy na equação de $y_{t}$ referente ao mês de novembro de 2002. Após isso, não há indicativos de que os resíduos do modelo não sejam considerados normais, considerando $5 \%$ de significância, porém há evidências de heterocedasticidade condicional, como mostra a Figura 5.6 e os testes na Tabela 5.2.
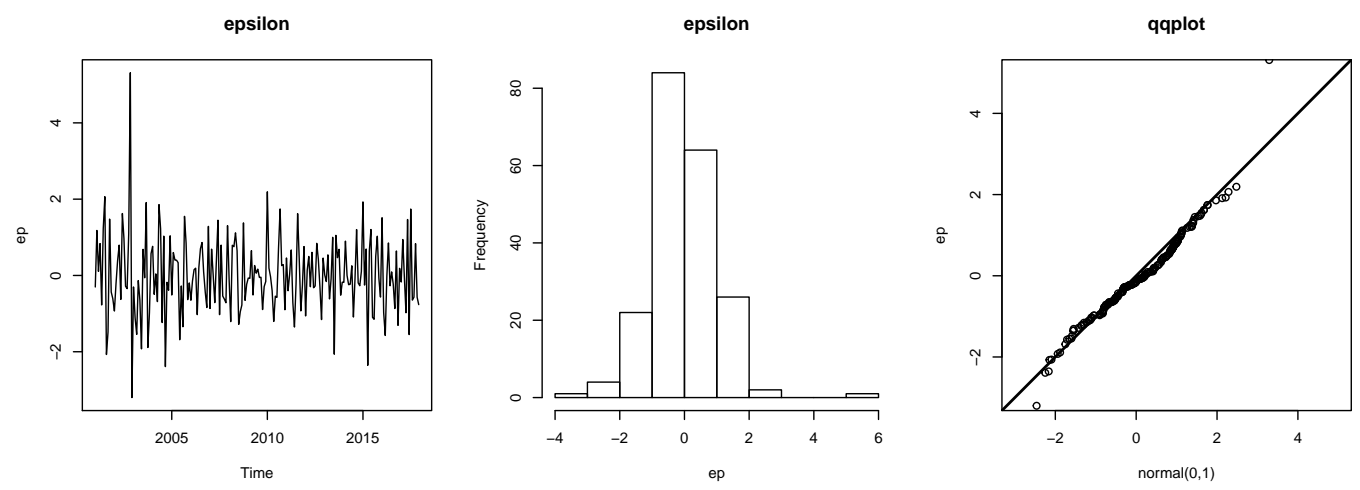

Figura 5.5: Análise residual modelo DCS-N 1.

\begin{tabular}{ccccccc}
\hline Assimetria & Curtose & Média & D. Padrão & $\begin{array}{c}\text { Jarque Bera } \\
\text { estat. (valor-p) }\end{array}$ & $\begin{array}{c}\text { Ljung-Box } \\
\text { estat. (valor-p) }\end{array}$ & $\begin{array}{c}\text { Ljung-Box* }^{*} \\
\text { estat. (valor-p) }\end{array}$ \\
\hline 0,56 & 6,31 & 0 & 1 & $103,82(0,00)$ & $17,31(0,14)$ & $18,51(0,10)$ \\
\hline
\end{tabular}

*Teste Ljung-Box aplicado aos resíduos ao quadrado com o intuito de avaliar heterocedasticidade.

Na aplicação do teste Ljung-Box, considerou-se lag 24.

Tabela 5.1: Estatísticas e testes nos resíduos do modelo DCS-N 1.
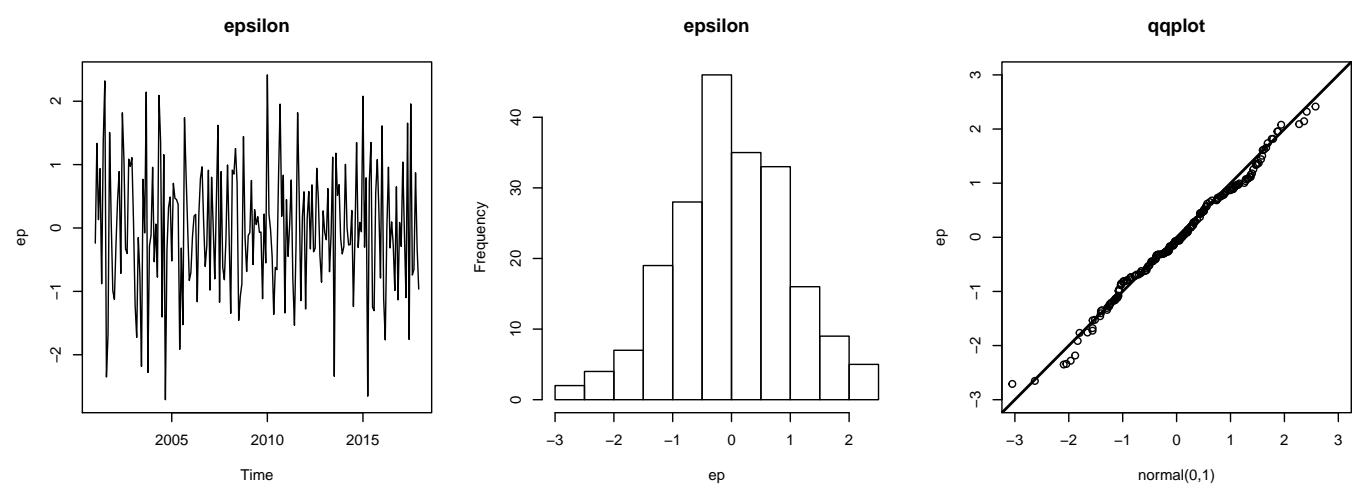

Figura 5.6: Análise residual modelo DCS-N 1 com dummy. 


\begin{tabular}{ccccccc}
\hline Assimetria & Curtose & Média & D. Padrão & $\begin{array}{c}\text { Jarque Bera } \\
\text { estat. (valor-p) }\end{array}$ & $\begin{array}{c}\text { Ljung-Box } \\
\text { estat. (valor-p) }\end{array}$ & $\begin{array}{c}\text { Ljung-Box* } \\
\text { estat. (valor-p) }\end{array}$ \\
\hline$-0,09$ & 2,91 & 0 & 1 & $0,35(0,84)$ & $16,72(0,16)$ & $26,51(0,01)$ \\
\hline
\end{tabular}

* Teste Ljung-Box aplicado aos resíduos ao quadrado com o intuito de avaliar heterocedasticidade.

$\mathrm{Na}$ aplicação do teste Ljung-Box, considerou-se lag 24.

Tabela 5.2: Estatísticas e testes nos resíduos do modelo DCS-N 1 com dummy.

A Tabela 5.3 mostra que grande parte dos parâmetros estimados por máxima verossimilhança pouco mudaram ao adicionar a dummy no modelo DCS-N 1, sendo a mudança mais notável a do parâmetro $\lambda$, que torna a variância condicional de $y_{t}$ ligeiramente menor $\left(\right.$ de $e^{-1,12}=0,33$ para $\left.e^{-1,24}=0,29\right)$.

\begin{tabular}{c|ccccccc}
\hline & $\theta$ & DCS-N 1 & $\begin{array}{c}\text { DCS-N 1 } \\
\text { dummy }\end{array}$ & DCS-N 2 & $\begin{array}{c}\text { DCS-N 2 } \\
\text { dummy }\end{array}$ & DCS-N 3 & $\begin{array}{c}\text { DCS-N 3 } \\
\text { dummy }\end{array}$ \\
\hline 1 & $\kappa_{1}$ & $0,90(0,07)$ & $0,90(0,08)$ & $0,55(0,08)$ & $0,58(0,09)$ & $0,00(-)$ & $0,12(0,08)$ \\
2 & $\kappa_{2}$ & $0,00(-)$ & $0,00(-)$ & - & - & - & - \\
3 & $\kappa_{3}$ & - & - & - & - & $0,53(0,07)$ & $0,47(0,10)$ \\
4 & $\kappa_{s}$ & $0,05(-)$ & $0,05(-)$ & $0,05(-)$ & $0,05(-)$ & $0,05(-)$ & $0,05(-)$ \\
5 & $\lambda$ & $-1,12(0,05)$ & $-1,24(0,05)$ & $-1,15(0,05)$ & $-1,27(0,05)$ & $-1,21(0,05)$ & $-1,33(0,05)$ \\
6 & $\phi$ & - & - & - & - & $0,70(0,09)$ & $0,55(0,15)$ \\
7 & $\beta_{1 \mid 0}$ & $0,00(0,02)$ & $0,00(0,02)$ & - & - & - & - \\
8 & $\mu_{1 \mid 0}$ & $0,16(0,32)$ & $0,13(0,29)$ & $0,25(0,28)$ & $0,23(0,26)$ & $0,51(0,06)$ & $0,72(0,20)$ \\
9 & $\psi_{1 \mid 0}$ & - & - & - & - & $-0,42(0,30)$ & $-0,68(0,31)$ \\
10 & $\alpha_{1,1 \mid 0}$ & $0,58(0,10)$ & $0,58(0,09)$ & $0,58(0,09)$ & $0,59(0,08)$ & $0,59(0,10)$ & $0,61(0,09)$ \\
11 & $\alpha_{2,1 \mid 0}$ & $-0,06(0,10)$ & $-0,05(0,09)$ & $-0,06(0,09)$ & $-0,06(0,08)$ & $-0,05(0,10)$ & $-0,04(0,09)$ \\
12 & $\alpha_{3,1 \mid 0}$ & $0,11(0,09)$ & $0,11(0,08)$ & $0,11(0,09)$ & $0,11(0,08)$ & $0,11(0,09)$ & $0,11(0,08)$ \\
13 & $\alpha_{4,1 \mid 0}$ & $0,14(0,09)$ & $0,14(0,08)$ & $0,11(0,09)$ & $0,11(0,08)$ & $0,12(0,09)$ & $0,12(0,08)$ \\
14 & $\alpha_{5,1 \mid 0}$ & $-0,03(0,09)$ & $-0,03(0,08)$ & $-0,06(0,09)$ & $-0,05(0,08)$ & $-0,05(0,09)$ & $-0,04(0,08)$ \\
15 & $\alpha_{6,1 \mid 0}$ & $-0,35(0,08)$ & $-0,34(0,07)$ & $-0,33(0,09)$ & $-0,32(0,08)$ & $-0,33(0,09)$ & $-0,33(0,08)$ \\
16 & $\alpha_{7,1 \mid 0}$ & $-0,14(0,09)$ & $-0,13(0,08)$ & $-0,14(0,09)$ & $-0,13(0,07)$ & $-0,15(0,09)$ & $-0,14(0,08)$ \\
17 & $\alpha_{8,1 \mid 0}$ & $-0,21(0,09)$ & $-0,20(0,08)$ & $-0,23(0,09)$ & $-0,21(0,08)$ & $-0,23(0,10)$ & $-0,22(0,08)$ \\
18 & $\alpha_{9,1 \mid 0}$ & $-0,22(0,10)$ & $-0,21(0,08)$ & $-0,23(0,09)$ & $-0,21(0,08)$ & $-0,23(0,10)$ & $-0,21(0,09)$ \\
19 & $\alpha_{10,1 \mid 0}$ & $-0,17(0,08)$ & $-0,11(0,08)$ & $-0,13(0,09)$ & $-0,09(0,08)$ & $-0,14(0,09)$ & $-0,09(0,09)$ \\
20 & $\alpha_{11,100}$ & $0,17(0,09)$ & $0,05(0,09)$ & $0,19(0,09)$ & $0,07(0,08)$ & $0,17(0,09)$ & $0,05(0,09)$ \\
21 & $d_{\text {nov } / 2011}$ & - & $1,62(0,22)$ & - & $1,70(0,24)$ & - & $1,72(0,23)$ \\
\hline
\end{tabular}

Os valores entre parênteses representam os desvios-padrão de cada parâmetro.

Alguns parâmetros não possuem desvio-padrão pois suas estimativas foram fixadas no limite inferior do intervalo que poderiam variar.

Tabela 5.3: Parâmetros estimados via máxima verossimilhança $(\theta)$ para os modelos DCS-N 1, DCS-N 2 e DCS-N 3.

A componente $\mu_{t}$ do modelo DCS-N 1 com dummy foi armazenada e aparece na linha pontilhada da Figura 5.4. A equação da componente $\beta_{t \mid t-1}$ nesse modelo com dummy foi estimada com parâmetro $\kappa_{2}=0$, tornando-a uma componente determínistica, isto é, $\beta_{t+1 \mid t}=\beta_{t \mid t-1}=\beta$. O valor inicial dessa componente $\left(\beta_{1 \mid 0}\right)$ foi estimado como um número muito próximo de zero e, por isso, tal componente foi removida da equação (4-6) e um novo modelo foi estimado, o DCS-N 2. 
Para o modelo DCS-N 2, a dummy para o mês de novembro de 2002 ainda foi necessária. Após a remoção de $\beta_{t \mid t-1}$, as estimativas para a condição inicial de $\mu_{t \mid t-1}$ e $\kappa_{1}$ foram consideravelmente modificadas, como se observa na Tabela 5.3. Os resultados da análise residual para esse modelo já corrigido por dummy encontram-se na Figura 5.7 e na Tabela 5.4, em que se observa, ainda, evidências de heterocedasticidade considerando $5 \%$ de significância. A linha tracejada em laranja na Figura 5.4 representa a componente $\mu_{t}$ do modelo DCS-N 2 com dummy.
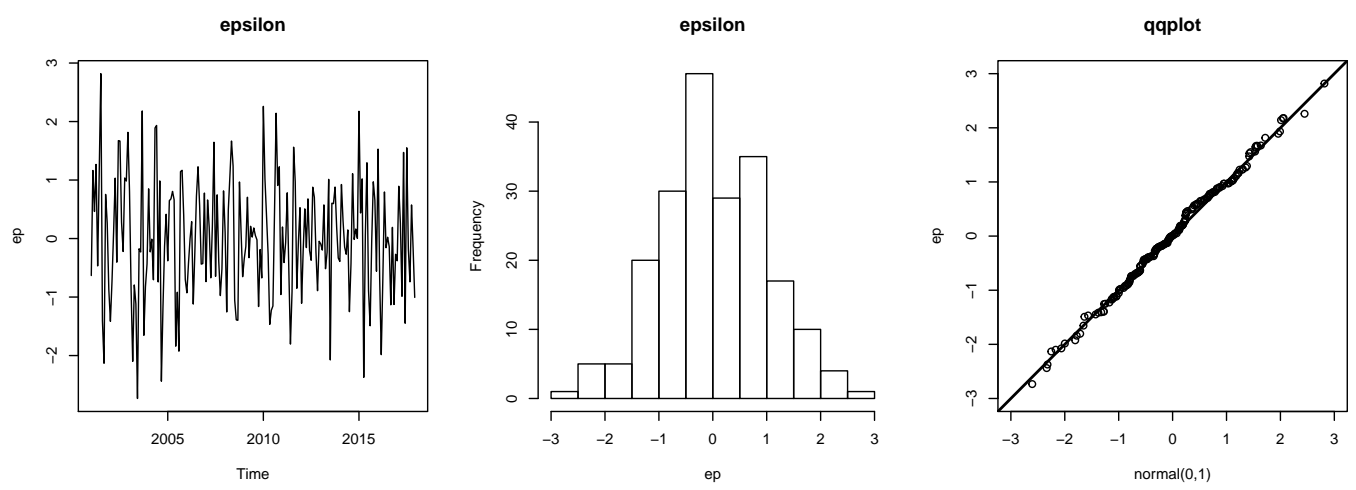

Figura 5.7: Análise residual modelo DCS-N 2 com dummy.

\begin{tabular}{ccccccc}
\hline Assimetria & Curtose & Média & D. Padrão & $\begin{array}{c}\text { Jarque Bera } \\
\text { estat. (valor-p) }\end{array}$ & $\begin{array}{c}\text { Ljung-Box } \\
\text { estat. (valor-p) }\end{array}$ & $\begin{array}{c}\text { Ljung-Box* } \\
\text { estat. (valor-p) }\end{array}$ \\
\hline$-0,02$ & 2,90 & 0 & 1 & $0,09(0,96)$ & $15,58(0,21)$ & $24,91(0,02)$ \\
\hline
\end{tabular}

*Teste Ljung-Box aplicado aos resíduos ao quadrado com o intuito de avaliar heterocedasticidade. $\mathrm{Na}$ aplicação do teste Ljung-Box, considerou-se lag 24.

Tabela 5.4: Estatísticas e testes nos resíduos do modelo DCS-N 2 com dummy.

Como é possível perceber na análise da Figura 5.4, as medidas de tendências extraídas dos modelos DCS-N 1 e DCS-N 2 são visualmente voláteis, similares aos núcleos existentes no Brasil (seção 3). Por isso, buscando uma componente mais suave, adicionou-se à equação do modelo DCS-N 2 uma outra componente $\psi_{t \mid t-1}$ (equação (4-9)). Tal componente busca capturar a parte estacionária autorregressiva de $y_{t}$.

Assim como nos modelos anteriores, a dummy para o mês de novembro de 2002 também foi necessária. Os resultados a seguir mostram o diagnóstico do modelo e os parâmetros estimados por máxima verossimilhança. 

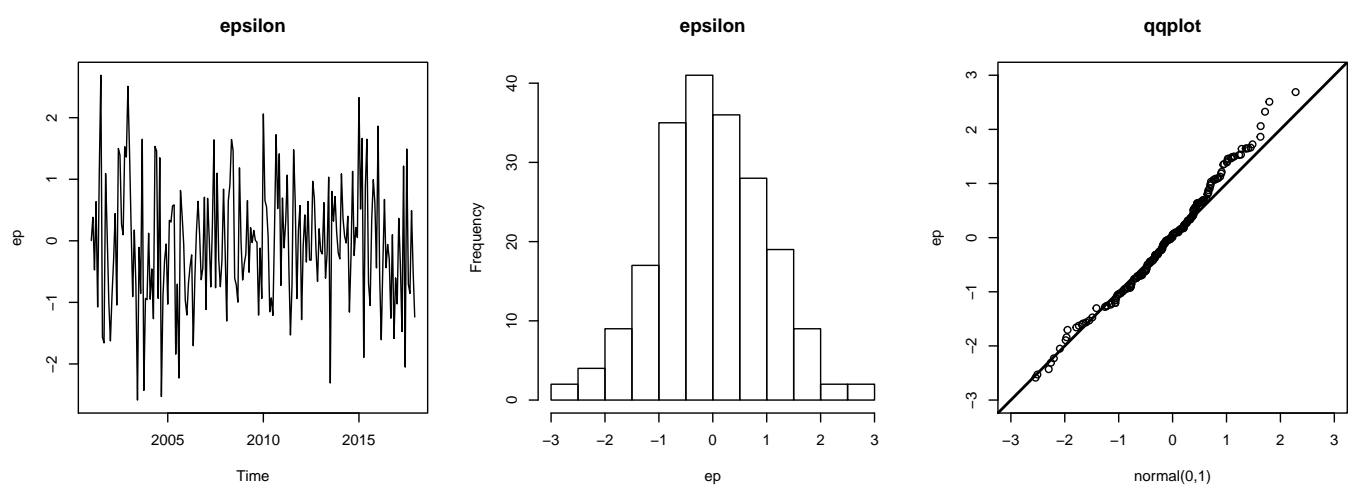

Figura 5.8: Análise residual modelo DCS-N 3 com dummy.

\begin{tabular}{ccccccc}
\hline Assimetria & Curtose & Média & D. Padrão & $\begin{array}{c}\text { Jarque Bera } \\
\text { estat. (valor-p) }\end{array}$ & $\begin{array}{c}\text { Ljung-Box } \\
\text { estat. (valor-p) }\end{array}$ & $\begin{array}{c}\text { Ljung-Box* } \\
\text { estat. (valor-p) }\end{array}$ \\
\hline 0,06 & 2,89 & $-0,05$ & 1 & $0,22(0,90)$ & $3,49(0,99)$ & $20,10(0,07)$ \\
\hline
\end{tabular}

*Teste Ljung-Box aplicado aos resíduos ao quadrado com o intuito de avaliar heterocedasticidade. $\mathrm{Na}$ aplicação do teste Ljung-Box, considerou-se lag 24.

Tabela 5.5: Estatísticas e testes nos resíduos do modelo DCS-N 3 com dummy.

Vale destacar que a inclusão da componente $\psi_{t \mid t-1}$ ao modelo alterou consideravelmente os parâmetros na equação de $\mu_{t \mid t-1}: \kappa_{1}$ reduziu de 0,58 para 0,12 , tornando a tendência mais suave; o valor inicial $\mu_{1 \mid 0}$ cresceu para 0,72 (antes 0,23). É importante chamar atenção também para a inclusão da dummy nesse modelo: sem incluí-la, a componente de tendência foi estimada como uma constante $\left(\kappa_{1}=0\right)$, confirmando que os outliers não modelados pela distribuição normal podem trazer estimativas inconsistentes para os parâmetros. A heterocedasticidade foi reduzida.

Inserir dummies para modelar os outliers quando se considera distribuição normal na construção do modelo é uma alternativa muito utilizada na academia. No entanto, talvez a distribuição mais adequada poderia ser alguma com cauda mais pesada do que a normal, como a $t$-Student, e assim tais outliers seriam encarados como qualquer outra observação. Portanto, no próximo passo, estimou-se os três modelos anteriores considerando distribuição $t$-Student para $\varepsilon_{t}$. O que se observou, no entanto, foi que a observação de novembro de 2002 também era um outlier nesse contexto. Após a inserção da dummy, os graus de liberdade estimados cresceram notoriamente, o que caracteriza a convergência da distribuição $t$-Student para a distribuição normal, tornando as estimativas dos parâmetros similares às observadas anteriormente no contexto da normal (Tabela 5.6). Além disso, tem-se a Tabela 5.7 com o diagnóstico adequado do modelo DCS-t 3 dummy. A Figura 5.9 apresenta a 
comparação entre as tendências obtidas via DCS-Normal e DCS-t. Nota-se grande similaridade entre as alternativas.

\begin{tabular}{|c|c|c|c|c|c|c|c|}
\hline & $\theta$ & DCS-t 1 & $\begin{array}{c}\text { DCS-t } 1 \\
\text { dummy }\end{array}$ & DCS-t 2 & $\begin{array}{c}\text { DCS-t } 2 \\
\text { dummy }\end{array}$ & DCS-t 3 & $\begin{array}{c}\text { DCS-t } 3 \\
\text { dummy }\end{array}$ \\
\hline 1 & $\kappa_{1}$ & $0,76(0,08)$ & $0,61(0,08)$ & $0,76(0,14)$ & $0,61(0,12)$ & $0,14(0,10)$ & $0,12(0,10)$ \\
\hline 2 & $\kappa_{2}$ & $0,00(-)$ & $0,00(-)$ & - & - & - & - \\
\hline 3 & $\kappa_{3}$ & - & - & - & - & $0,69(0,15)$ & $0,54(0,17)$ \\
\hline 4 & $\kappa_{s}$ & $0,05(-)$ & $0,05(-)$ & $0,05(-)$ & $0,05(-)$ & $0,05(-)$ & $0,05(-)$ \\
\hline 5 & $\nu$ & $9,56(3,67)$ & $36,40(53,94)$ & $9,60(3,68)$ & $36,83(55,41)$ & $7,22(2,61)$ & $23,04(30,09)$ \\
\hline 6 & $\lambda$ & $-1,32(0,06)$ & $-1,30(0,06)$ & $-1,32(0,06)$ & $-1,30(0,06)$ & $-1,42(0,07)$ & $-1,37(0,08)$ \\
\hline 7 & $\phi$ & - & - & - & - & $0,53(0,17)$ & $0,54(0,16)$ \\
\hline 8 & $\beta_{1 \mid 0}$ & $0,00(0,00)$ & $0,00(0,01)$ & - & - & - & - \\
\hline 9 & $\mu_{1 \mid 0}$ & $0,16(0,29)$ & $0,22(0,26)$ & $0,15(0,30)$ & $0,22(0,26)$ & $0,75(0,18)$ & $0,70(0,19)$ \\
\hline 10 & $\psi_{1 \mid 0}$ & - & - & - & - & $-0,73(0,26)$ & $-0,66(0,29)$ \\
\hline 11 & $\alpha_{1,1 \mid 0}$ & $0,58(0,07)$ & $0,58(0,07)$ & $0,58(0,07)$ & $0,58(0,08)$ & $0,59(0,08)$ & $0,60(0,09)$ \\
\hline 12 & $\alpha_{2,1 \mid 0}$ & $-0,05(0,07)$ & $-0,05(0,08)$ & $-0,05(0,07)$ & $-0,05(0,08)$ & $-0,02(0,08)$ & $-0,04(0,08)$ \\
\hline 13 & $\alpha_{3,1 \mid 0}$ & $0,12(0,06)$ & $0,12(0,07)$ & $0,12(0,06)$ & $0,12(0,07)$ & $0,11(0,07)$ & $0,11(0,08)$ \\
\hline 14 & $\alpha_{4,1 \mid 0}$ & $0,12(0,07)$ & $0,12(0,08)$ & $0,12(0,08)$ & $0,12(0,08)$ & $0,15(0,07)$ & $0,13(0,08)$ \\
\hline 15 & $\alpha_{5,1 \mid 0}$ & $-0,05(0,07)$ & $-0,05(0,07)$ & $-0,05(0,07)$ & $-0,05(0,07)$ & $-0,00(0,08)$ & $-0,02(0,08)$ \\
\hline 16 & $\alpha_{6,1 \mid 0}$ & $-0,29(0,08)$ & $-0,30(0,08)$ & $-0,29(0,08)$ & $-0,30(0,08)$ & $-0,27(0,09)$ & $-0,30(0,09)$ \\
\hline 17 & $\alpha_{7,1 \mid 0}$ & $-0,20(0,07)$ & $-0,16(0,08)$ & $-0,20(0,08)$ & $-0,16(0,08)$ & $-0,18(0,08)$ & $-0,17(0,09)$ \\
\hline 18 & $\alpha_{8,1 \mid 0}$ & $-0,20(0,07)$ & $-0,21(0,08)$ & $-0,20(0,08)$ & $-0,21(0,08)$ & $-0,24(0,08)$ & $-0,23(0,08)$ \\
\hline 19 & $\alpha_{9,1 \mid 0}$ & $-0,22(0,08)$ & $-0,21(0,08)$ & $-0,22(0,08)$ & $-0,21(0,08)$ & $-0,26(0,08)$ & $-0,22(0,09)$ \\
\hline 20 & $\alpha_{10,1 \mid 0}$ & $-0,08(0,07)$ & $-0,09(0,08)$ & $-0,08(0,08)$ & $-0,09(0,08)$ & $-0,11(0,08)$ & $-0,10(0,08)$ \\
\hline 21 & $\alpha_{11,1 \mid 0}$ & $0,09(0,07)$ & $0,07(0,08)$ & $0,09(0,08)$ & $0,07(0,08)$ & $0,05(0,08)$ & $0,05(0,08)$ \\
\hline 22 & $d_{\mathrm{nov} / 2011}$ & - & $1,72(0,23)$ & - & $1,72(0,24)$ & - & $1,76(0,22)$ \\
\hline
\end{tabular}

Os valores entre parênteses representam os desvios-padrão de cada parâmetro.

Alguns parâmetros não possuem desvio-padrão pois suas estimativas foram fixadas no limite inferior do intervalo que estão definidos.

Tabela 5.6: Parâmetros estimados via máxima verossimilhança $(\theta)$ para os modelos DCS-t.

\begin{tabular}{ccccccc}
\hline Assimetria & Curtose & Média & D. Padrão & $\begin{array}{c}\text { Jarque Bera } \\
\text { estat. (valor-p) }\end{array}$ & $\begin{array}{c}\text { Ljung-Box } \\
\text { estat. (valor-p) }\end{array}$ & $\begin{array}{c}\text { Ljung-Box* } \\
\text { estat. (valor-p) }\end{array}$ \\
\hline 0,08 & 2,81 & $-0,05$ & 1 & $0,55(0,76)$ & $3,01(1,00)$ & $19,80(0,07)$ \\
\hline
\end{tabular}

*Teste Ljung-Box aplicado aos resíduos ao quadrado com o intuito de avaliar heterocedasticidade. $\mathrm{Na}$ aplicação do teste Ljung-Box, considerou-se lag 24.

Tabela 5.7: Estatísticas e testes nos resíduos do modelo DCS-t 3 com dummy. 

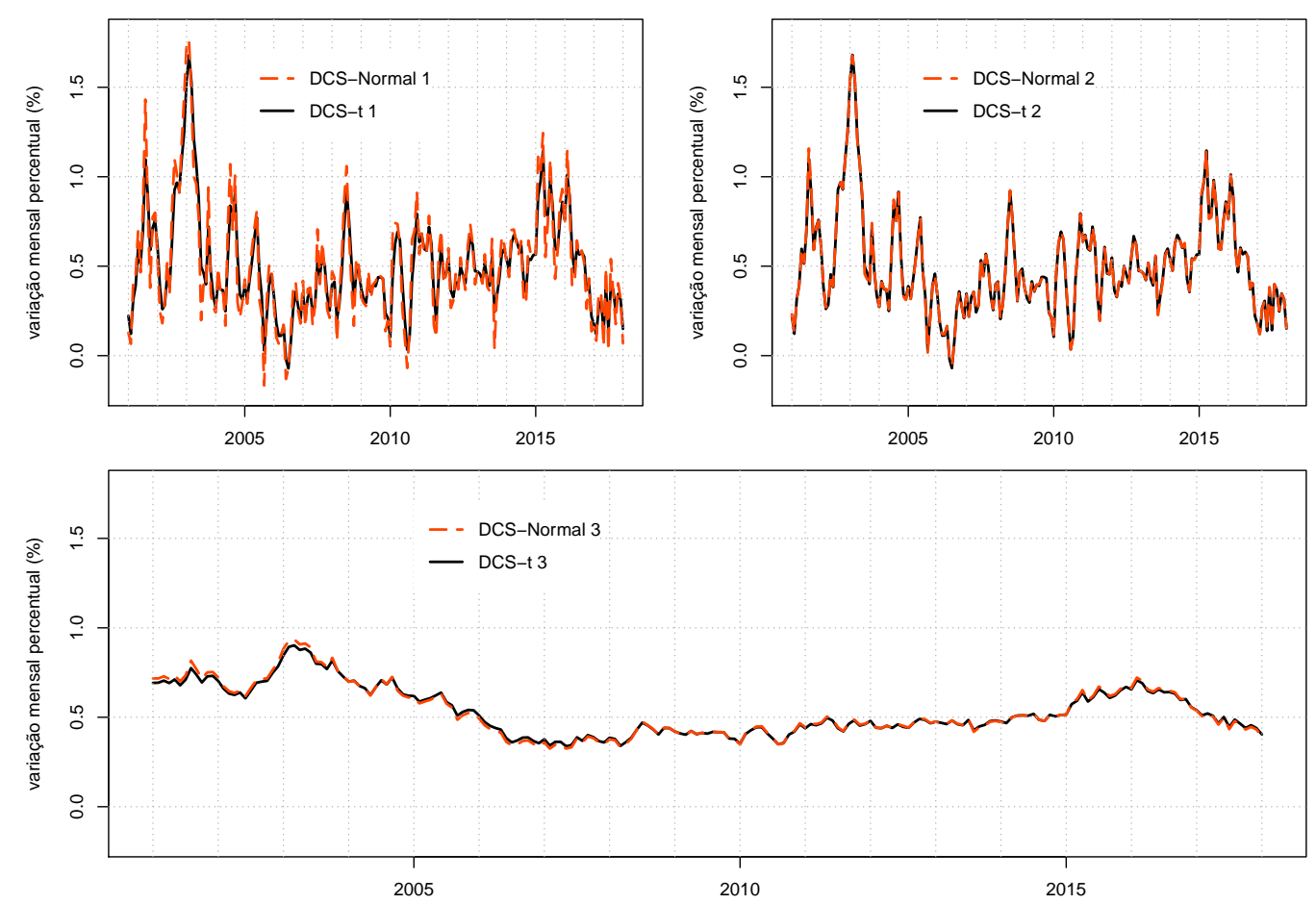

Figura 5.9: Tendências $\left(\mu_{t \mid t-1}\right)$ dos modelos DCS-Normal e DCS-t.

\section{- Análise de robustez dos modelos DCS}

Com a intenção de avaliar até que ponto as similaridades dos dois contextos (normal e $t$-Student) de modelos DCS se manteriam, decidiu-se reestimar os modelos para a série a partir de julho de 2003, removendo todo o período de alta inflação observado no início.

A Tabela 5.8, a seguir, apresenta os resultados de estimação para os três modelos, a saber: DCS-N (similar ao DCS-N 3), DCS-N dummy (similar ao DCS-N 3 dummy) e DCS-t (similar ao DCS-t 3). Tais medidas são observadas na Figura 5.10. Observaram-se as seguintes diferenças:

- Para que o modelo DCS-N fosse considerado adequado segundo as proposições assumidas, foi necessário a inclusão de uma dummy em jan/2016 (resíduo padronizado de 3,22). Para o modelo DCS-t, esse procedimento não foi necessário.

- A tendência $\mu_{t \mid t-1}$ foi estimada como uma constante no modelo DCS$\mathrm{N}$ (com/sem dummy). No DCS-t, a componente capturava a parte não estacionária da inflação.

Mesmo não existindo diferenças bruscas entre as estimativas de tendência vindas dos modelos DCS-N e DCS-t para o IPC-Br iniciando em jan/2001, optou-se pela tendência estimada via modelo DCS-t 3 pelos seguintes motivos: 
1) diagnóstico residual adequado completo: normalidade, não autocorrelação e homocedasticidade; 2) captura observações que seriam consideradas outliers no contexto normal sem a necessidade de intervenção, 3) o contexto normal não mostrou-se estável sugerindo que a tendência na verdade é constante, o que não faz sentido para o caso brasileiro.

\begin{tabular}{c|cccc}
\hline & $\theta$ & DCS-N & DCS-N dummy & DCS-t \\
\hline 1 & $\kappa_{1}$ & $0,00(-)$ & $0,00(-)$ & $0,07(0,09)$ \\
2 & $\kappa_{2}$ & - & - & - \\
3 & $\kappa_{3}$ & $0,47(0,07)$ & $0,47(0,08)$ & $0,60(0,15)$ \\
4 & $\kappa_{s}$ & $0,05(-)$ & $0,05(-)$ & $0,05(-)$ \\
5 & $\nu$ & - & - & $9,95(6,34)$ \\
6 & $\lambda$ & $-1,44(0,05)$ & $-1,45(0,05)$ & $-1,54(0,09)$ \\
7 & $\phi$ & $0,54(0,13)$ & $0,54(0,13)$ & - \\
8 & $\beta_{1 \mid 0}$ & - & - & - \\
9 & $\mu_{1 \mid 0}$ & $0,45(0,03)$ & $0,45(0,04)$ & $0,39(0,10)$ \\
10 & $\psi_{1 \mid 0}$ & $0,11(0,24)$ & $0,11(0,24)$ & $0,19(0,21)$ \\
11 & $\alpha_{1,1 \mid 0}$ & $0,59(0,08)$ & $0,55(0,08)$ & $0,57(0,08)$ \\
12 & $\alpha_{2,1 \mid 0}$ & $-0,06(0,08)$ & $-0,05(0,08)$ & $-0,04(0,08)$ \\
13 & $\alpha_{3,1 \mid 0}$ & $0,17(0,08)$ & $0,17(0,08)$ & $0,16(0,08)$ \\
14 & $\alpha_{4,1 \mid 0}$ & $0,10(0,08)$ & $0,10(0,08)$ & $0,11(0,08)$ \\
15 & $\alpha_{5,1 \mid 0}$ & $0,03(0,08)$ & $0,03(0,08)$ & $0,05(0,07)$ \\
16 & $\alpha_{6,1 \mid 0}$ & $-0,25(0,08)$ & $-0,25(0,08)$ & $-0,24(0,08)$ \\
17 & $\alpha_{7,1 \mid 0}$ & $-0,22(0,08)$ & $-0,22(0,08)$ & $-0,21(0,07)$ \\
18 & $\alpha_{8,1 \mid 0}$ & $-0,25(0,08)$ & $-0,24(0,08)$ & $-0,25(0,08)$ \\
19 & $\alpha_{9,1 \mid 0}$ & $-0,16(0,08)$ & $-0,16(0,08)$ & $-0,19(0,08)$ \\
20 & $\alpha_{10,1 \mid 0}$ & $-0,11(0,08)$ & $-0,10(0,08)$ & $-0,10(0,07)$ \\
21 & $\alpha_{11,1 \mid 0}$ & $0,03(0,08)$ & $0,03(0,08)$ & $0,02(0,07)$ \\
22 & $d_{\text {jan/2016 }}$ & - & $0,53(0,22)$ & - \\
\hline & & - & & \\
\hline
\end{tabular}

Tabela 5.8: Comparação DCS-N e DCS-t para o IPC-Br a partir de jul/2003. 


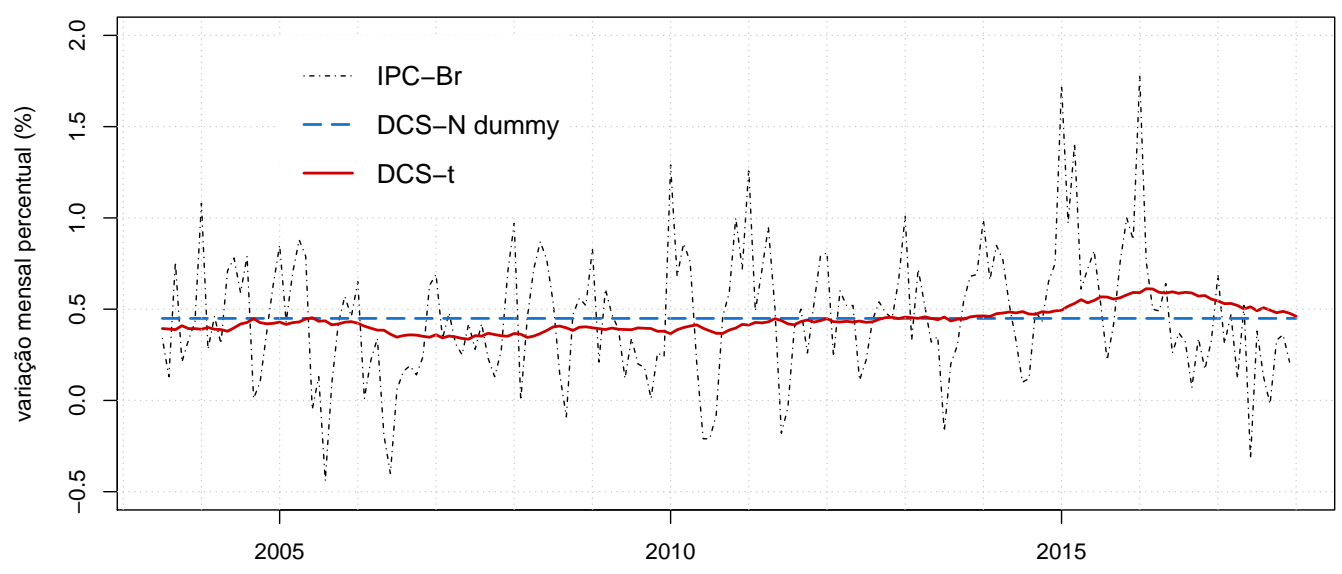

Figura 5.10: Tendências via DCS-N e DCS-t para o IPC-Br a partir de jul/2003.

\section{2}

\section{Comparação e avaliação segundo às características esperadas de um núcleo}

A Figura 5.11 e a Figura 5.12 a seguir mostram o IPC-Br e os dois núcleos finais que serão avaliados: Núcleo-S (via suavização) e Núcleo-DCS (via modelo DCS-t 3 com dummy). Os dois núcleos diferem consideravelmente no início da série e nos períodos de inflação alta.

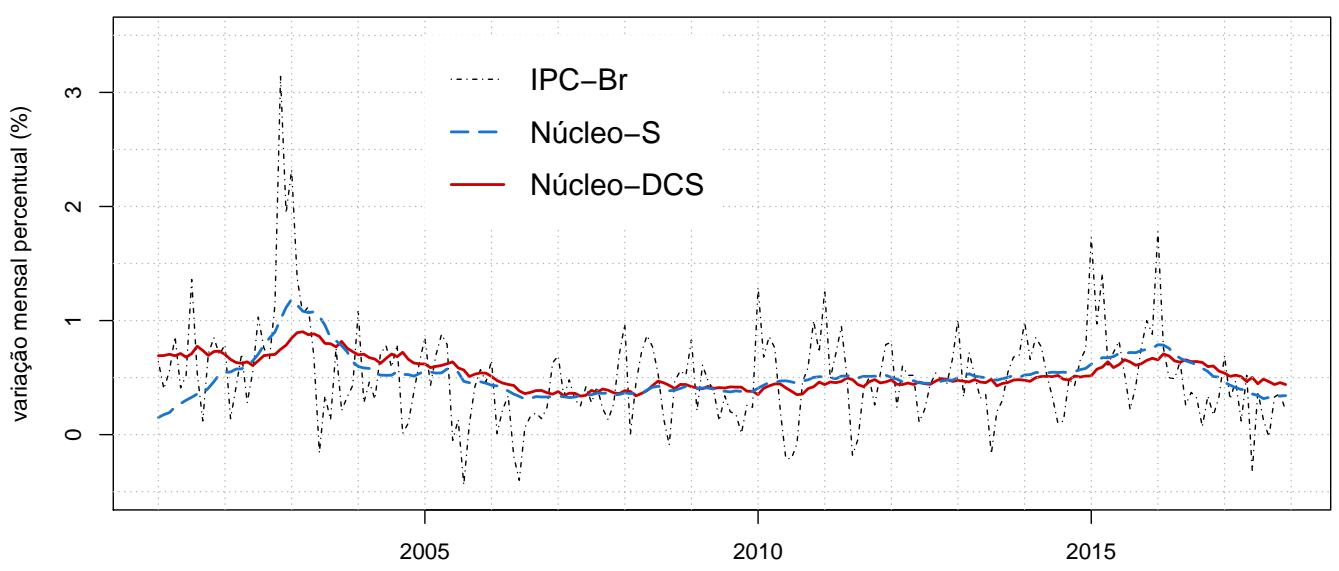

Figura 5.11: IPC-Br, Núcleo-S e Núcleo-DCS. 


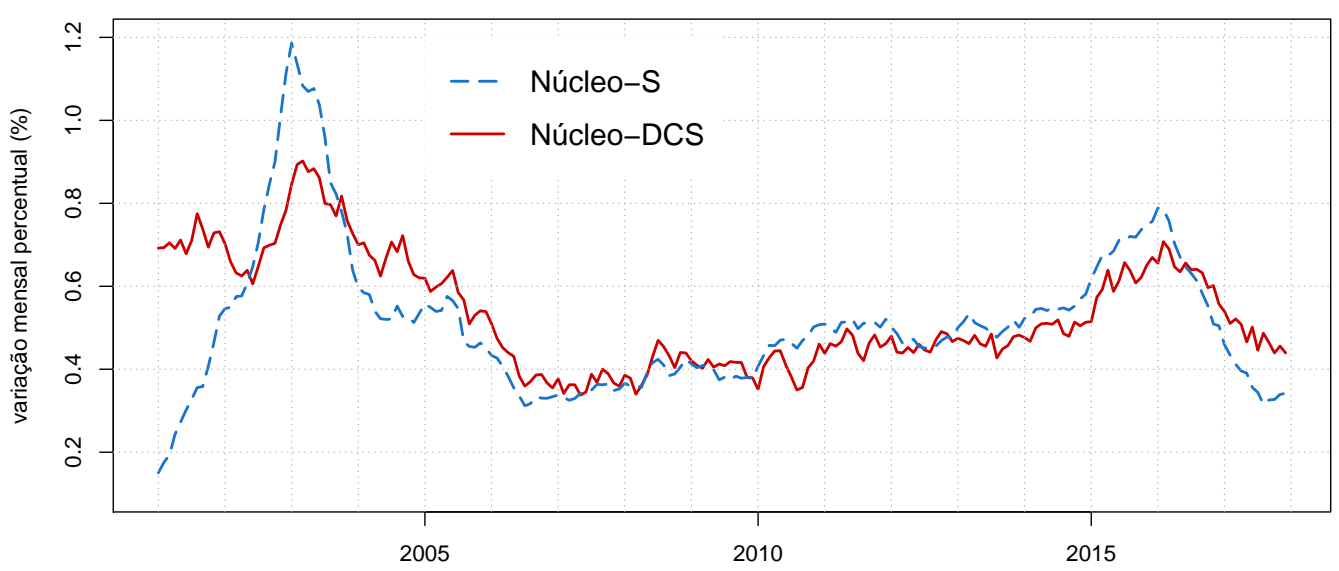

Figura 5.12: Núcleo-S vs. Núcleo-DCS.

Os diagnósticos apresentados a seguir serão feitos para o histórico completo da série (jan/2001 a dez/2017) e para a metade mais recente (jul/2009 a $\operatorname{dez} / 2017)$.

O que se percebe inicialmente (em comparação aos núcleos existentes no Brasil) é a remoção da sazonalidade. Visualmente os núcleos não apresentam tal componente e, segundo o teste de sazonalidade (Tabela 5.9), não há evidências de sazonalidade considerando $5 \%$ de significância.

\begin{tabular}{l|cc|cc|cc}
\hline & \multicolumn{2}{|c|}{ Total } & \multicolumn{2}{c}{ Parte inicial } & \multicolumn{2}{c}{ Parte final } \\
& qs-stat & p-valor & qs-stat & p-valor & qs-stat & p-valor \\
\hline Núcleo-S & 0,00 & 1,00 & 0,00 & 1,00 & 0,01 & 0,99 \\
Núcleo-DCS & 0,00 & 1,00 & 0,00 & 1,00 & 4,64 & 0,10 \\
\hline
\end{tabular}

$H_{0}$ : Não há sazonalidade na série temporal.

Tabela 5.9: Teste de Sazonalidade QS.

A Tabela 5.10 mostra as estatísticas descritivas do IPC-Br e dos dois núcleos propostos. Com respeito à média, ambos os núcleos têm média similar ao índice de inflação, lembrando que o Núcleo-S foi construído propositalmente para apresentar tal valor para o período em estudo. Para a parte mais recente do histórico, as médias se mantém similares. Com respeito à volatilidade, ambos os núcleos são muito menos voláteis do que o IPC-Br, sendo o NúcleoDCS o mais suave dentre os dois, tanto para o período completo quanto para o período mais recente.

A Tabela 5.11 apresenta o teste de raiz unitária Augmented Dickey Fuller (ADF). Apesar de o IPC-Br e o Núcleo-S terem sido considerados estacionários para o comprimento total da série, o teste aplicado para o período mais recente mostra evidências de que as medidas não são estacionárias. Por isso, conclui-se 


\begin{tabular}{l|ccccc}
\hline & Média & Mediana & Desvio-Padrão & Coef. Variação & Viés \\
\hline IPC-Br & $0,51(0,50)$ & $0,47(0,49)$ & $0,44(0,37)$ & $0,85(0,76)$ & - \\
Núcleo-S & $0,51(0,52)$ & $0,50(0,50)$ & $0,18(0,11)$ & $0,35(0,21)$ & $0,00(0,02)$ \\
Núcleo-DCS & $0,53(0,50)$ & $0,49(0,48)$ & $0,13(0,08)$ & $0,25(0,17)$ & $0,02(0,00)$ \\
\hline
\end{tabular}

Tabela 5.10: Estatísticas descritivas dos núcleos propostos e do IPC-Br.

não estacionariedade para todas as séries. O teste foi reaplicado nas séries em primeira diferença e não há evidências de que não sejam estacionárias.

\begin{tabular}{l|ccccc}
\hline & lag & equação & $\begin{array}{c}\text { Estatística } \\
\text { de teste }\end{array}$ & Valor Crítico & Conclusão \\
\hline \multirow{2}{*}{ IPC-Br } & 12 & $\mathrm{~s} /$ tend. c/ const. & $-2,89$ & $-2,88$ & estacionário \\
& $(12)$ & $(\mathrm{s} /$ tend. c/ const.) & $(-1,34)$ & $(-2,88)$ & (não estacionário) \\
\hline \multirow{2}{*}{ Núcleo-S } & 13 & $\mathrm{~s} /$ tend. c/ const. & $-2,94$ & $-2,88$ & estacionário \\
& $(12)$ & $(\mathrm{s} /$ tend. c/ const.) & $(-2,51)$ & $(-2,88)$ & (não estacionário) \\
\hline \multirow{2}{*}{ Núcleo-DCS } & 0 & $\mathrm{~s} /$ tend. c/ const. & $-1,62$ & $-2,88$ & não estacionário \\
& $(0)$ & $(\mathrm{s} /$ tend. c/ const.) & $(-1,71)$ & $(-2,88)$ & (não estacionário) \\
\hline
\end{tabular}

Os valores entre parenteses são obtidos sobre a série a partir de jul/2009.

O nível de significância considerado é de $5 \%$.

Tabela 5.11: Teste de raiz unitária (ADF) nos núcleos propostos e no IPC-Br.

Após isso, aplicou-se o teste de cointegração de Johansen para verificar se há relação de longo prazo entre as medidas. A conclusão foi favorável para os dois núcleos como se observa na Tabela 5.12.

\begin{tabular}{l|ccc}
\hline & $\begin{array}{c}\text { Estatística } \\
\text { de teste }\end{array}$ & Valor Crítico & Conclusão \\
\hline IPC-Br \& Núcleo-S & 58,75 & 14,90 & séries cointegradas \\
IPC-Br \& Núcleo-DCS & 70,59 & 14,90 & séries cointegradas \\
\hline
\end{tabular}

Tabela 5.12: Teste de cointegração de Johansen entre o IPC-Br e os núcleos propostos.

O próximo resultado tem a intenção de avaliar a forma com que as séries se relacionam no longo prazo: se o gap entre a inflação e seu núcleo diminui porque a inflação se desloca em direção ao núcleo e/ou o núcleo se desloca em direção à inflação (atratividade). A Tabela 5.13 mostra que para o Núcleo-S, a dinâmica se dá pelo movimento da inflação em direção ao núcleo. Dessa forma, pode se concluir, por exemplo, que quando o IPC-Br está acima do Núcleo-S, espera-se que seu valor diminua em algum tempo futuro. Para o Núcleo-DCS, no entanto, a conclusão é que tanto o IPC-Br quanto o núcleo se deslocam um em direção ao outro. Com isso, conclui-se, no exemplo anterior, que a diferença 
entre o núcleo e o IPC-Br diminuirá num tempo futuro em consequência do movimento dos dois (núcleo aumenta, IPC-Br diminui).

\begin{tabular}{l|cc}
\hline & $\lambda$ & $\lambda_{\text {núcleo }}$ \\
\hline IPC-Br \& Núcleo-S & $-1,9986^{* * *}\left(-2,8650^{* * *}\right)$ & $-0,0045(0,0035)$ \\
IPC-Br \& Núcleo-DCS & $-0,4020^{* * *}\left(-0,3966^{* * *}\right)$ & $0,0518^{* * *}\left(0,0551^{* * *}\right)$ \\
\hline
\end{tabular}

Nota: níveis de significância: $5 \%(*), 1 \%(* *)$ e $0,1 \%(* * *)$.

Os resultados entre parenteses são obtidos considerando o histórico de jul/2009 a dez/2017.

Tabela 5.13: Dinâmica entre IPC-Br e os núcleos propostos.

Os resultados a seguir são referentes à capacidade de previsão, isto é, uma análise da utilidade do núcleo em prever a inflação. A Tabela 5.14 tem o objetivo de avaliar se a diferença entre o núcleo e a inflação hoje é uma informação relevante para dizer o quanto a inflação irá variar daqui a $h=1,3,6$ e 12 meses. Para as duas amostras da série, essa diferença parece ser relevante ( $\beta$ significativo) e ainda mais informativa ( $R^{2}$ maior) para o médio prazo (3 e 6 meses). A análise foi feita (pseudo) fora da amostra também. Fez-se a previsão 1 passo à frente para os últimos 12 meses da série histórica. Observou-se menor erro de previsão para o horizonte de três meses para ambos os núcleos (ver Tabela 5.15). No entanto, não parece haver grandes diferenças. O erro varia entre 0,3 e 0,4 para praticamente todos os horizontes. Tais valores são piores em relação aos observados para os núcleos disponíveis hoje no Brasil.

\begin{tabular}{ll|ccc|ccc}
\hline & & \multicolumn{3}{|c|}{ jan/2001 a dez/2017 } & \multicolumn{2}{|c}{ jul/2009 a dez/2017 } \\
\hline \multirow{2}{*}{$h=1$} & $R^{2}$ & $\beta$ & t-stat & $R^{2}$ & $\beta$ & t-stat \\
\hline \multirow{2}{*}{$h=3$} & IPC-Br \& Núcleo-S & 0,25 & $0,53(0,06)$ & $8,1^{* * *}$ & 0,28 & $0,58(0,09)$ & $6,2^{* * *}$ \\
& IPC-Br \& Núcleo-DCS & 0,23 & $0,48(0,06)$ & $7,8^{* * *}$ & 0,25 & $0,52(0,09)$ & $5,8^{* * *}$ \\
\hline \multirow{2}{*}{$h=6$} & IPC-Br \& Núcleo-S & 0,40 & $0,88(0,08)$ & $11,4^{* * *}$ & 0,48 & $1,01(0,11)$ & $9,4^{* * *}$ \\
& IPC-Br \& Núcleo-DCS & 0,39 & $0,83(0,07)$ & $11,3^{* * *}$ & 0,43 & $0,91(0,10)$ & $8,6^{* * *}$ \\
\hline \multirow{2}{*}{$h=6$} & IPC-Br \& Núcleo-S & 0,51 & $1,17(0,08)$ & $14,2^{* * *}$ & 0,67 & $1,44(0,10)$ & $13,9^{* * *}$ \\
& IPC-Br \& Núcleo-DCS & 0,53 & $1,13(0,08)$ & $14,9^{* * *}$ & 0,64 & $1,33(0,10)$ & $12,9^{* * *}$ \\
\hline \multirow{2}{*}{$h=12$} & IPC-Br \& Núcleo-S & 0,22 & $0,61(0,08)$ & $7,4^{* * *}$ & 0,13 & $0,35(0,09)$ & $3,7^{* * *}$ \\
& IPC-Br \& Núcleo-DCS & 0,29 & $0,67(0,07)$ & $8,9^{* * *}$ & 0,14 & $0,34(0,09)$ & $3,8^{* * *}$ \\
\hline
\end{tabular}

Nota: desvio-padrão do coeficiente $\beta$ entre parênteses; t-stat é a estatística de teste para o parâmetro $\beta$.

Tabela 5.14: Análise da previsão da inflação utilizando núcleos.

O modelo DCS permite a previsão da variável de interesse como visto na seção 4.2.6. A Figura 5.13 apresenta a previsão fora da amostra para $h=1,3,6$ e 12 passos à frente. Foram feitas 2000 simulações para cada tempo $t$ variando 


\begin{tabular}{l|cccc|cccc}
\hline & \multicolumn{3}{|c|}{ jan/2001 a $\mathrm{dez} / 2017$} & \multicolumn{3}{c}{ jul/2009 a $\mathrm{dez} / 2017$} \\
\hline & $\mathbf{1}$ & $\mathbf{3}$ & $\mathbf{6}$ & $\mathbf{1 2}$ & $\mathbf{1}$ & $\mathbf{3}$ & $\mathbf{6}$ & $\mathbf{1 2}$ \\
\hline Núcleo-S & 0,32 & 0,28 & 0,35 & 0,38 & 0,31 & 0,28 & 0,41 & 0,39 \\
Núcleo-DCS & 0,33 & 0,32 & 0,40 & 0,37 & 0,34 & 0,36 & 0,53 & 0,39 \\
\hline
\end{tabular}

Tabela 5.15: Erro de previsão (RMSE) 1 passo à frente para os últimos 12 meses.

de jan/2016 a dez/2017 (24 meses). O que se observa é que o menor erro de previsão é para o curto prazo $(h=1)$. A previsão da inflação para longos horizontes costuma ser superestimada por esse modelo. Os RMSEs para cada $h$ são, respectivamente: 0,$29 ; 0,31 ; 0,35$ e 0,38 .

Por curiosidade, pesquisou-se os RMSEs para a previsão do IPCA feita pelo mercado (Focus - média) para os mesmos horizontes $h=1,3,6$ e 12 . Considerando-se apenas o ano de 2017, o erros de previsão são, respectivamente: 0,$11 ; 0,20 ; 0,21$ e 0,25 .
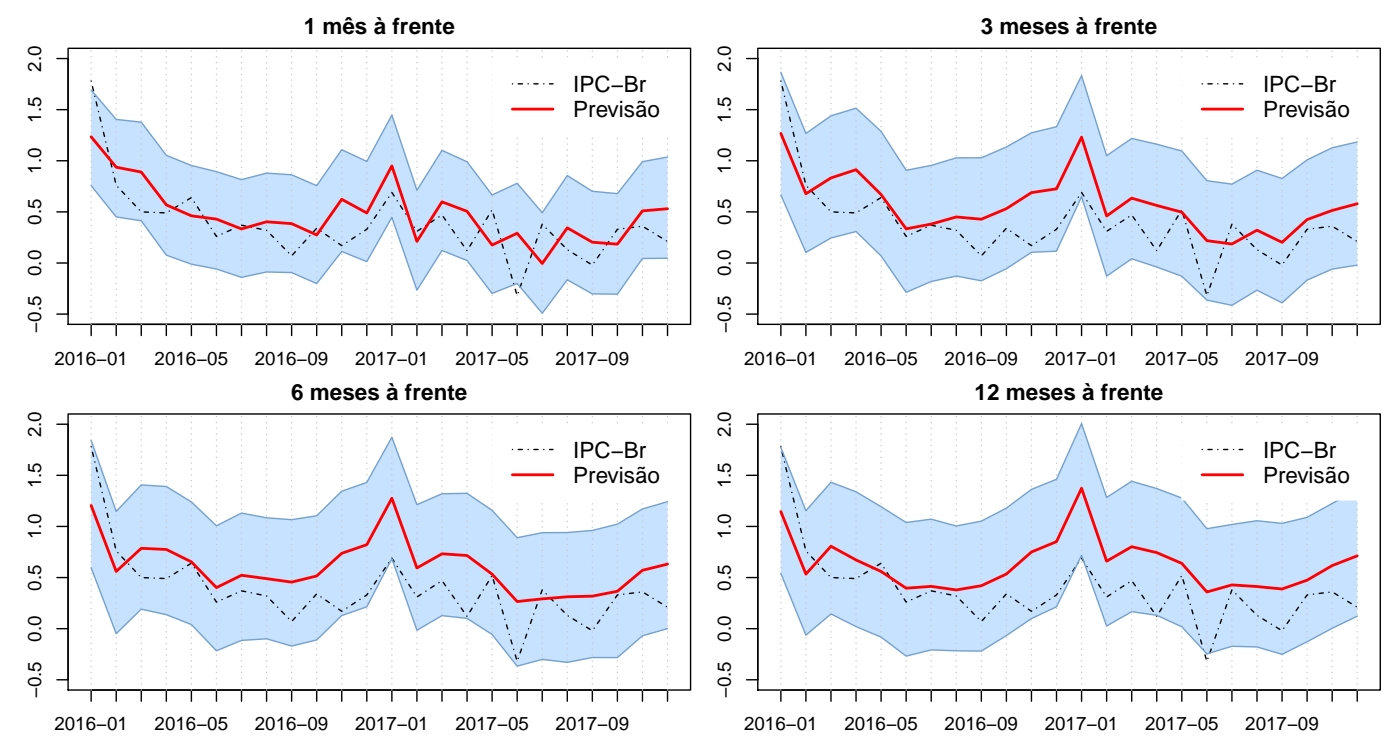

Figura 5.13: Previsão do IPC-Br via modelo DCS.

\section{- Estabilidade}

As duas metodologias propostas nesse estudo estão sujeitas a alterações do histórico da componente de tendência ao acrescentar novas observações da variável de interesse. No Núcleo-S isso ocorre devido ao ajuste sazonal e no Núcleo-DCS devido à otimização dos parâmetros via máxima verossimilhança. O intuito dessa seção é, então, verificar se a tendência, via as duas metodologias, se mantém similar ao longo do tempo para que a história contada através das medidas seja a mesma independente do tempo $t$ atual. Para isso, aplicou-se o seguinte procedimento: 
- Núcleo-S

1. definir a especificação do modelo de ajuste sazonal considerando os dados a partir de jan/2009 até dez/2015;

2. executar o ajuste sazonal mês a mês de jan/2016 a dez/2017 de acordo com a especificação definida em (1) mantendo a estimação dos parâmetros do modelo livre e armazenar o resultado (série com ajuste sazonal) de cada mês;

3. dessazonalizar a série completa de acordo com a especificação definida em (1) e compará-la com a série obtida em (2).

- Núcleo-DCS

1. estimar o modelo DCS com a especificação definida na equação (49) mês a mês a partir de jan/2016 e armazenar o valor da tendência para cada mês;

2. estimar o modelo DCS com a especificação definida na equação (49) usando a série completa e comparar com a tendência obtida em (1).

Os resultados desse procedimento são vistos na Figura 5.14. Nota-se que a similaridade é maior para o Núcleo-DCS (RMSE de 0,01 contra 0,03 do Núcleo-S). A respeito dos movimentos mensais o Núcleo-S não mantém o sinal da tendência durante alguns meses (áreas hachuradas na Figura 5.14).
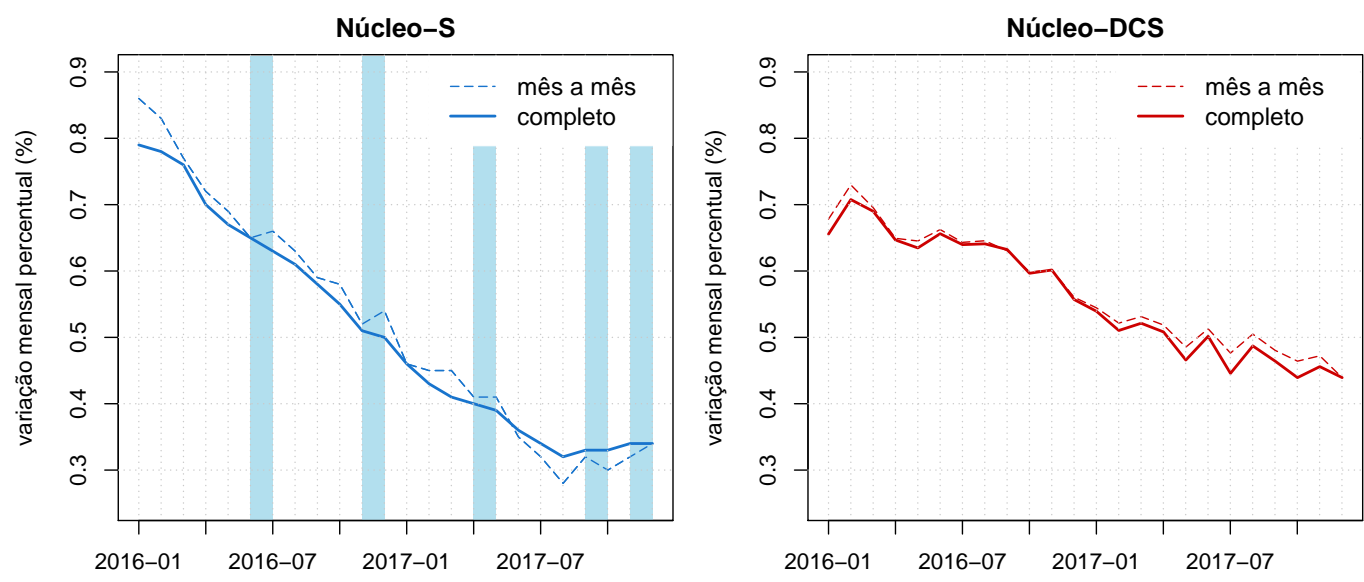

Figura 5.14: Estabilidade histórica dos núcleos. 


\section{3}

\section{Qual é a “melhor” medida de núcleo?}

Após a análise dos resultados apresentados na seção 5.2, é fácil concluir que, no que se refere à captura de tendência, os dois núcleos propostos são superiores aos núcleos divulgados hoje no Brasil. Ambas as medidas não apresentam viés, possuem baixa volatilidade, mostram indicativos dos movimentos futuros da inflação (atratividade) e são estáveis. No entanto, as medidas não são competitivas em relação a previsão da inflação pois apresentam erro maior do que os erros apresentados pelas medidas disponíveis hoje no Brasil.

Para eleger qual é a melhor dentre as duas medidas propostas, no que se refere a captura de tendência, é necessário refletir sobre o método de cálculo de cada medida. Enquanto o Núcleo-DCS é estimado via modelagem estatística, o que pode tornar difícil a comunicação com o público, o Núcleo-S carrega informação de até 12 meses passados, mesmo que suavizada.

Portanto, recomenda-se o seguinte: para a avaliação de tendência, os dois núcleos propostos devem ser utilizados em vez dos outros seis divulgados atualmente, e para um melhor entendimento do nível em que a inflação brasileira está hoje, recomenda-se a observação do Núcleo-DCS, pois este não carrega informação defasada. Ao incluir o Núcleo-DCS nas medidas de núcleos divulgadas no Brasil, o país passa a fazer parte da lista de países, ainda que pequena, que utilizam também outros modelos estatísticos para o cálculo de núcleos além dos métodos tradicionais.

\section{4}

\section{Análise Econômica e Previsão}

\subsection{1}

\section{Comparação entre a inflação acumulada em 12 meses e o Núcleo-DCS}

O índice de inflação acumulado em 12 meses é uma das principais ferramentas do público em geral para acompanhar a trajetória da inflação (Ferreira et al. (2016) (36); Gaglianone et al. (2016) (37)). Por isso, é relevante a comparação entre um núcleo e uma medida já consolidada na avaliação da trajetória da inflação.

A Figura 5.15 apresenta, além do IPCA acumulado em 12 meses (IPCA 12), o Núcleo-DCS e a taxa de juros Selic acumulada no mês. Todas as medidas estão anualizadas. O que se percebe entre as duas primeiras medidas é um movimento coincidente, todavia, o núcleo é menos afetado pelas variações de preços extremas que ocorrem mensalmente além de não considerar tanta 


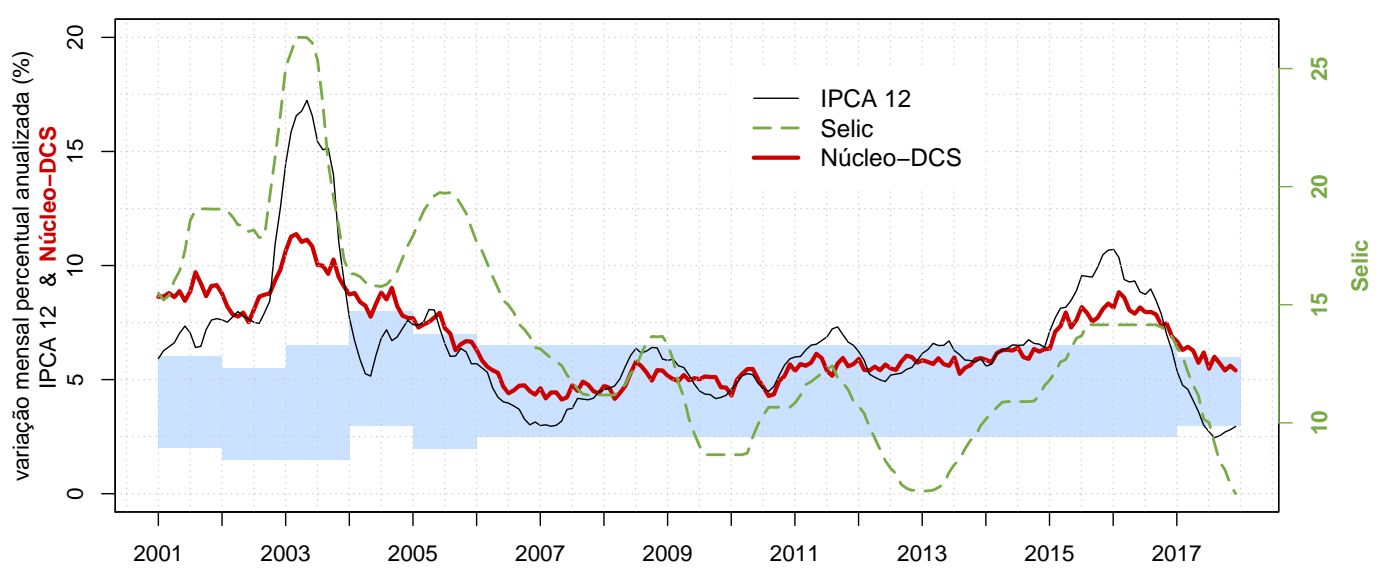

Figura 5.15: IPCA acumulado em 12 meses, Núcleo-DCS e Selic.

informação passada no valor presente. Por exemplo, observe a queda brusca da inflação acumulada no ano de 2003: em apenas 6 meses a medida varia de $15 \%$ para $7,5 \%$ enquanto o Núcleo-DCS varia de $10 \%$ para $8,5 \%$. No ano de 2006 e de 2015 a 2017, comportamentos similares se repetem.

O núcleo também oferece alguma informação visual sobre a trajetória da inflação acumulada. A partir de 2006 nota-se um trajetória ascendente nas duas medidas. Porém esse movimento é indentificado de forma mais clara e rápida sobre o núcleo. Veja que a inflação acumulada oscila entre o piso e o teto da meta durante o período 2006-2009 enquanto o núcleo passa pelo meio.

Essa lentidão da reação da inflação acumulada faz com que a medida saia da meta em abril de 2011 mas retorne antes do findar do ano. Em 2013 isso ocorre mais uma vez. Ainda nesse ano, ambas as medidas flutuam bem próximo do teto da meta e o núcleo mostra com mais nitidez a tendência crescente da inflação. A inflação acumulada ultrapassa o teto da meta em meados de 2014, no entanto fecha o ano dentro do intervalo. O Núcleo-DCS mostra crescimento mas só ultrapassa o intervalo em fevereiro de 2015. No primeiro mês de 2015 a inflação acumulada ultrapassa o teto da meta outra vez e só retorna para dentro do intervalo no final de 2017.

No ínicio do ano de 2016 as duas medidas alcançam o seu auge e começam a mostrar uma trajetória descendente a partir de então. A inflação acumulada cai de 10,71\% para 5,35\% entre jan/2016 e jan/2017. Já o Núcleo-DCS de 8,16\% para 6,67\%. O movimento decrescente continua em 2017 para as medidas, sendo mais intenso para a inflação acumulada que chega a ser inferior ao piso da meta. O Núcleo-DCS segue o mesmo movimento da inflação acumulada porém diminui de forma sutil a partir de 2016 e atualmente ainda mostra uma tendência decrescente em direção ao centro do intervalo.

Em resumo, o que se percebe nessa análise feita nos parágrafos anteriores é o seguinte: o IPCA acumulado carrega, por definição, muita informação do 
passado, e por isso seus movimentos são lentos. De forma contrária, o NúcleoDCS capta melhor os movimentos de curto prazo sem deixar de ser uma boa medida de tendência. Para corroborar com essas afirmações, fez-se o teste de causalidade de Granger (Tabela 5.16) em que conclui-se, considerando 5\% de significância, que o Núcleo-DCS ajuda a prever o IPCA acumulado.

\begin{tabular}{lccc}
\hline & F-stat & lag & p-valor \\
\hline $\mathrm{H}_{0}$ : Núcleo-DCS não granger-causa IPCA12 & 4,03 & 12 & 0,0000 \\
\hline
\end{tabular}

Tabela 5.16: Teste de causalidade de Granger entre IPCA e o Núcleo-DCS.

Dessa forma, pode-se dizer que o Núcleo-DCS pode ajudar o BCB na condução da política monetária e também ser uma boa medida de meta. Isto é, talvez considerar o Núcleo-DCS como uma medida de controle intermediária, resultasse no controle da inflação acumulada no ano. Além do mais, talvez também a política monetária poderia ser conduzida com mais parcimonia. Por exemplo:

- No segundo semestre de 2011, a inflação acumulada mostrava sinais de queda, bem como a Selic. Porém, 1 ano depois a medida retorna a subir quase ultrapassando o teto. Alguns meses depois nota-se a Selic crescendo também. Nesse intervalo de tempo, no entanto, o Núcleo-DCS mostrava o crescimento da tendência da inflação, sugerindo que a taxa de juros não fosse reduzida.

- Em 2017, a inflação fechou o ano abaixo do intervalo da meta. Observando o ano anterior, nota-se que a taxa de juros manteve-se muito alta durante bastante tempo. Nesse período, assim como a inflação acumulada, o Núcleo-DCS mostrava decrescimento. Dessa forma, talvez se a taxa de juros começasse a ser reduzida um pouco antes do tempo, a inflação no ano poderia ter permanecido dentro do intervalo da meta.

Outro ponto interessante na utilização do Núcleo-DCS é que, como já relatado anteriormente, o público em geral é influienciado pelo IPCA acumulado em 12 meses para formar suas expectativas de inflação futura. Sabese que tais expectativas afetam os preços no presente, por exemplo, negociação de salários, aluguéis, mensalidades escolares, etc. Isto é, o IPCA 12 no período $t$ é afetado pelas variações que ocorrem nos períodos de $t$ a $t-11 \mathrm{e}$, por isso, se ajusta à dinâmica dos preços de curto prazo mais lentamente, o que faz com que as expectativas de inflação dos consumidores siga uma dinâmica similar.

Observe o ano de 2015 na Figura 5.16. Neste ano ocorreram reajustes em diversos preços, por exemplo preços administrados como combustíveis e 


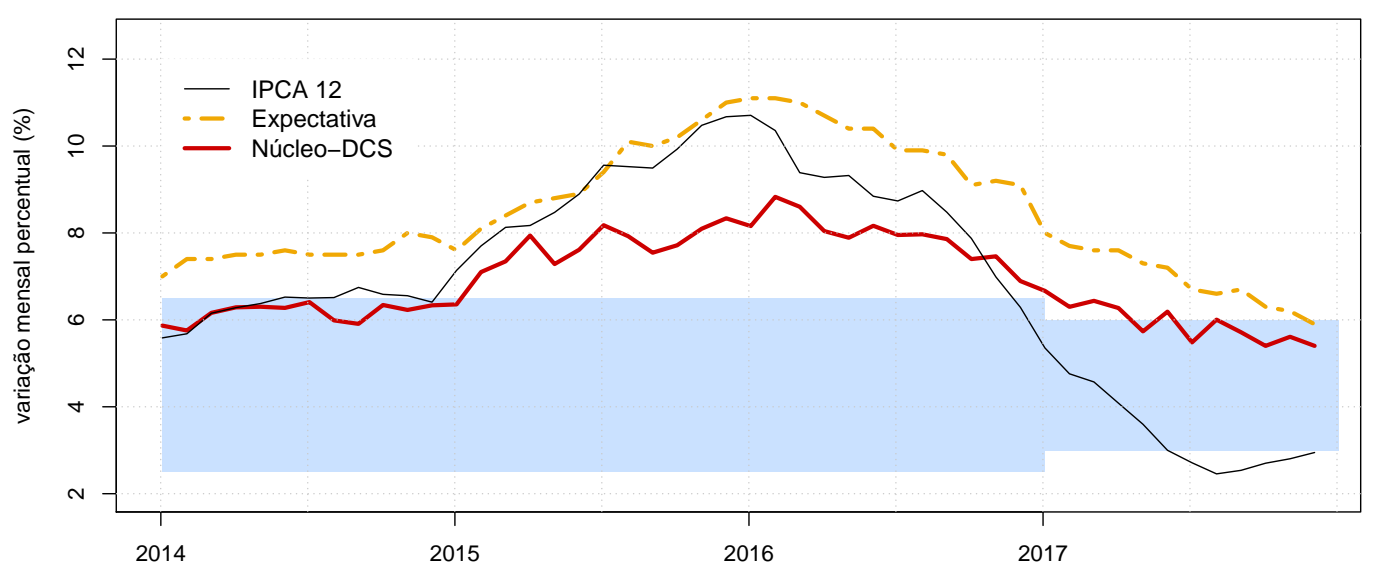

Figura 5.16: IPCA acumulado em 12 meses, Núcleo-DCS e expectativa da inflação do consumidor.

energia, que levaram o IPCA acumulado no ano a fechar em 10,67\%. Note que no início de 2015 o IPCA 12 estava em torno de $6 \%$ e subiu rapidamente 4 pontos percentuais em apenas 12 meses. Seguindo a mesma tendência, a expectativa da inflação dos consumidores saiu de algo em torno de $8 \%$ para 11\%. Após esses movimentos, enquanto o IPCA 12 iniciou uma trajetória de queda abrupta, as expectativas de inflação dos consumidores mostraram-se mais resilientes e cairam mais lentamente. O que nos permite especular que a variação do IPCA 12 afeta mais as expectativas dos consumidores sobre a inflação quando essa é ascendente do que quando é decrescente.

Imagine agora, apenas como um exercício teórico, que em vez de os agentes econômicos, banco central, firmas, consumidores "olharem" para o IPCA 12 para formarem suas expectativas futuras sobre a inflação, olhassem também para o Núcleo-DCS proposto nessa dissertação. Talvez as expectativas dos consumidores seriam menos voláteis e se ajustariam mais rapidamente à dinâmica de preços de curto prazo. Observe novamente a Figura 5.16. No início de 2015, onde os maiores aumentos dos preços estão concentrados, tanto o núcleo quanto o IPCA 12 sobem rapidamente. Contudo, já a partir de abril de 2015, o núcleo se estabiliza, indicando que a partir daquele momento os preços já não estão subindo na mesma velocidade, o contrário do que acontece com o IPCA 12.

Dessa forma, se os agentes econômicos estivessem olhando também para o núcleo, o que consequentemente poderia influenciar os consumidores, muito provavelmente as expectativas de inflação seriam menores pondendo tornar menos rígida a condução da política monetária. É claro que mais estudos e resultados empíricos são necessários para provar tais suposições. Contudo é relevante debater esse tema. 


\section{4 .2}

\section{Inflação no Brasil em 2018}

Apenas para fins de exercício, apresenta-se a seguir a previsão para a inflação do Brasil em 2018. Sabe-se que o BCB possui modelos mais robustos e que levam em consideração outras variáveis econômicas que aumentam substancialmente o poder de predição da inflação. A previsão apresentada aqui não considera nenhuma outra variável além do próprio indicador de inflação sobre a estrutura definida na seção 4.2 .

A Tabela 5.17 apresenta a previsão para o IPC-Br, para o IPCA e para o Núcleo-DCS para os 12 meses do ano de 2018. A previsão do Núcleo-DCS aparece anualizada (elevada a 12 para se ter uma ideia de seu valor anual). Além disso, apresenta-se as previsões divulgadas pelos especialistas (mercado) para o IPCA (Boletim Focus). Os dados do Boletim Focus podem ser coletados de forma gratuita no Sistema de Séries Temporais do Banco Central do Brasil.

Inicialmente obteve-se a previsão do IPC-Br e do Núcleo-DCS utilizando os procedimentos apresentados na seção 4.2.6. A previsão do IPCA foi obtida estimando uma regressão linear entre o IPCA e o IPC-Br e seus lags ${ }^{1}$. Acumulando os 12 valores previstos, tem-se a previsão para o ano de 2018, que para o IPC-Br e para o IPCA é, respectivamente, de 4,36\% e 4,69\%. Para o Núcleo-DCS, espera-se variação de 4,91\% no ano com intervalo de confiança de $95 \%$ de $[3,96$ - 6,39]. Todos os valores encontram-se contidos no intervalo da meta da inflação para o próximo ano (3 a 6\%).

\begin{tabular}{c|cccc}
\hline Meses & IPC-Br & IPCA & Núcleo-DCS & Focus $^{*}$ \\
\hline jan/2018 & 0,80 & 0,63 & $4,96[4,96-4,96]$ & 0,40 \\
fev/2018 & 0,25 & 0,38 & $4,95[4,30-5,60]$ & 0,44 \\
mar/2018 & 0,47 & 0,42 & $4,94[3,97-5,90]$ & 0,32 \\
abr/2018 & 0,45 & 0,48 & $4,93[3,79-6,11]$ & 0,38 \\
mai/2018 & 0,36 & 0,37 & $4,92[3,56-6,28]$ & 0,30 \\
jun/2018 & 0,08 & 0,21 & $4,90[3,38-6,43]$ & 0,20 \\
jul/2018 & 0,20 & 0,21 & $4,90[3,24-6,56]$ & 0,19 \\
ago/2018 & 0,18 & 0,25 & $4,91[3,08-6,72]$ & 0,19 \\
set/2018 & 0,19 & 0,28 & $4,91[2,95-6,93]$ & 0,29 \\
out/2018 & 0,30 & 0,34 & $4,91[2,90-6,99]$ & 0,35 \\
nov/2018 & 0,45 & 0,43 & $4,90[2,77-7,02]$ & 0,38 \\
dez/2018 & 0,54 & 0,58 & $4,90[2,68-7,17]$ & 0,47 \\
\hline *Previsão para o IPCA feita em 26/01/2018 para todo o ano de 2018 - Média
\end{tabular}

Tabela 5.17: Previsão do IPC-Br, do IPCA e do Núcleo-DCS para 2018.

\footnotetext{
${ }^{1} \mathrm{~A}$ representação da equação é a seguinte: $\mathrm{IPCA}_{t}=\alpha+\beta_{1} \mathrm{IPCA}_{t-12}+\beta_{2} \mathrm{IPC}-\mathrm{Br}_{t}+$ $\beta_{3} \mathrm{IPC}_{\mathrm{P}} \mathrm{Br}_{t-1}+\beta_{4} \mathrm{IPC}-\mathrm{Br}_{t-12}+\varepsilon_{t}$
} 


\section{6}

\section{Conclusão e trabalhos futuros}

Núcleo da inflação tem sido uma das ferramentas usadas pelos bancos centrais no mundo como suporte na condução da política monetária. Pode-se dizer, segundo a revisão de literatura vista no Capítulo 2, que um núcleo da inflação busca remover as variações de curto prazo de um indicador de inflação, restando apenas a tendência da variável.

observou-se que existem diversas formas de estimação de núcleo e as mais populares buscam encontrar os itens da cesta da inflação que acrescentam mais volatilidade ao índice final, removê-los ou suavizá-los e em seguida recalcular a inflação. No Brasil os núcleos estimados via tais métodos tradicionais não trazem grande informação sobre a tendência do nível dos preços (Capítulo 3). Por isso, buscando contribuir com o conjunto de ferramentas que o BCB poderia consultar na condução política monetária, propôs-se dois métodos de cálculo de núcleo: 1) o primeiro, denominado Núcleo-S, pode ser considerado um aprimoramento do núcleo de médias aparadas (seção 4.1). 2) O segundo, Núcleo-DCS, é estimado via Dynamic Conditional Score Models (seção 4.2).

Ambas as propostas forneceram uma informação mais clara a respeito da tendência da inflação e de seus possíveis movimentos futuros, sendo o NúcleoDCS o mais indicado para observação da tendência atual, uma vez que em sua construção não é influenciado por tantas observações passadas como o NúcleoS. As análises elaboradas no Capítulo 5 sugerem indícios de que o Núcleo-DCS pode auxiliar no controle da inflação acumulada com uma política monetária mais parcimoniosa. Isto é, a análise do núcleo mostra indicativos futuros sobre o IPCA acumulado em 12 meses e, portanto, buscar controlar a medida de núcleo pode trazer como consequência o controle da inflação acumulada no ano.

Os modelos DCS, além de permitirem a estimação de núcleos, possibilitam a previsão da variável de interesse: a inflação. As previsões para os últimos dois anos observados foram feitos e observou-se RMSE em torno de [0,28 - 0,53], erro superior ao obtido para a previsão do mercado [0,11 - 0,25] e também superior ao erro obtido via as medidas de núcleo disponíveis atualmente no Brasil $[0,18$ - 0,40]. Deve-se levar em conta que os modelos de previsões para inflação costumam considerar definições teóricas e outras variáveis econômicas. Nesse 
estudo em questão, considerou-se apenas o próprio passado da variável, o que pode tornar a comparação um pouca injusta. Apesar disso, tanto os exercícios feitos nesse estudo e o mercado prevêem a inflação dentro do intervalo da meta em 2018 (entre 3 e 6\%).

Após a análise dos resultados encontrados aqui, enfatiza a mesma cautela que a literatura do núcleo aborda: cada núcleo deve ser utilizado para a extrair a informação que este busca captar. Não há só uma medida de núcleo que supere todas as outras, cada uma possui seus prós e contras e juntas podem auxiliar na tomada de decisão.

Como trabalho futuro, tem-se o desejo de iniciar a divulgação do NúcleoDCS para o público através da Fundação Getulio Vargas e desenvolver estudos para avaliar a formação da expectativa dos consumidores a respeito da inflação futura com base na nova medida. Além disso, também há a intenção de estimar os núcleos diretamente para o IPCA e adicionar variáveis exógenas, como por exemplo o câmbio, na estimação do Núcleo-DCS para avaliar como a tendência da inflação é afetada por outros choques não capturados em essência apenas pelo histórico da inflação.

Nesse trabalho, estimou-se o núcleo apenas para o IPC-Br, uma proxy do IPCA, e mesmo assim os resultados foram satisfatórios para a análise do IPCA. Também tem-se a intenção de estimar modelos econométricos segundo a metodologia do BCB para a previsão da inflação incluindo os núcleos como variáveis explicativas para avaliar o impacto dos núcleos na previsão.

Para contribuir com a academia, os códigos desenvolvidos para a estimação e análise das medidas estão disponíveis para utilização livre em https://github.com/daianemarcolino/gascoreinflation e no pacote Inflation do R. 


\section{Referências bibliográficas}

[1] ECKSTEIN, O.. Core inflation / Otto Eckstein. Prentice-Hall Englewood Cliffs, N.J, 1981.

[2] WYNNE, M. A.. Core Inflation: A Review of Some Conceptual Issues. Federal Reserve Bank of St. Louis Review, 90:205 - 228, 2008.

[3] BRYAN, M. F.; PIKE, C. J.. Median price changes: an alternative approach to measuring current monetary inflation. Economic Commentary, (Dec):1, 1991.

[4] BRYAN, M. F.; CECCHETTI, S. G.. Measuring core inflation. In: MONETARY POLICY, p. 195-219. The University of Chicago Press, 1994.

[5] DOW, J.. Measuring inflation using multiple price indexes. unpublished manuscript, 1994.

[6] DIEWERT, W. E.. On the stochastic approach to index numbers. Technical report, University of British Columbia. Dept. of Economics, 1995.

[7] QUAH, D.; VAHEY, S. P.. Measuring Core Inflation? Economic Journal, 105(432):1130-44, September 1995.

[8] FREEMAN, D. G.. Do core inflation measures help forecast inflation? Economics Letters, 58(2):143-147, February 1998.

[9] WYNNE, M.. Core inflation: a review of some conceptual issues. Working Paper Series 0005, European Central Bank, 1999.

[10] CLARK, T.. Comparing measures of core inflation. Economic Review, (Q II):5-31, 2001.

[11] COGLEY, T.. A simple adaptive measure of core inflation. Journal of Money, Credit and Banking, 34(1):94-113, 2002.

[12] CRISTADORO, R.; FORNI, M.; REICHLIN, L. ; VERONESE, G.. A core inflation index for the euro area*. Temi di discussione (Economic working papers) 435, Bank of Italy, 2002. 
[13] STOCK, J. H.; WATSON, M. W.. Core inflation and trend inflation. Working Paper 21282, National Bureau of Economic Research, June 2015.

[14] RICH, R.; STEINDEL, C.. A review of core inflation and an evaluation of its measures. Staff Reports 236, Federal Reserve Bank of New York, 2005.

[15] IBGE. Instituto Brasileiro de Geografia e Estatística, 2017.

[16] IBRE. Instituto Brasileiro de Economia, 2017.

[17] BARROS, R. W. D. S.; SCHECHTMAN, J.. Medidas de núcleo da inflação para a economia brasileira: Utilização das médias aparadas no ipc-di/fgv. Anais do xxix encontro nacional de economia [proceedings of the 29th brazilian economics meeting], ANPEC - Associação Nacional dos Centros de Pósgraduação em Economia [Brazilian Association of Graduate Programs in Economics], 2001.

[18] DA SILVA FILHO, T. N. T.; FIGUEIREDO, F. M. R.. Has Core Inflation Been Doing a Good Job in Brazil? Revista Brasileira de Economia, 65, 2011.

[19] DA SILVA FILHO, T. N. T.; FIGUEIREDO, F. M. R.. Revisitando as Medidas de Núcleo de Inflação do Banco Central do Brasil. Working Papers Series 356, Central Bank of Brazil, Research Department, May 2014.

[20] PICCHETTI, P.; KANCZUK, F.. An application of quah and vaheys svar methodology for estimating core inflation in brazil. Anais do xxix encontro nacional de economia [proceedings of the 29th brazilian economics meeting], ANPEC - Associação Nacional dos Centros de PósGraduação em Economia [Brazilian Association of Graduate Programs in Economics], 2001.

[21] FIGUEIREDO, F. M. R.. Evaluating Core Inflation Measures for Brazil. Working Papers Series 14, Central Bank of Brazil, Research Department, Mar. 2001.

[22] FIORENCIO, A.; MOREIRA, A. R. B.. O núcleo da inflação como a tendência comum dos preços. Revista Brasileira de Economia, 56:175 - 198, 002002.

[23] FERREIRA, P. C.; MATTOS, D. M.; SPERANZA, T. ; TEIXEIRA, F. O.. Inflation: Core Inflation, 2017. 
[24] GAVIN, W. T.; MANDAL, R. J.. Predicting Inflation: Food for Thought. Regional Economist, 2002.

[25] MEHRA, Y. P.; REILLY, D.. Short-Term Headline-Core Inflation Dynamics. Federal Reserve Bank of Richmond Economic Quarterly, 2009.

[26] U.S. CENSUS BUREAU. X-13ARIMA-SEATS Reference Manual Acessible HTML Output Version, 2017.

[27] FERREIRA, P. C.; MATTOS, D. M. D. ; ARDEO, V. L.. Triple-Filter Core Inflation: A Measure of the Inflation Trajectory. Revista Brasileira de Economia, 71:397 - 411, 122017.

[28] SANTOS, C.; CASTELAR, I.. Avaliando as medidas de núcleo da inflação no brasil. Economia Aplicada, 20(1):35-56, 2016.

[29] CREAL, D.; KOOPMAN, S. J. ; LUCAS, A.. Generalized autoregressive score models with applications. Journal of Applied Econometrics, 28(5):777-795, 2013.

[30] HARVEY, A. C.. Dynamic models for volatility and heavy tails: with applications to financial and economic time series, volumen 52. Cambridge University Press, 2013.

[31] HARVEY, A.. Forecasting, Structural Time Series Models and the Kalman Filter. Cambridge University Press, 1989.

[32] DURBIN, J.; KOOPMAN, S. J.. Time Series Analysis by State Space Methods. Oxford University Press, 2 edition, 2012.

[33] KALLIOVIRTA, L.; OTHERS. Diagnostic tests based on quantile residuals for nonlinear time series models. 2009.

[34] JARQUE, C. M.; BERA, A. K.. A test for normality of observations and regression residuals. International Statistical Review / Revue Internationale de Statistique, 55(2):163-172, 1987.

[35] LJUNG, G. M.; BOX, G. E. P.. On a measure of lack of fit in time series models. Biometrika, 65(2):297-303, 1978.

[36] FerreiRA, P.; OliveIRA, I. ; TEIXEIRA, F.. How Brazilian Consumers' Inflation Expectations are created. unpublished manuscript, 2016. 
[37] GAGLIANONE, W. P.; ISSLER, J. V. ; MATOS, S. M.. Applying a Microfounded-Forecasting Approach to Predict Brazilian Inflation. Banco Central do Brasil - Working Paper, 436, 2016. 